\title{
Historical Background on the Performance Assessment for the Waste Isolation Pilot Plant
}

Rob P. Rechard

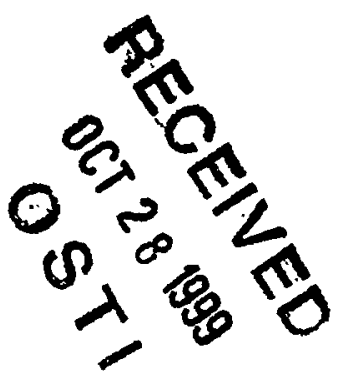

\begin{abstract}
In 1979, six years after selecting the Delaware Basin as a potential disposal area, Congress authorized the U.S. Department of Energy to build the Waste Isolation Pilot Plant (WIPP) near Carlsbad, New Mexico, as a tesearch and development facility for the safe management, storage, and disposal of waste contaminated with transuranic radioisotopes. In 1998, 19 years after authorization and 25 years after site selection, the U.S. Environmental Protection Agency (EPA) certified that the WIPP disposal system complied with its regulations. The EPA's decision was primarily based on the results from a performance assessment conducted in 1996, which is summarized in this special issue of Reliability Engineering and System Safety. This performance assessment was the culmination of four preliminary performance assessments conducted between 1989 and 1992. This paper provides a historical setting and context for how the performance of the deep geologic repository at the WIPP was analyzed. Also included is background on political forces.acting on the project.
\end{abstract}

Key Words: performance assessment; probabilistic risk assessment; risk assessment; radioactive waste disposal; Waste Isolation Pilot Plant; history

\subsection{Introduction}

In 1998, 25 years after selection of the Delaware Basin in southeastern New Mexico as a potential disposal site for radioactive waste, the U.S. Environmental Protection Agency (EPA) certified that the Waste Isolation Pilot Plant (WIPP), an underground geologic disposal system, complied with its regulations. This paper presents a historical summary of the system characterization, engineering analyses, and scientific investigations undertaken by the WIPP Project over the past 25 years and provides a context for the results presented in this special issue of Reliability Engineering and System Safety. Although it is not essential to know the WIPP's history to comprehend the engineering analysis, an understanding of the issues that the project faced can be helpful. Many paths were followed during these 25 years to discern which phenomena were important at the WIPP, and often these paths were initiated in response to evolving notions of what kind of scientific information was significant, what level of understanding was required, and how society could use this scientific information to decide whether deep geologic disposal of nuclear waste was acceptable. 


\section{DISCLAIMER}

This report was prepared as an account of work sponsored by an agency of the United States Government. Neither the United States Government nor any agency thereof, nor any of their employees, make any warranty, express or implied, or assumes any legal liability or responsibility for the accuracy, completeness, or usefuiness of any information, apparatus, product, or process disclosed, or represents that its use would not infringe privately owned rights. Reference herein to any specific commercial product, process, or service by trade name, trademark, manufacturer, or otherwise does not necessarily constitute or imply its endorsement, recommendation, or favoring by the United States Government or any agency thereof. The views and opinions of authors expressed herein do not necessarily state or reflect those of the United States Government or any agency thereof. 


\section{DISCLAIMER}

Portions of this document may be illegible in electronic image products. Images are produced from the best available original document. 


\subsection{Characterization of WIPP Disposal System}

The choice of New Mexico as a potential disposal site for nuclear waste in 1973 (Claiborne and Gera, 1974) was one in a series of episodes in which New Mexico had figured prominently with regard to nuclear phenomena. In 1942, the Manhattan Engineering District selected New Mexico as the location (including what are known now as Los Alamos National Laboratory and Sandia National Laboratories) for assembling the scientists, engineers, and technicians who would develop the first atomic bomb. As a direct consequence of that development, the first atomic explosion took place in 1945 in the desert near Alamogordo, New Mexico (Serber, 1992). Sixteen years later, in 1961, scientists with the Gnome Project detonated a device in the Delaware Basin in bedded salt near Carlsbad, New Mexico, as part of the Plowshare Program, which was exploring nonmilitary uses of nuclear explosives (Gard, 1968).

After a potential disposal site in bedded salt in Kansas had been rejected in the early 1970s, citizens invited the Atomic Energy Commission (precursor to the U.S. Department of Energy ${ }^{1}$ ) to New Mexico to consider the bedded salt deposits in the Delaware Basin. The search for a specific site in the basin occurred between 1973 and 1976 (Powers et al., eds., 1978). The site was then characterized by Sandia National Laboratories for the U.S. Department of Energy (DOE) in support of its Draft Environmental Impact Statement (EIS), which was completed in 1979 (DOE, 1979).

The wastes intended for the WIPP included waste contaminated with transuranic (TRU) nuclear elements and , hazardous chemicals generated during the production of nuclear weapons. The Atomic Energy Commission (AEC) had been segregating and storing these wastes above ground for eventual disposal since 1970 , three years before site selection (Perge, 1982). Nearly ten years later, in December 1979, Congress authorized the DOE to construct the WIPP for eventual disposal of this TRU waste (Public Law 96-164). The first shaft was drilled in 1981, and full construction began in 1983. Construction of the WIPP facility was substantially complete by the end of 1988 .

Along with construction, a suite of characterization studies were initiated in the $1980 \mathrm{~s}$ in response to agreements with the State of New Mexico. The final site characterization studies were completed in the 1990s. The characterization of the WIPP provided input for the 1996 performance assessment (PA), an engineering analysis documented in the Compliance Certification Application (CCA), which was submitted to the EPA in October 1996 (DOE, 1996a) and which is described in this special issue of Reliability Engineering and System Safety.

\subsection{Compliance Assessment of Waste Isolation Pilot Plant}

Over the past 25 years, the process for assessing performance of a deep geologic repository for nuclear waste developed concurrently with the characterization of the WIPP in New Mexico. The WIPP project's first major analysis was for the EIS in 1978. In 1985, the EPA promulgated its radiation protection standard for the management

\footnotetext{
'The Atomic Energy Commission (AEC) was formed by the Atomic Energy Act of 1946 (Public Law 585). The Energy Research and Development Agency (ERDA) and the Nuclear Regulatory Commission (NRC) were formed by splitting the Atomic Energy Commission in the Energy Reorganization Act of 1974 (Public Law 93-438). ERDA became the U.S. Department of Energy (DOE) in the 1977 Department of Energy Organization Act (Public Law 95-91).
} 
and disposal of spent nuclear fuel, high-level and transuranic wastes, in Title 40 of the Code of Federal Regulations Part 191 (40 CFR 191).

The overall process of assessing whether a nuclear waste disposal system meets a set of performance criteria is known as a performance assessment (PA), a term defined in 40 CFR 191. Similar to other risk assessments, a PA includes up to seven steps: (0) Definition of performance criteria; (1) system definition and/or characterization; (2) hazard identification and scenario development; (3) probability evaluation; (4) consequence evaluation; (5) performance characterization and compliance assessment; and (6) sensitivity analysis. In general, a consequence analysis consists of (a) a dose-response assessment, which evaluates the response of a receptor (or system) to a hazard (or stressor), and (b) an exposure pathway assessment, which evaluates the exposure intensity of a hazard that reaches a receptor, e.g., a human. As with any scientific modeling or policy process, steps may overlap. More importantly, an analyst may need to cycle through several of the early steps when building an appropriate model. Hence, the steps are not always truly sequential. However, the discretization is useful as a means of describing the process and so is used here. The computational mechanics of the seven-step process are described in Rechard (1995).

Because the main purpose of a PA is to serve as input to a management decision, it is an engineering analysis with constraints on time and resources specified by the decision makers (or tolerated by representatives of society) rather than a scientific analysis, which is in principle constrained only by human curiosity.

\subsection{Organization of Historical Material}

Historical events described here are generally categorized according to the steps of a PA. The discussion begins with the definition of performance goals. Next discussed is characterization of the three main components of the disposal system, i.e., site, waste and facility. The engineering analysis of the WIPP disposal system is then presented according to the remaining steps of a PA.

\subsection{Performance Goals for Waste Isolation Pilot Plant}

From 1955 through the 1960s, the AEC explored options for storage and disposal of nuclear waste. The AEC also undertook scientific and engineering studies for deep geologic disposal in salt, which eventually led to the selection of the salt beds of New Mexico. Later, in the mid 1970s through the early 1980s, an assessment process and risk-based performance criteria evolved for determining the acceptability of the risk of the WIPP disposal system.

\subsection{Criteria for Selecting a Site}

\subsubsection{Early Disposal Methods}

In the early years of nuclear research, it was very important to recover all of the radioisotopes produced, particularly ${ }^{239} \mathrm{Pu}$ and ${ }^{235} \mathrm{U}$. At Los Alamos National Laboratory, the site and methods for disposal of any waste that remained were initially the same as for any other waste: it was disposed of in nearby canyons. Around 1944, the 
Manhattan Engineering District decided to bury any solid nuclear waste in shallow trenches and augered holes at Los Alamos (NAS/NRC, 1957) and in railroad cars, trenches, and underground caissons at the Hanford Reservation in Washington.

The AEC, formed in 1946 (Public Law 585), continued the practices of the Manhattan Engineering District. The AEC also constructed storage tanks in the late 1940s at Hanford and completed a nuclear waste storage complex, the Radioactive Waste Management Complex at Idaho National Engineering and Environmental Laboratory (INEEL) in 1952.

\subsubsection{Selection of Bedded Salt}

Studies of permanent disposal options began in 1955 when the AEC asked the National Academy of Sciences (NAS) to examine the disposal issue. In 1957, the NAS reported that while various options and disposal sites were feasible, disposal in salt beds was the most promising method to explore (NAS/NRC, 1957). NAS reaffirmed that recommendation in 1961 (Carter, 1987; Claiborne and Gera, 1974). By 1966, frustration at the lack of a formal waste policy at the AEC provoked strong criticism from the NAS about the AEC's disposal practices (Carter, 1987; Claiborne and Gera, 1974). From 1961 through the early 1970s, Oak Ridge National Laboratory (ORNL) conducted radioactive-waste disposal experiments, most notably Project Salt Vault in an abandoned salt mine near Lyons, Kansas, from 1963 to 1967 (Bradshaw and McClain, eds., 1971) (Fig. 1). Based on the results of these tests, the Committee on Radioactive Waste Management, which had been established in 1968 at the request of the AEC and later became a permanent board, concluded in their 1970 report that bedded salt was satisfactory and the safest choice then available for nuclear waste disposal (NAS/NRC, 1970).

Fig. 1. Early history of nuclear waste disposal related to the WIPP (adapted from Figure 2-1, Rechard, 1999, which provides extensive references).

\subsubsection{Selection of Repository Site}

In May 1969, the Rocky Flats Plant, built by the AEC in 1951 to machine plutonium and other metals for nuclear weapons, caught fire. Located only 16 miles from Denver, Colorado, the fire and subsequent cleanup attracted public attention. The press reported that the waste from the cleanup was to be sent to Idaho. For the first time, the public and many Idaho state officials learned that TRU waste from the Rocky Flats Plant had been routinely buried in Idaho since 1954. Public anger over the events created high visibility for the issue of waste disposal from nuclear weapons production. The State of Idaho felt it was becoming the nation's waste disposal site for defenserelated waste by default. In addition, the Radioactive Waste Management Complex located there was not ideal for long-term disposal of nuclear waste because it was near the Snake River and its associated aquifer; hence, the AEC quickly moved to find a more suitable site. The AEC assured Senator Church from Idaho that the waste from Rocky Flats stored in Idaho would be removed by 1980 (Lipschutz, 1980). In June 1970, the AEC tentatively selected the abandoned Kansas salt mine at Lyons, the site of the ORNL experiments, as a demonstration repository (AEC, 1971). 
Although salt has many advantages, a disadvantage is the coexistence of minerals and hydrocarbons. In 1971, a large number of previously unknown drill holes for mineral exploration and some solution mining were discovered very near the proposed repository (Carter, 1987). Soon after, Congress directed the AEC to stop work on the Lyons project until safety was certified. In May 1972, the AEC officially abandoned the Lyons project and announced plans for a Retrievable Surface Storage Facility (Metlay, 1978); however, anti-nuclear groups and the EPA, through comments on the EIS for the facility, claimed the facility as de facto permanent disposal (MRSRC, 1989). The criticism prompted the AEC to search again for a more suitable disposal site (Jones et al., 1973, Bachman et al., 1973; Rechard, 1999). Soon after, ORNL and the USGS recommended to the AEC the extensive salt beds of southeastern New Mexico (Barnes, 1974).

The experience at Lyons provided two important site-selection criteria: (1) an absence of boreholes or solution mining near the repository, which meant ensuring minimal conflicts with other mineral resources by means of a buffer zone of one mile (ORNL used two miles) from existing deep wells, five miles from existing potash mines, and avoidance of known hydrocarbons and potash reserves, and (2) the presence of advantageous political characteristics such as public and government support in the area, low population density, and few or no land use conflicts, e.g., grazing. These two criteria were added to other criteria such as presence of high quality salt at a depth between 300 and $800 \mathrm{~m}$ to avoid potential problems with erosion, dissolution, or rapid salt creep.

\subsubsection{Segregation of TRU Waste}

In 1968, the Government Accounting Office (GAO) evaluated waste management practices within the AEC (Perge, 1982). Like the 1966 NAS Committee, the GAO criticized the documentation and organizational aspects of the AEC's disposal practices, especially for high-level waste. In response, the AEC formed a management task force that eventually recommended that liquid high-level waste be solidified and that low level waste, and what was then called plutonium-contaminated waste, be studied further. Because the 1969 fire at the Rocky Flats Plant increased concern about this waste, the AEC quickly defined TRU waste using a lower bound definition: any contaminated material with an activity density of $10 \mathrm{nCi} / \mathrm{g}$, which is about the activity density of ${ }^{226} \mathrm{Ra}$ in the earth's crust. The AEC's definition of TRU waste purposely used mass as its basis to avoid the issue of dilution, in contrast to the volume basis used by the International Atomic Energy Agency (IAEA) (Perge, 1982). Also, in March 1970, the AEC directed that TRU waste be stored so that it could be retrieved, rather than disposed of in trenches with low level waste (Perge, 1982). Thereafter, it was stored on the surface in Idaho and elsewhere.

\subsection{Preparation of Environmental Impact Statement}

The National Environmental Policy Act of 1969 (NEPA, Public Law 91-190), signed in January 1970 by President Nixon, and its implementing regulations, 40 CFR 1500-1508, required federal agencies to consider the environmental consequences of any major action through an EIS (environmental impact statement). Publication of the EIS was followed by a period for public comment. NEPA was the first environmental statute applied to the WIPP. Eventually, three EISs were prepared for the WIPP: one in 1979-80 during deliberations on whether to proceed with the construction phase (DOE, 1979; 1980), a supplement in 1989-90 to decide whether to proceed with 
a pilot phase (DOE, 1989, 1990c), and a supplement in 1996-97 to decide whether to proceed with the disposal phase (DOE, 1996b; 1997) (Fig. 2). Although NEPA required that federal agencies prepare an EIS, it did not provide specifics regarding content nor did it list criteria for making decisions on the acceptability of a project. Consequently, preparing the first EIS for the WIPP was particularly difficult and was delayed several times as the nation's notion of such a document changed from an initial expectation of a relatively short, 10-page report to an extensive document of several thousand pages.

Fig. 2. Development of performance goals for the WIPP (adapted from Figure 2-2, Rechard, 1999, which provides extensive references)

\subsection{Establishment of Regulatory Risk Goals}

\subsubsection{Historical Events}

In 1976, President Ford requested that the EPA accelerate development of applicable standards for proposed waste repositories. (Ford's request is noted in Volume 50 of the Federal Register, beginning on page 38067 [50 FR 38067] and the standards were first mentioned in 1976 [41 FR 53363].) The EPA conducted several public meetings to develop societal consensus on regulatory criteria (43 FR 2223). In 1978, the EPA proposed generic criteria on all radioactive waste (43 FR 53262), but after receiving an unfavorable response to these criteria, it withdrew the proposed regulations in March 1981 (EPA, 1985) and began to develop standards for individual categories of radioactive waste.

In 1982, in response to a requirement in the Nuclear Waste Policy Act (NWPA) of 1982 (Public Law 97-425), the EPA officially published a draft of the disposal regulation for high-level nuclear waste, 40 CFR 191 (47 FR 58196), which had seen more than 20 revisions. One year later, the DOE stated in letters to the Environmental Evaluation Group (EEG), an oversight group for the WIPP established by the DOE in 1978, that the WIPP would comply with the requirements in 40 CFR 191 once the facility moved from a test phase to an operational phase but did not consider them applicable in the test phase; the latter interpretation contributed to a growing opposition against the test phase of the project. The EPA did not promulgate the final version of 40 CFR 191 until 1985, three years after submitting the proposed regulation and then only after drawing a lawsuit to hasten promulgation (50 FR 38066).

The 1985 final version of 40 CFR 191 involved some changes from the 1982 draft that included Individual and Groundwater Protection Requirements. These requirements led to a lawsuit by the same group, the Natural Resources Defense Council (NRDC), that had sued earlier to accelerate promulgation. The courts remanded the regulation shortly thereafter (as noted in Volume 824 of the Federal Reporter, second series, beginning on page 1258 [824 F2d 1258]), but the EPA repromulgated the Standard in 1993 without changes to the Containment Requirements (58 FR 66398). These Containment Requirements strongly influenced the type of calculations necessary for the performance assessment.

6 - 3/9/99 Draft 
In 1992, Congress defined the process by which WIPP compliance would be evaluated, transferred ownership of the WIPP site to the DOE, and designated the EPA as the regulator of the WIPP. In 1996, the EPA promulgated 40 CFR 194 (61 FR 5224), a regulation to implement its 40 CFR 191 standard specifically for the WIPP, and imposed several new requirements and interpretations on modeling style. Basically, however, 40 CFR 194 adopted a process and methodology very similar to that used by Sandia for conducting a PA of the WIPP between 1989 and 1992 (Helton, 1993a; 1994; Helton et al., 1997c).

Besides complying with 40 CFR 191, waste intended for the WIPP also came under a legal ruling in 1984 (586 F. Supp. 1163) and subsequent changes in the EPA's and DOE's definitions of mixed waste in 1986 (51 FR 24504) and 1987 (52 FR 15937), causing as much as 60\% of the waste destined for the WIPP to be designated as chemically hazardous (DOE, 1996b). Thus, the WIPP had to comply with a set of regulations for hazardous waste (40 CFR 260270 and analogous New Mexico regulations) promulgated in response to the Resource, Conservation, and Recovery Act (RCRA) (Public Law 98-616; Public Law 94-580). In 1996, Congress eliminated the need for the WIPP to seek a no-migration variance from RCRA requirements (Public Law 104-201), which required calculations similar to those already provided for compliance with 40 CFR 191 . However, other RCRA requirements implemented in 40 CFR 260-270 still applied, such as specifying the types and amounts of waste in state permits. Further details of how the regulations were applied to WIPP are provided in this special issue (Howard et al., this issue).

\subsubsection{Containment Requirements of 40 CFR 191}

Although dose calculations to humans were still of interest to the WIPP Panel of NAS and were used in Supplemental EIS reports for the WIPP in 1989 (DOE, 1990c) and 1996 (DOE, 1996b; 1997), 40 CFR 191 required evaluating the cumulative release of radioisotopes $C(\mathrm{x})$, to the accessible environment. Furthermore, the definition of PA stated that "these estimates [of releases] shall be incorporated into an overall probability distribution of cumulative release to the extent practicable." That is, uncertainty was treated quantitatively, which in turn indirectly required a stochastic model for the geologic disposal system. To elaborate, if $C(\bullet)$ is a function of parameters $x=$ $\left[x_{1}, x_{2}, \ldots x_{n p}\right]$, where $n P$ is the total number of model parameters, and the parameters are uncertain (i.e., are described by a probability model by means of a distribution with a range of values), then the consequences $C(x)$ will also have a range and distribution. Uncertainty analysis involves determining the shape of the distribution for $C(\mathbf{x})$ (Fig. 3). Thus, the risk measure was not the expected value of the results, as in simple insurance annuity calculations, nor the variance of the results, as in financial risk analysis of stock portfolios (Markowitz, 1952). Rather the entire distribution of the results was used. Hence, in the United States, PA became a stochastic simulation of possible longterm behaviors of a real system by means of a computer-implemented mathematical model. In this respect, PA remained similar to probabilistic risk assessments (PRAs) for nuclear reactors (Helton, 1994; 1997).

In 40 CFR 191, the Containment Requirements specified (a) limits $\left(L_{i}\right)$ on the total activity (curies) that could be released from the disposal system for individual radioisotopes and (b) the chance that these limits could be exceeded, i.e., have less than 1 chance in 10 of exceeding $L_{i}$ and less than 1 chance in 1000 of exceeding $10 L_{i}$ (Fig. 3). For a 
mix of radioisotopes, the release $C(\mathbf{x})$ for each radioisotope $(i)$ is normalized with respect to its radioisotope limit $\left(L_{i}\right)$, and then summed, that is,

$$
\left.C(\mathrm{x})=\frac{1}{w_{f}} \sum_{i=1}^{n R} \frac{F_{i}(\mathrm{x})}{L_{i}}<1 \text { (or } 10\right)
$$

where $C(\mathrm{X})$ is the total normalized release ("EPA sum"); $w_{f}$ is a waste unit factor, various factors are defined (e.g., for transuranic waste $w_{f}=\sum \mathrm{A} / 10^{6} \mathrm{Ci}$ where $\mathrm{A}$ is activity (Ci) of alpha-emitting transuranic radioisotopes in the repository with half-lives greater than $20 \mathrm{yr}) ; L_{i}$ is the release limit specified by the EPA for radioisotope $i ; F_{i(x)}$ is the cumulative release of radioisotope $i$ to accessible boundary integrated over a 10,000 -yr period $\int f_{i}(x)$, during which system performance (such as actinide radioisotope transport in groundwater) had to be modeled, and $n R$ is the number of radioisotopes contributing to release to the accessible boundary.

The Containment Requirements specified the radioisotope limits $\left(L_{i}\right)$; in other words, as customary, the regulatory agency performed the dose-response assessment. ${ }^{2}$ Because the Containment Requirements used cumulative releases of radioisotopes $\left(F_{i}\right)$, the EPA dose-response assessment, through crude calculations, converted from dose, which depends upon rate of release (rather than cumulative release), to obtain the allowable EPA limits $\left(L_{i}\right)(E P A, 1985)$.

Fig. 3. Uncertainty in model parameters, $\mathbf{x}$ (expressed as a probability density function [PDF], or cumulative distribution function $[C D F]$, results in uncertainty in the results $C(x)$. This uncertainty (expressed as a complementary distribution function, CCDF or $1-C D F$ ) is compared to the probabilistic limits in 40 CFR 191 .

\subsection{Site Characterization}

To model a system, it is necessary first to define the system, regardless of whether the model's purpose is to gain insight or anticipate future behavior. System definition essentially describes the space of parameters, $\mathbf{x}$, and the relationship of those parameters through a model. The model may be only conceptual, but for the WIPP PA, it was a mathematical model. In a mechanical system, the various parts of the system are defined. With a radioactive waste disposal system, however, the existing geologic parts must be characterized. Characterization of the geologic subsystems of the WIPP was undertaken as soon as the site was selected to (1) satisfy needs for the Draft EIS in 1979 (DOE, 1979) and Supplemental EISs in 1989 (DOE, 1990c), (2) satisfy negotiated agreements with the State of New Mexico (State of NM, 1981), and (3) develop a general understanding of natural phenomena significant to nuclear waste disposal.

\footnotetext{
2 This dose-response assessment depended on bounding type dose evaluations that sought to limit deaths to no more than would have occurred from an unmined uranium ore body (i.e., less than 1000 deaths over 10,000 yr). Thus, a PA is not entirely probabilistic.
} 


\subsection{Selection of Site}

With the tacit approval of New Mexico's governor Bruce King, ORNL examined a portion of the Permian Basin called the Delaware Basin in southeastern New Mexico in the early 1970s for a suitable disposal site for nuclear waste. The area was semi-arid with little potable water and no significant, highly permeable aquifers near the surface. At that time, the area was being considered for disposal of both high-level waste and TRU waste generated during production of nuclear weapons. A potential site near the edge of the basin along the Capitan Reef was identified in 1973. ORNL drilled two wells, AEC-7 and AEC-8, in March 1974 near the northeastern and southwestern corners of the rectangular site for the first large-scale field test in the basin (Powers et al., eds., 1978). (Prior to this test, the USGS had conducted some tests for the AEC in 1961 for the Gnome Project and so some data on aquifers was already available [Gard, 1968].) The cores from the two wells indicated fairly predictable stratigraphy. However, the work by ORNL was suspended two months later for several reasons. First, the AEC wished to emphasize the Retrievable Surface Storage Facility as its primary option. Also, because of the Arab oil embargo, AEC Chairman Dixie Lee Ray would not withdraw the land around the site from oil exploration. Finally, Congress was considering a major reorganization of the AEC; .legislation signed in October 1974 split the AEC into the Energy Research and Development Administration (ERDA) and the Nuclear Regulatory Commission (NRC), effective January 1975.

One of New Mexico's ERDA laboratories, Sandia National Laboratories, began work at the site selected by ORNL in January 1975. In late March of that year, Sandia received funding and officially became the lead laboratory to characterize the site (Powers et al., eds., 1978), develop the conceptual design (Sandia, 1977), initiate scientific studies on nuclear waste disposal in bedded salt, and draft an EIS (DOE, 1979). In May 1975, Sandia drilled a combination geologic and exploratory well, ERDA-6, at the northwestern corner of the proposed site (Sandia and USGS, 1983). The well encountered up to $75^{\circ}$ dipping beds and, at a depth of $826 \mathrm{~m}$, artesian brine and $\mathrm{H}_{2} \mathrm{~S}$ gas, causing dismay on the part of ERDA staff who, as former AEC officials, had earlier struggled with difficulties at the Lyons site.

But the large Delaware Basin had other areas that met the various selection criteria. In late 1975, after examining the stratigraphy shown in the ERDA wells, along with confidential data from numerous private wells owned by oil companies and confidential geophysical seismic data, Sandia recommended locating the potential repository site nearer the basin center. The USGS independently suggested a similar location. The new site was about $11 \mathrm{~km}$ from the first location, away from the $\sim 10-\mathrm{km}$ band around the Capitan Reef where deformation of the salt beds occurred, and with more predictable horizontal stratigraphy (Powers et al., eds., 1978). In April 1976, Sandia drilled ERDA-9 through the Salado Formation into the Castile Formation (hereafter shortened to Salado and Castile) at the center of the proposed site, which was $42 \mathrm{~km}$ from the town of Carlsbad, New Mexico. The stratigraphy was horizontal and no brine was encountered. This site became the Waste Isolation Pilot Plant (WIPP) (Fig. 4).

Fig. 4. Physical setting of the WIPP in Delaware Basin (after Rechard, 1995, Figure 2.1-1). 


\subsection{Site Characterization Studies for EIS}

The EIS process, as required by NEPA (Public Law 91-190), exerted its influence on the characterization process during the 1970s as the AEC (then the ERDA, in 1975, and ultimately the DOE) continued investigations on bedded salt in New Mexico. During this time Sandia collected data on the ecological and archaeological features of the region and its socioeconomic facets (Weart, 1979). Sandia's description of the geology and hydrology (Powers et al., eds., 1978) drew heavily upon information that had been prepared during the search for a regional site location (Bachman et al., 1973; Jones et al., 1973; Bachman, 1973).

During site selection, interest in fluid flow in water-bearing units of the area had focused on its effects on dissolution; after selection, interest shifted to the role of these units as potential pathways for radionuclide release. Also 75 new line miles of seismic reflection data and 9000 resistivity measurements were collected across the site (Powers et al., eds., 1978). In addition, 47 boreholes were completed under the direction of the USGS (Mercer and Orr, 1979).

USGS geohydrologists had suggested that the Magenta and Culebra Members of the Rustler Formation (hereafter shortened to Magenta, Culebra, and Rustler) and the Rustler/Salado contact zone were potential pathways for radionuclide release. At the time, the relative importance of these units was unknown, so the first tests targeted all three. The Rustler/Salado contact was confirmed to be transmissive in Nash Draw but did not yield significant quantities of water at the site nor did it represent a significant pathway for fluid movement for either radionuclide transport or dissolution. The Culebra was more transmissive than the Magenta, and the transmissivities of these units varied by several orders of magnitude (Powers et al., eds., 1978; Mercer and Orr, 1979).

Experimental activities included determining the mineralogy of the bedded salts and the overlying formations (Powers et al., eds., 1978). Also, the sorptive properties of the clays in the salt and overlying dolomitic rocks in the Rustler were evaluated (Dosch, 1979), and the geochemical composition of the waters in the Rustler was determined (Powers et al., eds., 1978). The stability of the salt was also examined by determining whether $\mathrm{Rb}-\mathrm{Sr}$ isotope ratios suggested any significant recystallization or brine flow through the formation since its deposition about 255 million years ago (Powers et al., eds., 1978; Weart, 1979) (Fig. 5). Further information on the geologic setting is discussed in this special issue (Swift and Corbet, this issue).

Fig. 5. Stratigraphy above and below the WIPP repository (after Rechard, 1995, Figure 2.1-2).

\subsection{Long-Term Site Characterization Studies}

\subsubsection{Site Characterization Studies at Repository Horizon}

Data needs for the EIS engendered several characterization studies. Although the results were not ready to be reported in the supporting documents for the EIS, some data were available soon afterwards. For example, with regard to waste acceptance criteria, the potential magnitude of the pressure from gas generated by waste from microbial degradation of organic material was not known; thus in 1979 Sandia tested the AEC-7 well to determine the permeability of the Salado in order to ascertain the ability of the repository to contain gas. The test, using 
compressed air flow measurements, indicated a formation permeability over a 30-m test section between $5 \times 10^{-19}$ and $2 \times 10^{-17} \mathrm{~m}^{2}$ (permeability at an elevation of $548 \mathrm{~m}$ and at an elevation of $427 \mathrm{~m}$ [depth of $690 \mathrm{~m}$ ], respectively (Tyler et al., 1988). ${ }^{3}$ The range of in situ permeability, in turn, suggested that if gas from microbial action (and anoxic corrosion from brine migration to hot canisters) were generated by TRU waste at less than $5 \mathrm{~mole} / \mathrm{drum} / \mathrm{yr}$, the gas would dissipate into the rock without reaching lithostatic pressure; thus the TRU waste would be acceptable in the WIPP repository without incineration. Accordingly, a fledgling program to characterize gas generation, begun in 1978, was canceled after 1979 (see also Section 4).

Sandia did not originally intend to use the experimental region of the WIPP repository to study the permeability of the Salado. TRU waste generates relatively little heat, and so migration of brine because of a thermal gradient was of little concern after 1979 when high-level waste was excluded from the WIPP. Yet Sandia conducted some permeability tests around excavations because of continued interest in high-level waste disposal in salt beds elsewhere and as part of the sealing and waste canister programs (see also Section 5).

Sandia first measured injected nitrogen flow around an underground drift in 1984 to determine the extent of the disturbed zone and corresponding permeability of the Salado. In 1986, Sandia conducted similar measurements using injected brine to evaluate the permeability of the intact salt. The predicted permeability ranged between $10^{-21}$ and $10^{-20} \mathrm{~m}^{2}$, a factor of about 1000 less than the previously measured range in AEC-7 of $5 \times 10^{-19}$ to $2 \times 10^{-17} \mathrm{~m}^{2}$ (Tyler et al., 1988) (Fig. 6).

Fig. 6. Estimated permeability of Salado Formation near repository horizon continued to decrease over the years (Rechard, 1999).

In May 1987, Sandia reported that much more brine had migrated to the simulated high-level waste canisters than had been expected. Furthermore, a rough scoping calculation to evaluate repository performance identified inflow of intergranular Salado brine to the repository from a pressure gradient (rather than thermal gradient) as a concern for long-term performance if a human should inadvertently intrude into the repository with an exploratory well (Lappin et al., eds., 1989). By December, the national press was reporting on the issue of brine flow into the repository. In January 1988, New Mexico's congressional delegation asked the full Board of Radioactive Waste Management (BRWM) of the NAS to study the brine inflow controversy.

However also in 1987, Sandia made a concerted effort to theoretically study thermoelastic behavior of the salt and found that the seemingly contradictory in situ measurements of lower permeability but higher brine flow to simulated high-level waste canisters could be explained. The new theoretical model predicted less than $43 \mathrm{~m}^{3}$ brine entering a disposal room over the first $100 \mathrm{yr}$ (Nowak et al., 1988). Given the resolution of measurements, the BRWM concluded that not enough brine would seep into the rooms to form a slurry of radioactive waste before the

\footnotetext{
${ }^{3}$ This range was higher than that encountered in laboratory tests using argon, nitrogen, and hydrogen gases, which ranged between $1.5 \times 10^{-17}$ and an experimental limit of $5 \times 10^{-20} \mathrm{~m}^{2}$.
} 
rooms had closed through salt creep. On the other hand, the lower permeability of the Salado had implications for gas generation, as discussed below.

\subsubsection{Site Characterization Studies for Stipulated Agreement}

Although the political climate in New Mexico toward waste disposal was initially positive, the reevaluation of nuclear waste disposal by the Carter administration and the possibility of placement of commercial waste at the WIPP led the State of New Mexico to distrust DOE's intentions. To help with resolution of issues, the enabling legislation clearly stated the purpose of the WIPP and required a Consultation and Cooperation Agreement with the State of New Mexico. However, negotiations to reach such a cooperative agreement between New Mexico and the DOE were arduous. Thus, when DOE decided to proceed to preliminary design and construction in January 1981, the State of New Mexico sued along with several other parties. In response to the lawsuit, a Stipulated Agreement was negotiated between Governor King and Secretary of Energy Edwards in late summer of 1981, which included the Consultation and Cooperation Agreement (see Fig. 2).

As part of the negotiated settlement with the State of New Mexico, the DOE deepened WIPP-12 into the Castile in November 1981 (see Figs. 3 and 4). The WIPP Project encountered a brine reservoir at a pressure high enough that brine could flow to the surface. The discovery of the reservoir prompted the rotation of the waste panels from their planned location north of the experimental area to south of the shafts in 1982, thus moving the disposal region $\sim 1800 \mathrm{~m}$ to the south, which is the current configuration. This well was extensively tested through 1983 (Lappin et al., eds., 1989). Also, geophysical studies indicated that a brine reservoir could also extend to the south of WIPP-12. DOE-1 was drilled in 1982 to obtain geologic data and evaluate the brine reservoirs in the Castile. No brine was found, and the well was later used to test hydraulic conditions in the Culebra. Both the DOE and the EEG conducted consequence analyses of a drilling encounter with a brine reservoir similar to that found in WIPP-12, concluding that the health consequences were minor (Woolfolk, 1982; Channell, 1982). In addition, several new geophysical techniques were used to determine whether such brine reservoirs might exist under the waste panels, but by 1987, these studies were inconclusive. A zone of lower resistivity in the Castile existed under a portion of the waste disposal area and could be interpreted as brine; however, the zone was beneath the Castile's upper anhydrite layer where brine had been encountered earlier (Lappin, 1988; WIPP PA Division, 1991/1992) (Fig. 7).

In the 1980s, hydrologic charácterization focused on the Culebra. Mercer (1983) had provided additional information on the transmissivities of the Culebra as part of the Stipulated Agreement. In 1984, pumping tests at DOE-1 suggested fracture flow in the Culebra. By 1987, Sandia had estimated the Culebra transmissivity at 15 new locations and re-estimated the transmissivity of 7 wells (Mercer, 1983); by 1989, Sandia had estimated Culebra transmissivity at 41 locations in an 860- $\mathrm{km}^{2}$ area around the WIPP site (Lappin et al., eds., 1989; Lappin, 1988).

Fig. 7. Site characterization studies at the WIPP (adapted from Figure 3-4, Rechard, 1999, which provides extensive references).

12 - 3/9/99 Draft 


\subsection{Site Characterization Studies for CCA}

As summarized below, additional site characterization studies were conducted in the 1990 s for PA calculations needed to support the CCA (Compliance Certification Application) to be submitted to the EPA. These studies are detailed elsewhere in this special issue (Larson et al., this issue).

\subsubsection{Fluid Flow in Culebra}

In the 1990s, tests were conducted to characterize the Culebra at two relatively high-permeability locations. These high-quality tests included the seven-well tracer test conducted at $\mathrm{H}-19$, multiwell retesting at $\mathrm{H}-11$, and single-well injection and withdrawal tests at both $\mathrm{H}-19$ and $\mathrm{H}-11$. The purpose of the tests was to evaluate the complex fracture flow (Meigs et al., 1997).

In 1996, hydraulic tests and fluid logging at the H-19 hydropad suggested that the permeability of the upper portion of the Culebra was significantly lower than the permeability of the lower portion. In addition, the 1996 tracer tests at H-19 suggested that the upper portion of the Culebra did not substantially contribute to solute transport. These findings confirmed two previous observations (Mercer and Orr, 1979). Therefore, the hydrologic effective thickness of Culebra in the PA for the CCA was taken as $\sim 4 \mathrm{~m}(7 \mathrm{~m}$, less the $3 \mathrm{~m}$ for the upper portion of the Culebra) (Meigs et al., 1997).

\subsubsection{Sorption Studies in Culebra}

Sandia conducted several laboratory studies of sorption in the 1980s (Dosch, 1979, 1981; Lynch et al., 1981). These empirical studies used a variety of sorbents (dolomitic, anhydritic, and clay-rich rocks) and solutions (Salado, Castile, and Culebra brines), and in some cases included the effects of dissolved organics on sorption.

Because the State of New Mexico felt the early sorption studies were deficient, the DOE and the State of New Mexico modified the Consultation and Cooperation Agreement in 1988 to require New Mexico concurrence on any sorption distribution coefficients $\left(\mathrm{K}_{d} \mathrm{~s}\right)$ recommended for use in the final PA of the WIPP. While experimental data were being obtained, Sandia convened a panel of staff members to estimate ranges and probability distributions of $\mathrm{K}_{\mathrm{d}} \mathrm{s}$ in support of two preliminary PAs (Trauth et al., 1992). In addition, retardation of radioisotopes in the Culebra was more thoroughly studied in the laboratory. Early results from a batch experimental program using crushed dolomite, described in this special issue, were used in the CCA (Larson et al., this issue; Brush and Storz, 1996; Papenguth and Behl, 1996).

\subsection{Waste Properties}

\subsection{Changes in Purpose of WIPP Project}

Although the purpose of the WIPP as a general disposal site for radioactive waste was clear, decisions about what kind of waste would be sent there fluctuated throughout the 1970s. Under consideration were three kinds of waste-TRU waste, high-level waste from reprocessing spent nuclear fuel, and direct disposal of spent nuclear 
fuel-and whether the waste originated from defense or commercial activities. The initial focus of the AEC in the 1950s and 1960s with regard to disposal was on nuclear waste from reprocessing spent nuclear fuel (or high-level waste as it came to be called), because uranium was thought to be in such short supply that it would be necessary to recycle commercial fuel. The initial screening analysis of scenarios for the WIPP assumed 75,000 canisters of highlevel waste, enough to accommodate the anticipated volume of high-level waste from all commercial reactors through the year 2000 (Claiborne and Gera, 1974). However by 1975, the emphasis of the WIPP was disposal of TRU defense waste because of the prominence of the latter as a result of the Rocky Flats Plant fire, and the WIPP was officially removed from the commercial repository program within ERDA.

Yet the public expectation remained that the government should be responsible for disposal of wastes from commercial reactors. During the 1970 s, the lack of a proven waste disposal scheme was presented by the public, through comments on the EIS and at licensing hearings, as an argument against construction of nuclear plants. Furthermore, California passed a law in 1976 banning construction of nuclear power plants until disposal of nuclear waste was demonstrated (Carter, 1987). Therefore, the DOE seriously considered disposal of commercial waste at the WIPP between 1977 and 1979, at least as a means of demonstrating the disposal concept. Conceptual drawings of the WIPP repository in 1977 showed two levels: one for the cooler contact-handled TRU waste, $640 \mathrm{~m}$ below the surface, and the other for remote-handled TRU waste and the hotter high-level waste, $790 \mathrm{~m}$ below the surface (Weart, 1979; Sandia, 1977).

In March 1979, the Interagency Review Group formed by the Carter administration suggested that the WIPP be a candidate for commercial spent fuel. However, the then powerful House Armed Services Committee strongly opposed commercial waste disposal at the WIPP. In response, Congress clearly defined the mission of the WIPP in December 1979 (Public Law 96-164) as a “...research and development facility to demonstrate the safe disposal of radioactive waste resulting from the defense activities and programs of the United States exempted from regulation by the Nuclear Regulatory Commission" (Fig. 8).

Fig. 8. Project goals and characterization of waste properties (adapted from Figure 4-1, Rechard, 1999, which provides extensive references).

\subsection{Transuranic Nuclear Waste}

\subsubsection{Current Waste Description}

Wastes destined for the WIPP consist of laboratory and production materials such as glassware, worn-out equipment and tools, scrap metal and wood, disposable laboratory clothing, cleaning rags, spent solvents that were sorbed or solidified, and solidified sludges, which have been contaminated with TRU radioisotopes. Any waste contaminated by alpha-emitting TRU radionuclides with half-lives greater than $20 \mathrm{yr}$ and activities greater than $100 \mathrm{nCi} / \mathrm{g}$, is considered TRU waste in the United States. Most waste with less than this activity per mass is considered low-level waste.

14 - 3/9/99 Draft 
The DOE classifies TRU waste as either contact-handled $(\mathrm{CH})$ or remotely handled $(\mathrm{RH})$ based on the dose at the surface of the waste container. If this surface dose is less than or equal to $200 \mathrm{mrem} / \mathrm{hr}$, the waste is defined as CH-TRU; if the dose is greater than $200 \mathrm{mrem} / \mathrm{hr}$, the waste and its container are defined as RH-TRU (DOE, 1990c). The WIPP Land Withdrawal Act ratified previous agreements between the State of New Mexico and the DOE, stating that the total combined volumes of CH-TRU and RH-TRU waste were not to exceed 6.2 million cubic feet, and the emplaced RH-TRU waste was not to exceed a total activity of $5.1 \times 10^{6}$ curies or a total activity concentration of 23 curies per liter (averaged over the volume of the canister). Only RH-TRU waste producing a dose of less than or equal to $1000 \mathrm{rem} / \mathrm{hr}$ is eligible for disposal at the WIPP (DOE, 1996a). Furthermore, no more than $5 \%$ of the emplaced RH-TRU waste was to exhibit a dose in excess of $100 \mathrm{rem} / \mathrm{hr}$. While the capacity for CHTRU waste is adequate for all of the DOE's TRU waste produced after 1970, the legal limit is too small to include the CH-TRU waste buried prior to 1970 (Weart, 1979; DOE, 1979; 1980).

\subsubsection{Evolution of TRU Waste Definition}

As noted in Section 2, the definition of TRU waste as a material contaminated with TRU radioisotopes with an activity of $10 \mathrm{nCi} / \mathrm{g}$ was quickly proposed and used as a temporary but safe bound by the AEC in 1970 (Perge, 1982). In its early attempts at nuclear waste standards, the EPA, through simple calculations on resuspended plutonium in soil, concluded in 1979 that a limit of $100 \mathrm{nCi} / \mathrm{g}$ would keep doses below $500 \mathrm{mrem} / \mathrm{yr}$ and thus increased the bound by an order of magnitude (Sjoblom, 1982). The EPA changes in the definition required that the DOE reclassify only a small portion of its TRU waste because less than $20 \%$ was between 10 and $100 \mathrm{nCi} / \mathrm{g}$. The activity of most waste was around $10^{4} \mathrm{nCi} / \mathrm{g}$ (Smith, 1982; WIPP PA Division, 1991, Vol. 3).

\subsubsection{TRU Waste Inventory}

For preliminary PAs between 1989 and 1992, waste activities and mass were estimated from the Integrated Data Base, produced annually by ORNL for the $\mathrm{DOE}$ (see for example, $\mathrm{DB}, 1990$ ), and from requests for information by Westinghouse directly to the waste generator sites (see for example, WIPP PA Division, 1991, Vol. 3). For the CCA, the DOE assembled a baseline inventory, referred to as the Transuranic Waste Baseline Inventory Report (TWBIR) (DOE, 1995). This baseline included estimates of the radioisotope inventory for 569 stored or to-be-generated waste streams for CH-TRU waste and over 400 waste streams for RH-TRU waste. Waste-related input parameters for the CCA analysis were then developed from these data as described elsewhere in this special issue (Sanchez et al., this issue).

\subsection{Waste Characterization Studies}

Two aspects of the TRU waste destined for the WIPP were important to characterize for the compliance calculations: the estimated inventory of radioisotopes in the waste, ${ }^{4}$ and the mobility of these radioisotopes within the

\footnotetext{
${ }^{4}$ About 60 percent of the wastes may be co-contaminated with other hazardous constituents as defined under the Resource Conservation and Recovery Act of 1976 (Public Law 94-580 and subsequent amendments). Hazardous waste constituents are no longer important because Congress exempted the DOE from demonstrating "no migration" of hazardous components above
} 
disposal system. Properties of the waste that influence the chemical environment within the disposal system, and thereby radioisotope mobility, include the amount of iron and microbial nutrients such as wood, plastic, rubber, nitrates, and sulfates.

\subsubsection{Initial EIS Waste Studies}

Simultaneous with site characterization, Sandia began tests in early 1977 on the behavior of TRU waste forms and high-level waste (Molecke, 1978). These tests were to be used by Westinghouse, the technical support contractor for the WIPP, to develop waste acceptance criteria for the various forms of the waste (Sandia, 1979). To ensure waste acceptability, the WIPP Project had sent guidance to the generator/storage sites in 1976 that the waste be incinerated to remove combustible and organic material. However by 1979 , results from initial tests indicated that most characteristics of the TRU waste were acceptable and so incineration was no longer recommended (Sandia, 1979; Weart, 1979).

\subsubsection{Characterization for PA Studies}

Based on the characterization studies for the EIS, the DOE decided in 1980 that further studies of waste characteristics such as gas generation were unnecessary. Furthermore, after passage of the 1987 amendments to the Nuclear Waste Policy Act (Public Law 100-203), most experiments on high-level waste, degradation of container materials, and influence of heat were stopped. However, the decision not to perform waste characterization studies was reconsidered after new data were presented in 1989. The new data included estimates from Lappin et al. (1989) that anoxic corrosion of steel in the waste, if brine were available in the repository, could produce significant quantities of hydrogen gas in addition to any gas produced from microbial degradation of cellulosic material, e.g., wood, in the waste. Second, and as noted previously, in situ measurements of permeability in the Salado, taken while resolving the issue of brine flow into the repository, were found to be 1000 times smaller than those measured earlier (Nowak et al., 1988). An analysis conducted by Sandia (Lappin et al., eds., 1989), using the new assumptions and the new permeability measurements, demonstrated that gas could potentially influence the overall performance of the repository.

Based on initial analysis, the DOE funded Sandia to conduct laboratory studies of gas generation in February 1989. These studies predominately comprised single-process experiments on anoxic corrosion, microbial activity, and radiolysis, most with nonradioactive simulated CH-TRU waste (Brush et al., 1991, 1993). The experiments were completed by September 1995, and the observed gas generation rates were used in the PA for the CCA (Francis et al., 1997; Telander and Westerman, 1997).

Initially, a full-scale pilot phase for the repository had been envisioned by the DOE and Congress. But by the 1980s, the EEG and groups opposed to the WIPP Project saw the pilot phase as a way for the DOE to open the WIPP without certifying that it complied with regulations. They argued that institutional inertia would be so great

health concentration standards. However, the types of hazardous constituents are important for disposal permits with the State of New Mexico 
that the WIPP would remain open, even if it could not comply with all EPA regulations during the transition from the pilot to the operational phase. To justify a pilot phase, the DOE proposed tests to reevaluate gas generation using actual TRU waste in the repository. In 1990, Sandia and Westinghouse presented technical arguments for placing $0.5 \%$ of the waste capacity of the WIPP in the repository (DOE, 1990b). To resolve the issue between the DOE and opposition groups, Congress, in the 1992 WIPP Land Withdrawal Act, required the WIPP Panel of the NAS to certify the scientific need-not just an operational need-for the tests. The WIPP Panel did not see a scientific need for in situ tests, because the data could be obtained by laboratory tests, and so recommended in June 1992 that tests with actual waste be conducted in laboratories instead (NAS/NRC, 1992). The DOE concurred in October 1993. Without a pilot phase, the DOE decided to accelerate into the compliance phase for the WIPP in October 1993, halted most of the in situ experiments, and then completely closed the in situ experimental area in October 1995.

As described in Section 8.4, the waste properties that had been found to be most important in the preliminary PAs were solubility of actinides, primarily plutonium and americium. For the 1991 and 1992 preliminary PAs, an external expert panel had been convened in early 1991 to evaluate solubility data for the radioisotopes (Trauth et al., 1991; 1992). The panel examined existing data and developed probability distributions of solubilities to express the uncertainty thought to pertain at the WIPP repository. Also, related experimental programs were initiated. As described elsewhere in this issue (Ramsey et al., this issue), solubility experiments were conducted with one actinide (either Am, Np, Th, U, or $\mathrm{Pu}$ ) for each of four possible oxidation states $(+\mathrm{III},+\mathrm{IV},+\mathrm{V},+\mathrm{VI})$ at various $\mathrm{pH}$ and brine compositions. Behavior of other actinides with an equivalent oxidation state was assumed to be similar, e.g., the measured solubility of $\mathrm{Pu}(\mathrm{III})$ was assumed to be similar to the solubility of $\mathrm{Am}(\mathrm{III})$. The influence of organic ligands on solubility was also studied, and the solubility of actinides in high ionic strength brines was modeled (see Section 7.3.3). The experimental and modeling results were then combined to produce a distribution of solubility from which to sample for the 1996 PA calculations in support of the CCA (Fig. 9).

Fig. 9. Solubility of radioisotopes used in calculations between 1989 and 1996 for (a) plutonium and (b) uranium (Rechard, 1999).

\subsection{Design, Construction, and Behavior of Repository}

The repository, or underground facility, of the WIPP disposal system is $655 \mathrm{~m}$ beneath the surface at an elevation of $384 \mathrm{~m}$ above mean sea level. In the 1977 conceptual design, the basic room layout for CH-TRU disposal was developed (Sandia, 1977), which remained essentially unchanged in the final design although some room dimensions were modified in 1980 in response to numerical modeling results. The modifications to the room dimensions were validated in 1982 by observing deformations in several test rooms (Tyler et al., 1988). In situ experiments also helped to refine constitutive equations in numerical models in the mid 1980s and to evaluate concepts such as backfilling the repository and estimating potential amounts of brine inflow to the repository in the late 1980s and early 1990s (Tyler et al., 1988).

$17-3 / 9 / 99$ Draft 


\subsection{Design of Repository}

\subsubsection{Early Conceptual Design}

Concurrent with site selection and writing the EIS, Sandia prepared the conceptual design of the WIPP surface and underground facilities (Sandia, 1977). The basic design drew on information gained from experience with nearby potash mines in the Delaware Basin. However, the extraction ratio was dramatically reduced to $-33 \%$ overall ( $\sim 40 \%$ in any one disposal panel) to increase room stability and mine safety. The design for the transport containers and other hardware was based on Sandia's experience with equipment design at the Nevada Test Site. The conceptual design was completed in 1977 (Sandia, 1977). The disposal area for the CH-TRU waste was set at $373 \mathrm{~m}$ elevation and consisted of eight closely spaced panels with eight rooms in each panel. Each room was $5 \mathrm{~m}$ high, $14 \mathrm{~m}$ wide, and $137 \mathrm{~m}$ long (Fig. 10a). In the rooms, the $\mathrm{CH}$-TRU waste was to be stacked four barrels high. The experimental area and disposal area for the high-level waste (RH-TRU waste, high-level waste, and spent nuclear fuel) was set at a 200-m elevation near the base of the Salado. The repository had five shafts.

Although expansion was contemplated, space for CH- and RH-TRU waste buried prior to 1970 and TRU waste produced from future decontamination and decommission of facilities was not included in the initial design. Also, the volume of high-level waste was not known. However, in December 1979, Congressional legislation limited the WIPP to the disposal of defense TRU waste only. The second level was abandoned and the repository was reconfigured for the Final EIS as a single-level facility with four shafts (DOE, 1980).

Fig. 10. Designs for WIPP repository including (a) 1977 conceptual design (Sandia, 1977) and (b) final construction plans for WIPP. repository (Rechard, 1995).

\subsubsection{Detailed Design}

In 1978, the DOE contracted with Bechtel National, Inc., to be the architect/engineer for the WIPP Project, and Westinghouse Electric Corporation, for technical support. The preliminary design of the WIPP (or "Title I design" in the language of the DOE orders) began in July 1979 and moved to a detailed design ("Title II") phase by February 1981. The disposal area provided enough space for the disposal of the projected $176,000 \mathrm{~m}^{3}$ of waste and consisted of eight panels spaced $61 \mathrm{~m}$ apart with eight rooms in each panel, $30.5 \mathrm{~m}$ apart. Each room was $4 \mathrm{~m}$ high, $10 \mathrm{~m}$ wide, and $91 \mathrm{~m}$ long. The detailed design envisioned that waste would be emplaced in all drifts, including those that connected rooms, and not just in the rooms as shown in the conceptual design. Also plans indicated that waste would fill the center section, where the panels joined the main drifts; this section was divided into southern and northern equivalent panels, bringing the panel total to 10 . The extraction ratio for a panel was similar to the conceptual design (38\%), but the overall extraction ratio of the disposal area was decreased further to $22 \%$.

In March, Bechtel began final design ("Title III") of the repository, and a design report was published in 1986 (Bechtel, 1986). Some modifications were necessary after the final report was published concerning the backfill (discussed in a later section) and drum emplacement. In the design submitted for the CCA, the TRU waste is to be placed in 55-gallon drums, grouped as 7-packs, 3 drums high (Fig. 10b). The change from a 6-pack drum grouping to

$18-3 / 15 / 99$ Draft 
a 7-pack was in accordance with container modifications as they evolved from the initially proposed TRUPACT I transportation container, whose design was rejected by the EEG in 1985 (Channell et al., 1986), to the TRUPACT II container certified by the NRC in August 1989. (According to the 1987 modification to the Consultation and Cooperative Agreement between the DOE and the State of New Mexico, the NRC had jurisdiction over transportation of all types of nuclear waste.)

\subsection{Construction of Repository}

After publication of the Final EIS in 1980 and a record of decision in January 1981, the DOE began the Site and Preliminary Design Validation (SPDV) program to further characterize stratigraphy near the repository and validate room dimensions in the preliminary design. As part of the SPDV program, Fenix \& Scisson, Inc., Sandia's contractor for the conceptual design and DOE's SPDV contractor, drilled two shafts starting in May and June, 1981. The first shaft, 3.6-m in diameter, was initially called the exploratory shaft, then renamed the construction and salt handling shaft, and finally referred to as the salt handling shaft. The second shaft drilled, the $1.8-\mathrm{m}$ ventilation shaft, was later renamed the waste shaft (DOE, 1996a).

In June 1982, the Army Corps of Engineers assumed responsibility for managing the SPVD and subsequent construction. Once the second shaft was completed in March 1982 and the repository level selected, excavations were begun in October to connect the two shafts, which was completed by the end of November. In the second half of the year, four full-sized disposal rooms were excavated, $4 \mathrm{~m}$ high, $10 \mathrm{~m}$ wide, and $91 \mathrm{~m}$ long, separated by $31-\mathrm{m}$ wide pillars. Although Bechtel's initial repository design placed the waste disposal area north of the experimental area, the disposal area was moved south of the shafts at the end of 1982 after the discovery of a brine reservoir in WIPP-12. Shortly thereafter, a drift to the south end of the disposal area was excavated and instrumented to confirm the stratigraphy and evaluate deformations around the repository.

In March 1983, the results from in situ experiments in the SPDV rooms were reported (Tyler et al., 1988). Sandia helped analyze data from these and other geologic field activities and from geomechanical instrumentation to determine whether the design criteria were suitable and to confirm the reference design for the underground opening (Tyler et al., 1988). Also that month, excavation began on rooms for Sandia's geotechnical experiments.

The WIPP Panel of NAS toured the underground excavation for the first time in April 1983 to examine the SPVD rooms. Four months later, DOE announced its decision to proceed with full construction of surface facilities and continued excavation of the underground facility. The pilot hole for the third shaft, the exhaust shaft, was drilled in September 1983. Reeming of the pilot hole to $3.6 \mathrm{~m}$ from the underground to the surface, and then blasting to the final $4.6 \mathrm{~m}$ diameter was finished by January 1985 (DOE, 1996a). Between April and June 1984, the waste shaft diameter was enlarged from 1.8 to $6 \mathrm{~m}$. In preparation for operations, the Management and Operations (M\&O) contract was awarded to Westinghouse, which conducted the remaining construction activities after October 1986. In 1988, a fourth shaft was added for increased air circulation (Fig. 11). A pilot hole was first drilled from the surface and then reemed to a final $6.2 \mathrm{~m}$ diameter from the underground to the surface. By the end of 1988 the surface and underground facilities were essentially complete; they were declared officially complete in January 1990.

$19-3 / 15 / 99$ Draft 
Fig. 11. Events associated with design, construction, and modeling of the WIPP repository (adapted from Figure 5-2, Rechard, 1999, which provides references).

\subsection{Experiments and Model Development of Repository Behavior}

Early in the history of the WIPP Project, the DOE viewed the WIPP as a research and development facility that would conduct experiments that supported model development of salt creep and experiments on backfilling and sealing the repository, brine movement, and areas of interest to high-level waste disposal concepts such as canister material behavior.

\subsubsection{Experiments with Salt Creep Behavior}

Sandia began to build a salt creep laboratory in 1974. Testing on specimens from mines and salt domes was in progress by 1975, and creep in salt from ERDA-9 cores was studied in 1977. Sandia initiated a 3-year program in 1979 to evaluate, through in situ and laboratory experiments, salt deformations around mine openings and the effects of heat on acceleration of salt creep. The in situ experiments were conducted in a nearby potash mine and at the Avery Island salt dome in Louisiana. Laboratory creep tests were started on larger specimens from the underground workings of the WIPP in 1982; in situ salt creep experiments at the WIPP also began in 1982 as the main drift through the disposal area, the "south drift," was excavated. Sandia began fielding more extensive in situ salt creep experiments in 1984 as experimental rooms were completed; heat was turned on in these rooms in 1985 to measure accelerated salt creep. However, when Congress decided in 1987 to characterize only the Yucca Mountain site in Nevada as a commercial spent-fuel and high-level waste repository (Public Law 100-203), the DOE canceled the simulated high-level waste experiments at the WTPP.

\subsubsection{Modeling of Repository Behavior}

The first modeling efforts in 1975 reviewed empirical constitutive creep laws developed during Project Salt Vault and numerical modeling capabilities available in the mining industry. Some of the first calculations, completed in 1978, evaluated a potential concern that hot canisters would become buoyant in the plastic salt and move significant vertical distances (Dawson and Tillerson, 1978). Sandia modeled the repository, with Sandia-developed codes and constitutive laws (Tyler et al., 1988), and used the results in 1980 (Krieg et al., 1981) to examine the reasonableness of various proposed modifications to the room dimensions in the 1977 conceptual design, which had been based on experience with the area's potash mines. Predictions from other numerical codes were compared extensively to test data in 1980, and more calculations on predicted room deformation were conducted in 1982 and 1985 (Morgan et al., 1985). Although from a practical standpoint, the predicted and measured values of salt creep were close, the manually measured salt creep in the south drift in 1982 and the automated measurements of the SPDV rooms and various other experimental rooms in 1982-83 were nevertheless about three times greater than predicted values (Morgan et al., 1985). Thus between 1985 and 1989 an alternate conceptual model and mathematical expression were incorporated into codes and tested. Thereafter, agreement of predictions with in situ measurements was excellent (Munson et al., 1989).

$20-3 / 9 / 99$ Draft 


\subsection{Repository Backfill}

\subsubsection{Use of Backfill in Disposal Area}

The DOE had considered the use of backfill in the disposal area from the time of the initial conceptual design (Sandia, 1977). In 1976, some thought was given to placing sorptive minerals such as apatite or bentonite around the drums to sorb radioisotopes. More importantly, it was assumed that backfill would be emplaced in the repository to help fill the void space and reduce the magnitude of subsidence in overlying units, in addition to mitigating the potential for any underground fire (DOE, 1980). Although backfill in the disposal area was considered part of the baseline design for the repository (Sandia, 1977; DOE, 1980), as reported in the supporting documents for the Supplemental EIS (Lappin et al., 1989) and the four preliminary PAs through 1992, the need for the backfill to mitigate subsidence and fire propagation diminished during the 1980s. These findings were formally reported in 1990 in the Safety Analysis Report (DOE, 1990a), which concluded that fire propagation in the waste disposal region was unlikely even without backfill, and in a 1994 Westinghouse study (WEC, 1994), which indicated that the addition of backfill would have a negligible impact on the subsidence of overlying units.

For the 1996 PA in support of the CCA, however, backfill was reconsidered and again included in the design. A chemical backfill of $\mathrm{MgO}$ was proposed that would combine with any microbially produced $\mathrm{CO}_{2}$ so that brine present in the repository would not become acidic, thereby increasing the solubility of the actinide radioisotopes. Modeling of the $\mathrm{MgO}$ chemical backfill is discussed further in this special issue (Hansen et al., this issue).

\subsubsection{Shaft Backfill and Sealing Methods}

Because of the difficulty presented by the presence of boreholes in the vicinity of the abandoned Lyons, Kansas, site, experiments on borehole plugs were immediately pursued by the WIPP Project in 1975. By 1977, three grouts had been selected and tested by plugging ERDA-10 drilled south of the WIPP site (near the Gnome site) (see Fig. 3). In 1979, an experiment in AEC-7 tested the ability of a plug to withstand the 12.7-MPa pressure of the Ramsey Sands aquifer in the Bell Canyon Formation (Tyler et al., 1988).

Initial concepts for backfilling shafts were described and the first laboratory tests on compacting crushed salt conducted in 1982. Sandia presented the first conceptual design for shaft backfill in 1984, which continued to evolve during the late 1980s. Crushed salt, the primary backfill for the shafts through the Salado (usually referred to as "seals" in the WIPP Project), was expected to limit the creation of a preferred pathway for contaminant migration. Sandia developed a machine to build salt bricks from crushed salt in 1986 such that portions of the salt backfill in the drifts and shafts would be compacted to ensure adequate densities. Studies were conducted and reported in 1987 to estimate the density of reconsolidated salt under the lithostatic pressure from creep closure of the shaft (Nowak and Stormont, 1987). This study suggested $95 \%$ of intact salt densities could be obtained in the lower portions of the shaft in less than $100 \mathrm{yr}$, provided some brine $(-2.5 \% \mathrm{wt})$ was added to the crushed salt. As described in this special issue (Hansen et al., this issue), compacted salt (through tamping) is planned to obtain a highly dense backfill during emplacement.

\footnotetext{
$21-3 / 9 / 99$ Draft
} 
Stopping brine flow to the salt backfill from aquifers in the Rustler and upper units was also thought necessary because significant volumes of brine might delay or even prevent consolidation of the crushed salt. The first shaft sealing concepts envisioned large plugs of concrete, concrete-grout, or possibly other mixtures directly below the Rustler and halfway down the salt column to protect the lower crushed salt component prior to consolidation (Stormont, 1988; Lappin et al., 1989, Figure 4-10). However in 1990, bentonite clay, a swelling clay shown to be stable and with low permeability in brines in 1979 and 1984 studies, was added as a separate long-term component to the seais in the Rustler and at other seal locations in the Salado (Nowak et al., 1990). Details of the various options were developed in 1993 (Van Sambeek et al., 1993). In the 1990s, a more complete testing program was begun to demonstrate and develop confidence in the sealing concepts of the backfill and asphalt was added as a longterm component, as described in this special issue (Hansen et al., this issue).

\subsubsection{Panel Sealing Methods}

Initially, the repository design did not include constructed barriers to separate the waste into modules. But when the WIPP Panel of the NAS expressed concern that fire in combustible portions of the waste could pose a hazard to mine workers, barriers throughout the disposal area were proposed to enhance mine safety. Shortly thereafter, plans called for isolating individual panels over the long term, with 30- to 40-m-long seals composed of preconsolidated salt and large concrete plugs at each end (Lappin et al., 1989; Nowak et al., 1990). During the early 1990s, the value of panel seals was questioned (Rechard et al., 1990) because of their limited ability to contain gas given the presence of anhydrite layers above and below the drifts. However, because they afforded some protection, the EPA stipulated that panel seals be used at the WIPP in its ruling on the compliance of the WIPP in 1998 (62 FR 58792; 63 FR 27354).

\subsection{Hazard Identification and Scenario Development}

The first list of hazards for consideration at the WIPP was published in 1974 about the same time as site selection (Claiborne and Gera, 1974). The list was updated in 1979 for the EIS (Bingham and Barr, 1979, 1980), in 1989 for the preliminary PAs (Hunter, 1989), and in 1995-96 for the final PA (Galson and Swift, 1995). The latter* update is described further in this special issue (Galson et al., this issue). Although the process of identifying hazards and then selecting specific hazards for modeling was relatively informal initially, with each iteration the process of identifying hazards became more rigorous. Engineering analysis can be conducted without hazard identification as an explicit step, but in PA it is not only useful for the step to be formal but is also one aspect that sets it apart from small-scale analysis.

\subsection{Description of Hazard Identification}

\subsubsection{Categories of Hazardous Agents}

By the late 1980s, agents of hazards were typically categorized as features, events (i.e., short-term phenomena), and processes (i.e., continuous phenomena) or "FEPs" that act upon the system whereby a hazard might occur. The

$22-3 / 9 / 99$ Draft 
event category had already been used in the Reactor Safety Study of 1975 (Rasmussen, 1975), which inaugurated large PRAs. When this work was applied to a geologic disposal system in 1976, the definition of agents was broadened to include processes. Then in 1981, the IAEA formally considered "undetected features" (IAEA, 1981).

\subsubsection{Scenarios}

In the WIPP Project, a future (or "elementary event" in the terminology of probability theory) is a hypothetical chain of physical events and processes, including particular features. A scenario (or scenario class) is a group of futures; it is sometimes represented by a key future with specific common attribute(s), e.g., human intrusion. Futures were grouped into various scenarios in the WIPP Project to focus attention on certain hazards, such as human intrusion. Grouping is feasible and practical if the probabilities of a FEP residing in the scenario class are easily calculated and if behavior within the scenario class is similar enough that a single, key future can characterize and represent the whole scenario class.

Given that a mathematical model of the disposal system exists, $C(\bullet)$, "future" and "scenario" can be precisely defined in terms of the parameter space, $\mathbf{x}$, as follows. The parameter space $\mathbf{x}$ can be arbitrarily divided into two subsets: a subset defining conditions of scenarios, $x_{s}$, and a subset of remaining model parameters, $x_{s b}$, i.e., $x=\left[\mathbf{x}_{s t}\right.$, $x_{s b}$. A future is one point in parameter space for scenarios, $x_{s t}$, and a scenario is a grouping of similar futures or subsets of $x_{s s}$, i.e., $S_{j} \subset x_{s t}$ where $S_{j}$ is a scenario of what can occur to produce an unwanted outcome. For example, a scenario might be described as $S_{j}=\left\{x_{s t, 1}<a\right.$ and $\left.x_{s t, 2}>b\right\}$, where $x_{s t, 1}$ and $x_{s t, 2}$ defined conditions for human intrusion and location of a brine reservoir, respectively. Characterization of scenarios and their uncertainty, $x_{5 s}$ came to be known as stochastic uncertainty within the WIPP Project to distinguish it from the more general epistemic (or subjective) uncertainty associated with model parameters, $\mathbf{x}_{s b}$. Both are described further in this special issue (Helton et al., this issue-a; Tierney et al., this issue).

\subsection{Hazard Identification After Site Selection}

\subsubsection{Features, Events, and Processes Considered}

After site selection in 1973-74, ORNL identified hazards not eliminated by the selection process for the WIPP (Claiborne and Gera, 1974). Natural events considered were volcanism, faulting, erosion, and meteorite impact (the latter not site specific). Climatic change and nuclear criticality were mentioned only. Anthropogenic events were drilling, sabotage, and nuclear warfare (the latter two events were not site specific). The primary process considered was groundwater transport of radioisotopes following faulting or meteorite impact. No undetected features were considered.

\subsubsection{Screening Calculations}

Claiborne and Gera (1974) also qualitatively evaluated the consequences and/or probabilities of the FEPs, although a few FEPs were analyzed deterministically. Readily dismissed were effects after closure from sabotage (which would require an occupying army to drill into the repository) and a crater from a surface blast of a nuclear 
weapon (which could not reach the repository). Exposure from drilling was thought to be limited to the drilling crew. Failure of borehole plugs after a well had been abandoned was considered, however potentiometric heads at the site were believed to favor flow to aquifers below the repository and it was argued as unlikely that an individual would drill so deeply to obtain salty water (Culebra brine flowing through the Salado into the deep aquifers would become even more salty). Measurable consequences from a meteorite impact or faulting that moved the repository near the Culebra aquifer were estimated but the probabilities of the events were thought to be very low. The WIPP site is in one of the most tectonically stable parts of the United States and the probability of a catastrophic meteoritic impact was believed to be about $1.6 \times 10^{-13}$ per year.

\subsection{Hazard Identification and Scenario Development for EIS}

In 1976, Sandia first began to develop descriptions of potential mechanisms through which radioactive waste could be released for the safety analysis to be included in the EIS. The purpose was to enumerate which processes might need further experimental study, which should be included in computer modeling, and which could be eliminated.

\subsubsection{Features, Events, and Processes Considered}

For the EIS, Sandia considered events similar to ORNL's list but in a more formal manner. Sabotage, nuclear warfare, erosion, and meteorite impact were quickly dismissed as single events, although retained as initiating events for other events that would affect release. In addition to groundwater transport, new processes included climatic change, subsidence, continued dissolution of salt directly over the site, diapirism (i.e., formation of salt domes in the strata overlying the salt beds because of repository heat), and buoyancy of canisters (i.e., vertical movement of canisters because of repository heat). Nuclear criticality, diapirism, and buoyancy of canisters had been added because of public attention, but were dismissed after evaluation (Bingham and Barr, 1979, 1980; Dawson and Tillerson, 1978).

\subsubsection{Construction of Scenarios}

To link FEPs into futures, the WIPP Project first attempted to use fault trees but found the method untenable for three main reasons: the fault tree quickly became large and unmanageable; it was difficult to determine whether futures were mutually exclusive; and it was difficult to include time dependent events. Instead, Sandia developed a method based on event trees that began with a system that was not disrupted, and subsequent events that provided mechanisms for moving radioisotopes through the disposal system (Fig. 12a). The WIPP futures fell into three scenario classes (Bingham and Barr, 1979, 1980): (1) those that exposed waste directly to the biosphere, e.g., drilling through the repository, (2) those in which water flowed between two aquifers after borehole plugs had failed in exploratory drill holes, and (3) those in which water flowed from only one aquifer, requiring diffusion and convection to move radioisotopes through the salt. These three categories of scenarios were analyzed early in 1978 for inclusion in the Draft EIS (DOE, 1979). 
Fig. 12. Technique to construct scenarios from various features, events, and processes changed between WIPP EIS in 1979 and PA calculations after 1989.

\subsubsection{Hazards Related to Waste Acceptance Criteria}

As described in Section 4, potential hazards from the waste were evaluated for the EIS while attempting to establish waste acceptance criteria. These hazards included combustibility, microbial gas generation and enhanced mobilization of actinides related to organic content, nuclear criticality, and excessive mobilization, corrosion, and gas generation related to volume of liquids in sludge wastes. The repository was found capable of mitigating all existing hazards, except for sludge waste with high liquid content. For sludge waste, insufficient tests had been run to estimate consequences and so free liquids in the waste were limited instead (Sandia, 1979).

\subsection{General Scenario Development}

While the DOE was examining hazards at the WIPP, the NRC funded another group within Sandia (separate from the WIPP Project) at the end of 1976 to pioneer work on a PRA on geologic disposal of commercial high-level waste and spent nuclear fuel (Campbell et al., 1978). Their work benefited from the early work at the WIPP and the commercial disposal program at ORNL. Later the WIPP Project was to benefit from the NRC's efforts.

\subsubsection{Defining Universe (FEPs List)}

In 1976, the NRC funded a panel of earth scientists to generate a generic list of FEPs as a starting point in assessing the performance of a geologic repository (Cranwell et al., 1990). In a related international effort in 1981, the IAEA recommended a list of FEPs for initial consideration, along with a suggested procedure for performing an assessment (TAEA, 1981).

\subsubsection{Screening Universe and Forming Scenarios}

At first, the NRC requested that this Sandia group pursue a scenario development process similar to the Reactor Safety Study (Rasmussen, 1975). However, like the Sandia WIPP Project, they found discretization of a highly coupled geologic disposal system by means of fault trees was not a simple or useful task. In a draft report in 1981 (final report published in 1990) (Cranwell et al., 1990), Sandia proposed to the NRC a method to screen out unreasonable FEPs and form a limited number of scenarios. The procedure included forming scenarios by combining specific remaining FEPs by means of a logic diagram in which each pathway led to a scenario class. Combinations of all events were used to construct scenarios, and the time (or order) of occurrence was not considered (Fig. 11). Hence, fewer scenarios were generated. Instead broad classes of scenarios were developed that were convenient for modeling and construction of complementary cumulative distribution functions (CCDFs); time and order of occurrence of the FEPs were included during modeling.

\subsubsection{Including the Human Intrusion Event}

Because injection boreholes and the salt dissolution around them at the proposed repository at Lyons, Kansas; were discovered after site selection, human intrusion, both intentional and inadvertent, was included in the initial 
repository analysis for the WIPP. However, the inclusion of human intrusion eventually became controversial. During the late 1970s, each site with previously buried TRU waste and low level radioactive waste, such as INEEL or Los Alamos, prepared an EIS that evaluated disposal alternatives, e.g., leaving the waste as is, improving the trench covers, or retrieving and shipping the waste to the WIPP. Usually human intrusion of some type provided a significant portion of the calculated consequences but attaching a probability to the event was difficult (Smith, 1982). Also, no one knew how the human intrusion event related to the robustness of the disposal system except that more varied types of intrusion would likely occur for disposal sites at shallow depths or for sites near unique mineral resources.

In the draft of 40 CFR 191 (47 FR 58196) published in 1982, the EPA reduced the scope of human intrusion to an inadvertent activity, specifically from exploratory drilling primarily for oil and gas deposits. Thus, the risk from human intrusion became a measure of the type of media selected, the depth of the repository, and its association with economic minerals. A natural extension, although unstated until 1996 in 40 CFR 194 (61 FR 58499), was to assume the exploratory drilling used technology currently operating in the region. This assumption was conservative given acceptance of the proposition that the repository presented the greatest hazard to a society with capabilities similar to ours rather than to a society with less or greater technical prowess. In 1995, the NAS recommended that the calculation of risks from human intrusion be distinctly separate from those from natural migration of disposed waste (NAS/NRC, 1995).

\subsection{Hazard Identification for Preliminary PAs}

\subsubsection{Hazards Identified in $1980 \mathrm{~s}$}

Several natural processes that might compromise the disposal system had been postulated during the early $1980 \mathrm{~s}$ and mandated investigations by agreements with the State of New Mexico. The possibilities of dissolution of the Salado (to form "breccia pipes") and dissolution at great depths in the Culebra at the site (causing "karst" hydrologic flow) were examined by the USGS (Snyder et al., 1982) and Sandia (Lambert, 1983). They were resolved as either not likely to occur at all or not in a manner that would impair WIPP performance, respectively. However by 1987 , the presence of a brine reservoir under the repository in the Castile could not be unequivocally dismissed and so became a potential undetected feature. In addition, the Supplemental EIS of 1989 identified gas generation as an important process to reexamine.

\subsubsection{Features, Events, and Processes Retained}

The FEPs for the WIPP were reevaluated in 1989 (Hunter, 1989) in conjunction with a demonstration of the PA methodology. The basic features retained included an undetected brine reservoir under a portion of the repository, seals in the shafts to limit downward movement of Culebra brine or upward movement of contaminated gas and brine from the repository (see Section 5), an overlying, fractured brine aquifer in the Culebra, spatial variability of transmissivity fields (zones were analyzed in 1989-1990, and random fields analyzed thereafter), and fractured anhydrite beds slightly above or below the repository horizon (see Section 3) (Fig. 13).

$26-3 / 16 / 99$ Draft 
Fig. 13. Engineering analysis of the illustrated behavior of the disposal system (adapted from Fig. 6-2, Rechard, 1999, which provides references).

The primary basic event considered was human intrusion from exploratory drilling. However, disturbance of the stratigraphy from potash mining above the repository and nuclear criticality were also identified, although not included as events until the 1996 analysis for the CCA. No disruptive natural events with probabilities greater than $10^{-4}$ per $10^{4}$ yr were identified for any of the PAs conducted for the WIPP (Hunter, 1989; Galson et al., this issue).

Natural processes retained for the preliminary PAs included climate variability (analyzed separately in 1989 and included in PAs after 1990), hydrologic transport in fractures of the Culebra (alternative models explored in 1992), generation of gas from container corrosion or microbial degradation of organic material such as cellulose in the waste, two-phase (brine and gas) Darcy flow in and around the repository in the Salado, pressure-dependent creep of salt around the waste in 1992, and fracturing of anhydrite layers in 1994.

\subsubsection{Undisturbed Scenario}

The undisturbed scenario, E0, represented the performance of the disposal system from the time of disposal through the 10,000-yr regulatory period and incorporated all expected changes in the system and associated uncertainties (Fig. 12b). In the 1989 PA, two potential pathways for migration of contaminants were considered. In the first path, the pressure gradient between the waste disposal panels and the Culebra might cause brine and radioisotopes to migrate either through drifts or anhydrite interbeds to the base of the shafts and then upward to the Culebra. In the second path, brine and radioisotopes migrated laterally from the undisturbed repository through thin anhydrite interbeds toward the subsurface boundary of the accessible environment within the Salado. In all PAs conducted for the WIPP, no radioisotope releases occurred for the undisturbed scenario. In November 1996, the NAS echoed the findings of WIPP analyses that showed that the excellent isolating properties of bedded salt at the WIPP could be compromised only by human intrusion (NAS/NRC, 1996).

\subsubsection{Human Intrusion Scenarios}

In the PAs, the only disruptive event for scenario construction was inadvertent human intrusion. As described further in Section 8, after 1990 the future inadvertent drilling events were assumed to occur randomly in time and space, that is, each drilling event was independent of every other drilling event, mathematically described as a Poisson process (Helton, 1993c).

In the human intrusion scenario, it was assumed that if the disposal area of the repository were penetrated by an exploratory borehole, radioisotopes could be released in two different ways over two different time scales. First, an immediate release could occur during the drilling process, because the drill bit was assumed to bore vertically through a stack of CH-TRU waste containers or through a single RH-TRU waste container. Material within the containers could be ground up by the drill bit (called cuttings) and transported to the surface by the circulating drilling fluid. Additional material might be eroded from the walls of the borehole by the swirling action of the drilling fluid (called cavings) or the spalling of solid material into the hole as the panel depressurizes. Second, 
although it was assumed the boreholes would be plugged upon abandonment according to current industry standards, selective degradation of these plugs, accompanied by an eventual shift to a permeability similar to that of sand (as suggested in Appendix C of 40 CFR 191), could lead to the possibility of long-term releases by means of transport through the repository, up the boreholes to the aquifer in the Culebra, and then laterally through the Culebra toward the boundary of the accessible environment.

In a refinement of FEP screening in 1990 (Guzowski, 1990), the presence of the brine reservoir in the underlying Castile was combined with exploratory drilling to produce three representative intrusion scenarios: E1, a borehole drilled through the repository and the brine reservoir; E2, a borehole drilled through the repository only; and E1E2, a combination of the two. In the scenarios, the borehole plugs were assumed to degrade so that contact was maximized between the pressurized Castile brine and the panel of waste. These plug configurations were chosen to facilitate examination of the specific scenarios and did not reflect the most realistic conditions expected. Any brine entering through the boreholes was assumed to access all waste within one panel. For improved computational resolution, the three scenarios were divided further into computational scenarios on the basis of time of intrusion and radioactivity of the intersected wastes beginning in 1991 (Helton and Iuzzolino, 1993). In addition, E2-type intrusions were not analyzed explicitly but rather assumed to have the same consequences as E1-type intrusions (WIPP PA Division, 1991/1992).

\subsection{Hazard Identification for 1996 PA}

For the 1996 PA in support of the CCA, a formal hazard identification and screening process was conducted that fully documented the reasons for omitting or retaining specific FEPs, as described further in this special issue (Galson et al., this issue) and elsewhere (Galson and Swift, 1995). Hazard identification began with lists developed in the 1990s for international programs and relied heavily on the comprehensive list developed by Sweden in 1993 (Stenhouse et al., 1993). Two human-initiated events were added to the initial list: (1) subsidence in the Culebra after potash had been mined above the repository, as mandated by the implementing regulation for the WIPP, 40 CFR 194, and (2) the potential for inadvertently injecting large volumes of water into the repository through anhydrite layers in the Salado because of failed casing. The latter event was based on experience in the Delaware Basin from drilling new oil wells in areas where water flooding had previously occurred to enhance oil recovery in deep reservoirs (Stoelzel and O'Brien, 1996). Prior to 1996, the uncertainty about whether the most appropriate FEPs had been included for analysis had not been formally reviewed. However, during its 1997 review of the CCA, the EPA closely examined the justifications for eliminating various FEPs. In particular, the removal of the water flood event was scrutinized and the EPA requested additional analysis. These analyses are discussed further in this special issue (Stoelzel et al., this issue).

\subsection{Consequence Analysis}

Although various components of the disposal system had been analyzed independently since project startup, the first major consequence analysis of the disposal system as a whole was conducted in 1979 for the EIS (DOE, 1979; 
DOE, 1980). Thereafter, the whole system was analyzed for the Supplemental EIS in 1989 (Lappin et al., 1989; DOE, 1990c), during the four preliminary PAs between 1989 and 1992 (Marietta et al., 1989; WIPP PA Division, 1991/1992; WIPP PA Department, 1992/1993), and for the 1996 PA in support of the CCA (DOE, 1996a), as described in several articles in this special issue. Currently, component and system analysis continues in preparation for recertification, which is required every five years during operation of the WIPP.

As previously mentioned, the consequence model is typically divided into two major model categories: (1) a model for the human receptor for a toxicity assessment and (2) a model, $f(\bullet)$ of the environment around the receptor, to conduct an exposure assessment that includes uncertainties. For the original EIS, the EPA performed the toxicity assessment, based on a simple linear bounding response curve, when it established its release criteria in 40 CFR 191, as promulgated in 1985 and 1993 (50 FR 38066; 58 FR 66398).

The various physical scales in the WIPP geologic disposal system made one detailed exposure pathway model, $f(\bullet)$, impractical. Instead $f(\bullet)$ was further divided into many complex component models $f_{\alpha}(\bullet)$; results from one model, $f_{\alpha}(\bullet)$, became variables used by the next model, $f_{\beta}(\bullet){ }^{5}$ All models $f_{\alpha}(\bullet)$ were dependent on the scenario $S_{j}$ (stochastic model parameters, $\mathbf{x}_{s t}$ ) under consideration and the subset of epistemic model parameters $\mathbf{x}_{\mathrm{sb}}$ related to that scenario. The following sections discuss the component models, $f_{\alpha}(\bullet)$, used for the WIPP.

\subsection{Analysis for Site Selection and EIS}

\subsubsection{Site Selection Analysis}

Although the consequence analysis performed during site selection by ORNL (Claiborne and Gera, 1974) is closer to a screening analysis, it influenced the assumptions and modeling techniques for the original EIS on the WIPP and so is described here. The analysis included assumptions about two component models $f_{f}(\bullet)$ : the source term model and the flow and transport model in the Culebra.

Source Term Modeling. In 1974, the radioisotope source was assumed to be high-level waste in 75,000 borosilicate glass canisters that were placed in the repository floor. Water from over- or underlying aquifers was assumed to have access to only a portion of the inventory-either 98 canisters in a short row or 765 canisters in a long row. The leach rate was set at $10^{-7} \mathrm{~g} / \mathrm{cm}^{2}$ per day, based on measured leach rates in borosilicate glass, and resulted in release rates of between $130 \mathrm{Ci} / \mathrm{yr}$ after $10^{3} \mathrm{yr}$ and $5 \mathrm{Ci} / \mathrm{yr}$ after $10^{6} \mathrm{yr}$.

Culebra Flow and Transport Modeling. In general, flow through the repository was assumed to be from the Culebra aquifer to deeper aquifers. However, transport of radioisotopes after catastrophic faulting placed the repository at the same level as the Culebra aquifer was analyzed. The radioisotope inventory was simply diluted by the volume of flow through the Culebra and by the minimum annual flow of the Pecos River at Malaga Bend. The

\footnotetext{
${ }^{5}$ For example, a cuttings and cavings model, $f_{C}$ was used and called CUTTINGS_S; the two-phase flow model, $f_{B}$, was called BRAGFLO in the 1996 PA; both models are discussed further in this special issue.
} 
dilution from the Culebra, as estimated from data from the Gnome site (Gard, 1968), was $1.1 \times 10^{5} \mathrm{~m}^{3} / \mathrm{yr}$ based on a 2.4-km-wide repository, 9-m-thick Culebra, and a Culebra porosity of 0.10 .

\subsubsection{EIS Analysis}

In support of the EIS on the WIPP (DOE, 1979; 1980), the consequences of release were evaluated in terms of human exposure to radioisotopes that had reached the biosphere by some mechanism (Powers et al., eds., 1978). As described in Section 6, three pathways to humans were of concern: direct release and two groundwater pathways. The consequences of release by these three pathways were treated deterministically and individually. The period considered for evaluating the environmental impact of the WIPP was $2.5 \times 10^{5} \mathrm{yr}$, roughly ten half-lives of ${ }^{239} \mathrm{Pu}$. The consequence analysis used four component models $f_{\alpha}(\bullet)$ : the direct release model, the source term model, the Culebra flow model, and the Culebra transport model.

Direct Release Modeling. In the original EIS, consequences measured as dose were evaluated from direct release to either a geologist on the drill rig examining the core or a single-farm family living $500 \mathrm{~m}$ downwind of the abandoned mud pits. Direct release to the surface from an intrusion into the repository was estimated simply as the amount of radioisotopes that would be removed by a $25-\mathrm{cm}$ (10-in) rotary drill for oil and gas exploration and deposited in the mud pit or a 7.6-cm (3-in) core drill for mineral exploration and deposited in a small pit.

Source Term Modeling. Release of radioisotopes from the WIPP repository via the groundwater pathway was assumed to be congruent with dissolution of salt encapsulating the waste, regardless of the solubility of the radioisotope (DOE, 1980). Disruption of the repository was assumed to occur after 1000 yr for all scenarios, except the bounding case scenario, with catastrophic flow of the Rustler aquifer through the repository, which was assumed to occur at $50,000 \mathrm{yr}$.

Culebra Flow and Transport Modeling. In the EIS, flow through the repository was assumed to be from the deep aquifers into the overlying Rustler. The Culebra and Magenta were combined and modeled as a 12-m-thick layer, referred to as the Rustler aquifers, using a finite difference code, SWIFT (Sandia Waste Isolation Flow and Transport code [Dillon et al., 1978]), whose development was being funded by the NRC (see following section). The three-dimensional regional flow model constructed for Sandia by INTERA, Inc. encompassed most of the area shown in Fig. 4. Each layer was assumed to be an isotropic porous medium with several hydraulic conductivity zones. The Rustler aquifer layer was assumed to have a uniform porosity of 0.10 , a hydraulic conductivity of $0.3 \mathrm{~m} / \mathrm{s}$ above the repository and to the north, a hydraulic conductivity of $1.2 \mathrm{~m} / \mathrm{s}$ in Nash Draw and to the south of the WIPP site, and higher conductivity along the Pecos River (DOE, 1980, Table K-2, Figure K-7). At this time, no regulatory exclusion zone or boundary had been defined, so regional flow, assumed to be toward the southwest, was discharged at Malaga Bend on the Pecos River. Transport calculations used a one-dimensional model along several flow paths to the Pecos River and included retardation.

30 - 3/9/99 Draft 


\subsubsection{NRC Analysis}

For the NRC, Sandia initially described a consequence analysis method in 1978 (Campbell et al., 1978). In 1981 that process was more thoroughly developed and then applied to a hypothetical bedded salt repository (Cranwell et al., 1987) along with the scenario development procedure discussed in the previous section. The analysis process was similar to that used in the WIPP EIS and proposed at Pacific Northwest Laboratory in 1977 (Bartlett et al., 1977). The exposure pathway model, $f(\bullet)$, comprised a series of loosely connected codes specifically developed for the task. The study simulated a steady-state groundwater flow field using the finite-difference flow code, SWIFT (Dillon et al., 1978), evaluated a particle pathway, and then calculated radioisotope transport along this pathway using a network model, NWFT/DVM (Campbell et al., 1981), which was the forerunner to NEFTRAN (Longsine et al., 1987). The groundwater releases to the surface were then input to a lumped parameter (compartment) model to evaluate radioisotope concentrations in surface water, sediments, and soil. These concentrations were then propagated through various food chains that eventually led to humans (Iman et al., 1978; Campbell et al., 1978; Cranwell et al., 1987).

\subsubsection{Supplemental EIS Analysis}

The Draft and Final Supplemental EISs for the WIPP, completed ten years later in 1989 and 1990 (Lappin et al., 1989; DOE, 1989; 1990), modeled release in a manner similar to that used for the original EIS but incorporated the pressurized brine reservoir feature. As before, four major components $f_{\alpha}(\bullet)$ of the exposure pathway model, $f(\bullet)$, were constructed: the direct release model, the Culebra flow model, the Culebra transport model, and the source term model. However, the latter model included some aspects of the repository and brine reservoir.

Direct Release Modeling. For direct release in the Supplemental EIS, an estimate was made of the volume of waste removed through erosion by the circulating drilling mud and then added to the volume removed by the drill bit, resulting in an upper bound of three full drums of CH-TRU waste. For dose, the same pathways were used as in the EIS.

Source Term/Repository Modeling. A distinct source term/repository model was developed for the Supplemental EIS, using an updated finite-difference code, SWIFT II (Reeves et al, 1986), to evaluate the concentration of radioisotopes injected into the Culebra. Four deterministic cases for the human-intrusion scenario were run using best and degraded values for parameters. The inventory was limited to either one panel or one room based on assumptions of the compaction and permeability of the salt backfill. Unlike the original EIS, the source term concentration was limited by a general actinide solubility in addition to the inventory. A range was established for the solubility limit for all actinide radioisotopes but in the calculations was set at either $10^{-3}$ or $10^{-1} \mathrm{mM}$ (see Fig. 8).

The use of a solubility limit to determine concentration required an estimate of the amount of brine available to dissolve the radioisotopes. A constant flow from the Salado of either $1.3 \mathrm{~m}^{3} / \mathrm{yr}$ or $0.1 \mathrm{~m}^{3} / \mathrm{yr}$ was used, based on calculations completed in 1988 in conjunction with the brine inflow controversy (Nowak et al., 1988). The amount of 
brine flow from the Castile brine reservoir was estimated using a well bore submodel in SWIFT II and a numerical mesh of the brine reservoir.

Characterization Study of Culebra in 1987. In 1987, Haug et al. (1987) of INTERA, Inc. calibrated a twodimensional flow model to the H-3 pumping test (Beauheim, 1987) and the effects from the excavation of the shafts for Sandia. Data from several boreholes that had been drilled and tested since 1980 were included in this model. The boundaries of the model were slightly larger than the WIPP site (see Fig. 4). As a secondary calibration target, measured brine densities were used; they were assigned at the boundaries and subsequently modified to match the observed fluid densities. Vertical leakage was included in an effort to calibrate the brine densities, which led to the recommendation that future modeling studies treat the Culebra as a leaky-confined aquifer. The transmissivity field was estimated by kriging and modified by the addition of artificial transmissivity well measurements ("pilot points"), which were positioned manually by trial and error. Haug et al. (1987) found that to match the low water levels at wells $\mathrm{H}-11$ and DOE-1 required placing a highly transmissive zone south of these wells.

Modeling of Culebra Fluid Flow in 1989. The 1987 study was followed by another modeling study in 1989 (LaVenue et al., 1990) in support of the Supplemental EIS. The differences in the models were that vertical leakage was not included and brine density varied spatially but was held constant over time. Also, the boundaries of the 1989 study were much larger than those of the 1987 study, extending approximately $30 \mathrm{~km}$ north and south and $20 \mathrm{~km}$ east and west, with the WIPP site at the center. These boundaries were selected to include the region for which head data were available and to minimize the boundary effects during simulation of the H-3, WIPP-13, and H-11 pumping tests. Fixed heads, based upon the regional head values, were assigned around all four boundaries. Transmissivities were estimated by kriging from measurements at 41 well locations. As before, pilot points were added to modify the transmissivity field during steady-state and transient calibration; however, pilot point locations were selected using an adjoint sensitivity analysis technique rather than manual trial and error. Fluid flow was calculated on the basis of a fully confined Culebra with an effective thickness equal to the total average thickness of $7 \mathrm{~m}$.

Culebra Transport Modeling. For contaminant transport, a one-dimensional model was used with a dualporosity formulation (i.e., fracture transport with matrix diffusion) along a selected flow path (Lappin et al., 1989). However, the effect of lateral dispersion was estimated. Some transport parameters such as fracture block length $(0.25$ to $7 \mathrm{~m})$ and fracture porosity $(0.0015)$ were based on best estimates from nonsorbing tracer tests at $\mathrm{H}-3$ and $\mathrm{H}-11$ wells. Other transport parameters such as matrix porosity, matrix tortuosity, and grain density were evaluated from 73 core samples taken from 15 different wells. Longitudinal dispersivity was set at a maximum of $100 \mathrm{~m}$.

\subsection{Analysis Logistics for PA}

The practical aspects of performing the exposure pathway calculations is daunting for a system comprised of several model components, such as the WIPP disposal system. Important practical problems in the WIPP Project were how to gain proficiency in PA calculations and how to link the component models together, so that they were sufficiently comprehensible, traceable, and repeatable for regulatory review. Another important consideration was determining the appropriate level of detail for the individual models that comprised the exposure model. 


\subsubsection{Iteration of Calculations}

In 1989, the WIPP PA analysts adopted the idea of conducting sequential PAs, that is, conducting an initial PA with simple or incomplete models and preliminary data, followed by other PAs with better data and/or more detailed models (Rechard, 1989). The idea had been used before, e.g., repeated NAS studies of ozone depletion in 1975 through 1982 (Morgan et al., 1990) or the 1975 Reactor Safety Study (Rasmussen, 1975) and its 1990 update (Breeding et al., 1992). The value of repeating the PA process was that engineers and scientists could gain an understanding about the disposal system and how best to model it and also replace weak links in the simulation chain as improved models and data became available.

In addition, multiple PA iterations achieved other benefits. First, a long, multiyear project could be divided into annual tasks, with more easily agreed-upon goals and schedules. Also, iterations allowed annual peer reviews so that the project received feedback that not only provided insights on the models and engineering analysis but also facilitated communication about controversial waste disposal issues and fostered interactions among members of the multidisciplinary teams. For instance, the PA group at Sandia formed a special external review group in 1987 that met through 1992 to review the preliminary PAs. In addition, the WIPP Panel of the NAS and the EEG, though not set up in 1978 exclusively to review PA-like calculations (or evaluate compliance), received quarterly presentations and commented on PA calculations.

Also, later iterations based on more advanced models or newly collected data could sometimes answer critical questions posed in earlier iterations. For example, the choice of the most appropriate conceptual model (i.e., whether to use single porosity or dual porosity to model radioisotope transport) in the brine aquifer above the WIPP repository resulted in the design of a field test to address this specific question in 1994. Finally, in combination with sensitivity analysis (Section 8), iterative PAs allowed project managers, PA analysts, and experimentalists to decide how best to allocate resources for supplementary data collection and whether models should be elaborated upon or simplified in later iterations. Consequently, Sandia conducted four preliminary PAs from 1989 through 1992, with each PA building upon the preceding PAs (Marietta et al., 1989; Rechard et al., 1990; Bertram-Howery et al., 1990; WIPP PA Division, 1991/1992; WIPP PA Department, 1992/1993).

\subsubsection{Detailed Modeling Style}

The analysis that Sandia conducted for the 1979 EIS relied heavily on detailed, phenomenological mathematical modeling to evaluate potential exposures (DOE, 1979; DOE, 1980), particularly because public expectations, expressed as comments on early nuclear reactor EISs or the promulgation of regulations, suggested a preference for "realistic" analysis. By the 1990 PA, analysts had also chosen to emphasize the detailed modeling style. An important reason for using a detailed modeling style was the general acceptance in the United States of its use in PRAs (Rasmussen, 1975; Breeding et al., 1992). Also comments received from the EPA (Bertram-Howery et al., 1990 ) and the WIPP Panel of the NAS on the 1989 PA encouraged Sandia to move from the simplified NEFTRAN (Longsine et al., 1987) models to a more detailed modeling. Some models, such as PANEL, remained simplified, but in general phenomenological models were used extensively in 1992 and 1996 . However, the phenomenological 
models often used fairly coarse numerical descriptions, and in a few instances, the results of some models (e.g., SANTOS and FMT mentioned in Section 7.4) were abstracted into simplified descriptions rather than used directly.

\subsubsection{CAMCON Development for PA}

The major role of modeling in a PA makes computer software fundamental to the process. Modeling a detailed complex system meant that models must be linked together reliably throughout a large number of repetitive computer simulations, as in a Monte Carlo analysis. Also, results must be properly identified for traceability.

Although Sandia had developed codes that were loosely connected for the NRC in the late 1970s and early 1980s, the Canadians developed the first integrated system, SYVAC (Dormuth and Sherman, 1981) in 1981. By the time Sandia was assigned the task of assessing the WIPP in August 1986, several other software systems had been built to meet the general requirements of PA. One approach was to build one code with numerous submodels (e.g., SYVAC), and another was to place one analysis code into a package that included data preparation, Monte Carlo sampling, and results display (e.g., NEFTRAN-S [Campbell et al., 1991]). Serious work on developing a software system for WIPP calculations began about mid-1987, with the CAMCON system developed primarily between 1988 and 1990. During the first year, a prototype was rapidly developed for the 1989 PA demonstration. Simultaneously, a more carefully constructed version was developed for the first complete PA in 1990.

The original concept for CAMCON was to provide an analysis "toolbox" (more than one tool) whereby any number of either complicated numerical or simple analytical codes could be linked together (Rechard, 1989; Rechard et al., 1989). With this toolbox, any one of several codes that were interchangeable but not identical could be used

for a model component, i.e., $f_{\alpha}^{1}, f_{\alpha}^{2} \ldots f_{\alpha}^{n M}$ where $n M$ designates the number of codes that perform a similar function, and $\alpha$ designates a specific model component such as the Culebra transport model mentioned earlier. Section 7.3 discusses the different codes selected for the model components. The selected model components could then be linked with other model components to form the exposure pathway model, $f(\bullet)$. The toolbox also included tools such as MATSET (Rechard, ed., 1992), ALGEBRA (Gilkey, 1988), and RELATE (Rechard, ed., 1992) to extract data from a parameter database, to algebraically manipulate output to evaluate new parameters or results (e.g., evaluation of a line integral to calculate release across a boundary), and to interpolate results across different meshes in order to make linkages between codes practical. The toolbox also included tools to help implement software quality assurance procedures.

The early version of the CAMCON system consisted of six components (Rechard et al., 1989; Rechard, 1991; Rechard, ed., 1992): (1) code modules (or grouping of codes), (2) a directory structure that facilitated configuration control; (3) a series of procedural files, CAMCONexec, that allowed an analyst to link the individual component codes and execute portions or all of a compliance assessment; (4) a set of libraries to interface with codes and users (Rechard et al., 1993a); (5) a series of help files containing instructions on use and history of updates; and (6) two data bases-CAMDAT (Compliance Assessment Methodology DATabase), a computational data base containing 
code outputs in .CDB files, and a secondary database of .SDB files containing parameter values (discussed in Section 8). CAMDAT, which was based on a simple neutral file format, was the link between the computer modules.

The concept for the calculational system for the 1996 PA in support of the CCA was essentially the same, although some details were changed. By the time of the $1996 \mathrm{PA}$, the costs associated with the stringent QA procedures required the selection of one code for each major component of the consequence model. Codes specifically developed for the PA task were selected, and thus code modules were not necessary. Second, software specifically designed for configuration management was used rather than an ad hoc directory structure. Finally, a disinterested third party built the batch scripts for run management and control, instead of using batch scripts built by PA analysts through CAMCONexec. Efficiency of computer use increased as the result of these changes, although the driving force behind them was to provide the EPA auditors with objective evidence that the PA process was truly traceable, understandable, and repeatable by others. Further details of the final system are discussed in this special issue (Froehlich et al., this issue-b).

\subsection{Consequence Models in PAs}

For the WIPP PAs, the exposure pathway model grew from four major components to seven: the direct cuttings release model, the direct brine release model, the repository fluid flow model, the source term model, the Culebra transmissivity model, the Culebra fluid flow model, and the Culebra radioisotope transport model. Before 1996, any uncertainty associated with a model's mathematical form or its application was considered only through general reviews of the preliminary PAs. However, for the 1996 PA, a Conceptual Model Peer Review Group studied the issue of correct model form.

\subsubsection{Direct Cutting and Brine Release Modeling}

For the 1989 PA, the direct release was the same as that estimated for the Supplemental EIS (i.e., three drums of waste). However by 1990, the CUTTINGS model (Rechard, ed., 1992) had been developed to calculate releases caused by erosion of material from the sides of the borehole from standard rotary drilling and was used through 1992. CUTTINGS could estimate erosional removal assuming either laminar or turbulent flow in the annulus between the drill stem and borehole, based on the Reynold's number. CUTTINGS also decayed the radioisotopes based on the time of intrusion into the repository. The contribution of these direct releases to the total releases in the 1996 PA is discussed further in this special issue (Berglund et al., this issue).

Concurrent with the 1992 PA (but not part of the 1992 PA), the quantity of waste particulates released through the spalling of the borehole wall was estimated, i.e., waste released due to the movement of high-pressure gas generated from degradation of containers and organic material to the borehole when the repository was penetrated (Berglund, 1992). Several types of calculations were made and an experimental program was begun to more thoroughly understand the phenomenon. A conservative estimate was made initially and included in the first version of the PA for the CCA submitted in October 1996. However, in reviewing the CCA, the EPA found that the spallings model, though conservative, lacked sufficient realism to be easily defended scientifically; hence, they requested 
redevelopment in the supplemental analysis for the CCA. The mathematical model for spallings was included in the 1996 PA as CUTTINGS_S, as discussed in this special issue (Knowles et al., this issue).

In response to requests since 1989 by the EEG, Sandia evaluated in the 1996 PA the potential release of contaminated brine to the surface during drilling. The WIPP two-phase flow code BRAGFLO was used to simulate the direct brine releases. However, to more accurately capture the flow patterns associated with direct releases of short duration, a conceptual model different from the repository model described below was constructed to represent the excavated rooms, drift passageways, and salt pillars. The actinide source term model, PANEL, described later, was used to estimate the activity of radioisotopes in the brine released (Fig. 14). Direct brine releases are discussed further in this special issue (Stoelzel et al., this issue).

Fig. 14. Changes in components of the exposure pathway ("consequence") model for immediate releases after exploratory drilling for evaluating compliance of the WIPP.

\subsubsection{Repository Fluid Flow Modeling}

In the PAs, the intrusion borehole and repository were represented as a separate model component, $f_{\ell}(\bullet)$, from the source term model. The primary purpose of the repository fluid flow model was to estimate the movement of fluids, both brine and gas, into and out of the repository. In the 1989 PA, the repository, shafts, and intrusion boreholes were represented as distinct legs in the network model NEFTRAN (Fig. 15). In 1990, the movement of brine into the repository from the Salado was estimated using the single fluid phase finite-element code, SUTRA (Voss, 1984). Another code, PANEL (Rechard, ed., 1992), estimated, through solution of ordinary differential equations, the time history of flow from the hypothesized underlying brine reservoir in the Castile into the Culebra.

Prior to and during 1990, Sandia explored the behavior of fluid flow and radioisotope migration in and around the repository. Studies included gas flow from the disposal area to the shaft using the two-phase code BOAST (Fanchi et al., 1987), Salado brine flow through a panel to a borehole using SUTRA, effects of anhydrite layers on Salado brine flow through a panel, and flow from a brine reservoir through a disposal room (Rechard et al., 1990). A useful concept from this exploration was the practice of varying the size of the gridblocks in the third dimension, i.e., the direction perpendicular to the plane of the grid, in an otherwise two-dimensional numerical mesh. This "element flaring" allowed the analyst to approximately account for volume changes and thereby approximate the very small borehole or shaft, moderate repository volume, or the much larger volumes beyond the repository. The technique had evolved into a fine art by 1992 and was carried forward to the 1996 PA.

Although SUTRA was again used in 1991 for the undisturbed scenario to estimate flow of brine in the repository, all estimates of brine inflow for the human-intrusion scenarios were calculated by the newly developed two-phase fluid flow code, BRAGFLO (i.e., PANEL and BOAST were replaced). The roots of BRAGFLO formulation are in TSRS, a multiphase multicompositional thermal reservoir simulator developed for the DOE for modeling in situ processing of tar sand (Vaughn, 1986). BRAGFLO was developed with a fully implicit numerical formulation because no other code in the public domain, including BOAST, was then available for simulating the 
convergent flow of gas and brine to the intrusion borehole. Also, a gas generation submodel was incorporated into the 1991 version of BRAGFLO to account for gas generated by the anoxic corrosion of metals and the degradation of organic material in the TRU waste.

In 1992, the effects of salt creep, which reduced porosity in the repository, were incorporated by using a generalized porosity reduction surface abstracted from numerous simulations using the salt creep code, SANCHO (Stone et al., 1985), previously developed for characterizing the WIPP facility (see Section 5.3). As described in more detail elsewhere in this issue (Vaughn et al., this issue), this surface was refined using SANTOS (Stone, 1997) and used for each grid block in the disposal area in 1996. Also in 1996, a submodel was added to account for brittle fracture of the anhydrite layers caused by pressure buildup from gas generated in the repository.

Fig. 15. Changes in components of the exposure pathway model for long-term releases via leaking borehole and Culebra brine aquifer (Rechard, 1999).

\subsubsection{Source Term Modeling}

The 1989 PA used a source-term submodel in the transport code NEFTRAN, as in the Supplemental EIS (Lappin et al., 1989), to evaluate the radioisotope concentrations released into the Culebra. However, the source term model quickly evolved from a submodel within NEFTRAN to a separate, lumped parameter ("mixing cell") model, PANEL, in 1990 (Rechard, ed., 1992). PANEL determined radioisotope concentrations based on solubility limits and decayed inventory values based on brine passing through a specified volume (e.g., disposal panel). PANEL had the capability to either internally estimate the brine flow or read in external estimates. In 1990, PANEL internally estimated the brine flow from the hypothesized underlying brine reservoir, but used an external estimate by SUTRA for the brine flow from the Salado. In the 1991 PA and thereafter, however, only the features for solubility limits and decayed inventory were used; all brine flow estimates into the repository were calculated by BRAGFLO.

The 1996 PA used the code FMT (WIPP PA Department, 1995) to evaluate radioisotope solubility for the E1 and E2 scenarios as a function of oxidation state of the radioisotopes, based on the oxidation capability (Eh) of the repository and the type of brine dominating the water chemistry (i.e., ionic strength and dominate constituents) (Fig. 15). The dissolved concentrations of radioisotopes as evaluated by FMT were combined with the concentration estimates of four categories of colloids (mineral, intrinsic, microbial, and humic) for input to the finite difference code, NUTS (Stockman et al., 1996), in its evaluation of radioisotope transport within the repository. The source term and radionuclide transport in the vicinity of the repository for the 1996 PA are discussed further in this special issue (Stockman et al., this issue).

\subsubsection{Culebra Transmissivity Modeling}

The transmissivity parameter of the Culebra (i.e., hydraulic conductivity times strata thickness) varies spatially across the region surrounding the WIPP site. Incorporating the uncertainty of this continuously distributed parameter was necessary to properly evaluate the uncertainty in the PA results. However, the tools to incorporate this type of parameter uncertainty did not exist within the WIPP Project in 1989 and had to be developed.

$37-3 / 9 / 99$ Draft 
Zonation of Culebra in 1989 and 1990. Although a calibrated spatially distributed transmissivity distribution had been developed for the Supplemental EIS (Lappin et al., eds., 1989), it represented only one of several possibilities. To propagate the uncertainty represented in the transmissivity field required developing numerous calibrated fields, which would have had to have been done manually in 1989 or 1990 and so was not feasible. Instead, the 1989 PA used the one-dimensional network code, NEFTRAN, and divided the Culebra into different legs, each with a different transmissivity distribution. Similarly, the 1990 PA used a two-dimensional finite difference code specifically developed for the WIPP, SECOFL2D (Roache, 1993; Rechard, ed., 1992), and divided the Culebra into either 8 or 13 fixed zones. Uncertainty ranges of transmissivity were developed solely from well measurements from each zone in the first case, or well measurements and pilot points of the calibrated fields from the Supplemental EIS (LaVenue et al., 1990; Lappin et al., eds., 1989). In both years, the ranges of the transmissivity distributions did not overlap between zones and the distributions of each zone were not correlated.

Culebra Transmissivity Fields in 1991. In 1991, the PA group at Sandia devised a relatively simple process to generate numerous transmissivity fields that agreed with estimated transmissivity measurements in wells and, when used as input to a fluid flow code, would generate aquifer pressures that reasonably matched known pressures (or "heads") in wells around the WIPP, i.e., the fields were "conditioned" or "made coherent" with measured transmissivity and well pressure data. First, transmissivity fields were generated (with a code, GARFIELD) (Rechard, ed., 1992). Next, randomly measured transmissivity fields were conditioned with actual measurements of transmissivity. The fields were further indirectly conditioned with the measured head data by evaluating the sensitivity of changes in the specified heads at the model boundary (with GENOBS and SWIFT II) (Rechard, ed., 1992), and appropriate fixed boundary heads were assigned. The transmissivity fields were then ranked by estimated travel time from a point directly above the disposal panels to the $2.4-\mathrm{km}$ boundary of the accessible environment and then randomly selected as input for the fluid flow calculations using SECOFL2D.

Culebra Transmissivity Fields in 1992. Sandia convened an expert working group that met in 1991 and 1992 to provide advice on various ways to propagate the uncertainty represented in the transmissivity fields of the Culebra (Zimmerman and Gallegos, 1993). Based on discussion within this group, the original method of Haug et al. (1987) and LaVenue et al. (1990) was automated by 1992, which made the procedure feasible for use in the WIPP PA. First, multiple transmissivity fields were generated (using TUBA [LaVenue and RamaRao, 1992]) and conditioned on transmissivity data as in 1991 (but using CONSIM [LaVenue and RamaRao, 1992]). The fields were then conditioned directly on steady state and transient head data by the technique originally used for the Supplemental EIS (i.e., pilot points) (LaVenue et al., 1990). Pilot points were automatically located (PILOTL) and assigned transmissivity values (PAREST) using an optimization routine (GRASP II) (LaVenue and RamaRao, 1992). By 1996, this series of codes was tightly coupled and referred to as GRASP-INV (Ramsey et al., this issue).

\subsubsection{Culebra Flow and Transport}

For flow and transport in the Culebra, all of the WIPP PAs calculated the fluid flow field assuming a singleporosity Culebra aquifer but estimated radioisotope migration through this flow field, assuming advective transport 
in fractures and diffusion into the surrounding matrix. The flow and transport models changed from the twodimensional flow evaluation and one-dimensional transport evaluation for the Supplemental EIS to a twodimensional flow and transport evaluation in 1992.

Culebra Flow and Transport in 1989 and 1990. In 1989, the analysis of fluid flow and transport with SWIFT II and NEFTRAN was similar to that used in the Supplemental EIS although uncertainty was evaluated for the PA. In 1990, SECOFL2D was used to evaluate numerous flow fields based on sampled values for various parameters, e.g., parameter values for each transmissivity zone, as previously mentioned. The two-dimensional, finite-element code, STAFF2D (Huyakorn et al., 1991), was used to evaluate radioisotope transport within the Culebra to the WIPP site boundary at $\sim 2.3 \mathrm{~km}$.

Culebra Flow and Transport in 1991. The 1991 PA rotated the model mesh $38^{\circ}$ from a north-south orientation to align one boundary of the mesh with the axis of Nash Draw such that a no-flow boundary could be specified along a portion of that boundary. In addition, the northeastern corner of the model was treated as a no-flow boundary because of the low transmissivities in the area and the lack of any nearby wells to provide head estimates. SECOFL2D was used for fluid flow and STAFF2D for radioisotope transport.

Culebra Flow and Transport in 1992. The 1992 PA used SECOFL2D to evaluate fluid flow in the Culebra, but radioisotope transport was evaluated with the newly developed, two-dimensional, finite-difference code, SECOTP2D (Roache, 1993; Ramsey et al., 1996). SECOTP2D easily read the flow fields calculated by SECOFL2D. As in earlier analyses, the 1992 PA considered both single-porosity (fracture-flow only) and dual-porosity (fracture flow with matrix diffusion). Although fracture spacing was sampled in each simulation, only a single spacing was assigned to the entire aquifer. The distribution of fracture spacing was weighted heavily toward large values, and the calculations assumed an effective thickness of the Culebra equal to its total thickness $(7 \mathrm{~m})$.

Culebra Flow and Transport in 1996. The same codes (SECOFL2D and SECOTP2D) were used in the 1996 PA, but between 1992 and 1996, the hydrologic and transport parameters of the Culebra were refined and used in calibrating flow fields. The refined parameter values were based on information from the tracer test at the new H-19 well, additional measurements at $\mathrm{H}-11$, reevaluation of transmissivity and tracer measurements at $\mathrm{H}-3$ and $\mathrm{H}-6$, and measurements from the DOE's Water- Quality Sampling Program conducted annually around the site. Also, the effective thickness for the Culebra in the 1996 PA was set at $4 \mathrm{~m}$ (see Section 3.4). As described in this issue, in the article on radionuclide and colloidal model transport in the Culebra (Ramsey et al., this issue), Sandia has concluded that the Culebra is adequately represented by a dual-porosity continuum model on the scale of PA calculations.

\subsection{Probability Evaluation and Sensitivity Analysis}

In general, three elements are required for a stochastic model simulation used in a PA (Rechard, 1995; Tierney and Rechard, 1997) a model, $f(\bullet)$, which was discussed in the previous section; a space of model parameters, $\mathbf{x}$, which was conceptually developed during system characterization and hazard identification; and a joint probability density function of the model parameters, $D(\mathbf{x})$. However, given that the parameter space, $\mathbf{x}$, was divided into two 
disjoint parts (those parameters associated with scenarios and the remaining parameters, i.e., $X=\left[\mathbf{X}_{s t}, \mathbf{x}_{s b}\right]$ ), two types of probability evaluations were necessary for the WIPP PAs. Using scenarios for stochastic uncertainty, $\mathbf{x}_{s t}$, was first attempted for the initial WIPP EIS in 1979 (Bingham and Barr, 1979, 1980). Probabilistic descriptions for the model parameters, or subjective uncertainty, $\mathbf{X}_{s b}$ was not attempted until the 1989 PA (Marietta et al., 1989).

\subsection{Scenario Probabilities and Parameter Selection for the EIS}

\subsubsection{Scenario Probabilities}

The use of fault trees to develop scenarios or calculate probabilities was found to be impractical during preparations for the EIS and therefore abandoned (Bartlett et al., 1977; Bingham and Barr, 1979, 1980). Hence, the models for evaluating scenario probabilities for the EIS (see Section 7) were chiefly subjective judgments. The remaining scenarios were grouped into three scenario classes, which were evaluated by means of consequence models (see Section 7). Typically, probabilities were estimated for three or four time periods: $10^{3}, 10^{4}, 10^{5}$, and sometimes $10^{6} \mathrm{yr}$ (Bingham and Barr, 1979, 1980). However, some probability models were created from measured failure rate data. For example, historical "failure rates" based on estimates of meteorites striking the earth, extreme erosion rates of land masses, geometrical arguments on probability of striking buried canisters, or faults intersecting the repository were all used. The probability of a scenario occurring was evaluated to screen out those with low probabilities.

\subsubsection{Parameter Selection}

Like the Reactor Safety Study (Rasmussen, 1975) conducted four years earlier, there was no attempt to evaluate how the epistemic (subjective) uncertainty in the model parameters $\left(\mathbf{X}_{s b}\right)$ contributed to the uncertainty in the results in the original EIS. Only stochastic uncertainty $\left(\boldsymbol{X}_{s}\right)$ was evaluated using scenarios. Furthermore, the EIS did not attempt to combine the various conditional consequences into an overall distribution. Model parameters were selected for the EIS for each scenario independent of other scenarios. The overall philosophy was to present conservative results when possible.

\subsection{Scenario Probabilities for Performance Assessments}

As described earlier, PA analysts continued to define scenarios to simplify modeling and call attention to human intrusion through exploratory drilling as specifically identified in 40 CFR 191 . Therefore, the probability of the scenarios, $P\left(S_{j}\right)$, had to be calculated by some method. In the $1989 \mathrm{PA}$, the probabilities of various scenarios were based on subjective judgment with no ranges of uncertainty as for the 1979 EIS.

After 1989, the inadvertent human intrusion event was assumed to be a Poisson process and so the probability of various numbers and combinations of intrusions was analytically calculated (i.e., $P\{n>0\}=1-e^{-\lambda t}$ ) (Helton, 1993c). Usually the Poisson process was assumed to have a constant expected rate of intrusion, $\lambda$, over the 10,000 -year regulatory period. The rate was constant throughout any one simulation in the preliminary PAs between 1989 and 1992; however, a different value between 0 and the maximum value, $\lambda_{\max }$, of 30 boreholes $/ \mathrm{km}^{2}$ per $10,000 \mathrm{yr}$ was

$40-3 / 9 / 99$ Draft 
selected for each of the many simulations. Varying $\lambda$ accounted for uncertainty in the scenario probabilities. The probability of all permutations of intrusion geometry (e.g., one intrusion only, two intrusions into one panel of the repository, two intrusions into two different panels, etc.) and permutations of fixed intrusion times (e.g., at 2000-yr intervals for the groundwater pathway as in 1991 or only one at $1000 \mathrm{yr}$ as in 1992) was evaluated directly with the code CCDFPERM (Fig. 14) (Helton and Iuzzolino, 1993).

In 1990, as an alternative, the WIPP Project conceptually examined the influence on results when the rate of intrusion was assumed to vary with time, $\lambda(t)$ (nonstationary Poisson process) (Tierney, 1991). For the 1992 PA, an actual function $\lambda(t)$ was constructed based on input from an expert panel that had considered future societies (Hora et al., 1991) and the effectiveness of markers at the site to convey the existence of hazards (Trauth et al., 1993). As a result, the overall number of intrusions decreased dramatically in comparison to a companion 1992 analysis with a constant $\lambda$ (stationary Poisson process) (Helton et al., 1996). In addition, the probability of all permutations of the intrusion geometry and of the intrusion times was no longer evaluated analytically but rather estimated through Monte Carlo sampling procedures (Helton and Shiver, 1996).

In 1996, $\lambda$ varied with time but used the same function for all simulations. The function was as follows: (1) $\lambda=$ 0 while active institution controls, such as land control, were present, $t<100 \mathrm{yr} ;(2) \lambda=0.01 \bullet \lambda_{\max }$ while passive institutional controls, such as markers about the WIPP site, were present, $100 \mathrm{yr}<\mathrm{t}<700 \mathrm{yr}$; and (3) $\lambda=\lambda_{\max }$ thereafter where the maximum rate of intrusion, $\lambda_{\max }$, was increased to 48.5 boreholes $/ \mathrm{km}^{2}$ per $10,000 \mathrm{yr}$ based on guidance in 40 CFR 194 (61 FR 5224), as described further in an article on stochastic uncertainty in this special issue (Helton et al., this issue-b).

\subsection{Parameter Uncertainty in PAs}

In 1985, when 40 CFR 191 requested the DOE applicant to "assemble all of the results of the PAs to determine compliance with $\$ 191.13$ into a "complementary cumulative distribution function [CCDF]'," an important goal for PA became a consistent evaluation of system consequences such that individual consequences and the uncertainty from each could be combined in an overall distribution of the consequences. Hence data bases and procedures for developing parameter distributions were important administrative controls.

\subsubsection{Data Bases for Model Parameters and Results}

In early 1989, the WIPP Project conceptually described three categories of data bases (Rechard, 1989): the primary, secondary, and computational data bases. The several primary data bases held measured field and laboratory data gathered by investigators from experiments during characterization of the WIPP disposal system (e.g., Munson et al., 1990). The secondary data base contained distributions of parameters that had been derived from the primary databases specifically for various component models of the exposure pathway model, $f(\bullet)$. The computational data base, generated during each PA, comprised the calculated results. By 1990, the WIPP Project used the latter two data bases directly in the PA calculations; however, the computational database existed only as a collection of catalogued files rather than as a true database.

$41-3 / 9 / 99$ Draft 


\subsubsection{Quality Assurance Procedures}

For the 1991 and 1992 PAs, the WIPP Project developed rudimentary quality assurance procedures. The purpose was to provide a reasonable degree of assurance to those outside the PA community that the results from the PA process presented a logically consistent view of WIPP performance, based on current knowledge and explicitly identified sources of uncertainty. The early procedures specified requirements in three primary areas of the analysis process (Rechard, 1995): Parameter Selection (Rechard et al., 1992a), Software (Rechard et al., 1991), and Analysis (Rechard et al., 1992b). In addition, procedures were prepared to ensure quality in two secondary areas: Report Review and Expert Judgment Panels.

The Parameter QA procedures sought to provide the PA analyst with consistent computational model parameters. The fundamental requirement was the development of a secondary data base managed by a Task Leader responsible for selecting appropriate data in consultation with investigators and PA analysts. Transferring data from investigative or experimental groups to the secondary data base was an important method by which the PA analysts interacted with WIPP Project investigative groups. The fundamental requirement of the Software QA procedures was the development of a Software Management System (the CAMCON Modeling System; see Section 7). For the 1996 PA supporting the CCA, these procedures were developed into a full suite of quality assurance procedures, as discussed further in this special issue (Froehlich et al., this issue-a).

\subsubsection{Describing Parameter Uncertainty}

To evaluate the epistemic or subjective uncertainty of PA results, a joint cumulative distribution function, $D\left(\mathbf{X}_{s u}\right)$, was required that characterized the uncertainty of model parameters, $\mathbf{X}_{s u}=\left[\mathbf{X}_{s u, 1}, \mathbf{X}_{s u, 2,}, \ldots, \mathbf{X}_{s u, n,}, \ldots, \mathbf{X}_{s u s U} \ldots\right.$, $\left.\mathrm{x}_{s u, n}\right]$ where $n U$ is the number of uncertain parameters and $n P$ is the total number of parameters. As is standard practice, $D(\mathbf{x})$ was approximated by the product of the cumulative distribution functions (CDFs) of the individual parameters, $D_{l}\left(x_{1}\right) \cdot D_{2}\left(x_{2}\right) \cdot \ldots D_{n}\left(x_{n}\right) \ldots \cdot D_{n v}\left(x_{n U}\right)$, an approximation that is exact when the parameters vary independently. Parameter independence was assumed for the preliminary PAs; however in the 1996 PA, very strong correlations $(-0.99,-0.99$, and -0.75$)$ were specified between two parameters, permeability and bulk compressibility, in three materials (Salado halite, Salado anhydrite, and brine reservoir anhydrite).

The cumulative distribution function, $D_{n}\left(x_{n}\right)$, of a parameter, $x_{n}$, ideally represented what was known and not known about the parameter range and the likelihood that these values were appropriate for consequence or probability models without assuming a "conservative" bias (see Fig. 6). The avoidance of a conservative bias was an important shift from the philosophy pursued for the EIS (DOE, 1979; 1980) and Supplemental EIS (DOE, 1990c).

Because each parameter distribution function must be tailored to the type of data available and to the parameter's role in the computational models, parameter distribution characterization was not guided by a rigid series of steps. In most cases, each $D\left(x_{n}\right)$ included subjective factors representing the "degree of belief" of the WIPP investigators. Beginning in 1990 (Rechard et al., 1990), a maximum entropy formalism was tried and then used extensively by 1991 (WIPP PA Division, 1991/1992) to provide a consistent procedure for constructing the distributions (Tierney, 
1994). In practice, the maximum entropy formalism involved connecting data points or subjectively estimated points with straight lines, as discussed further in this special issue (Tierney et al., this issue).

The use of a consistent set of parameter values was initiated for the 1989 PA (Rechard et al., 1990) and had become an important aspect by the 1990-1992 calculations. The data preparation code, MATSET (Rechard, ed., 1992) extracted data directly from the secondary data base for use by the modeling codes. This process ensured that the same parameter values were used consistently throughout the calculation. The 1989 PA primarily used parameter values from the Supplemental EIS (Lappin et al., 1989). Uniform, normal, lognormal, and beta distributions were fit to available data by the PA analysts as appropriate. Each year thereafter, however, more data were elicited directly from investigators, a process that was formalized in a quality assurance procedure (Rechard et al., 1992a). In some cases, parameters were evaluated through a formal expert panel while experimental data were collected, such as values for solubility of actinides in the repository and retardation in the Culebra for the 1991 PA (Trauth et al., 1992; Rechard et al., 1993b). The model parameters in the database were described formally beginning in 1990 and thereafter (Rechard et al., 1990; WIPP PA Division, 1991/1992; WIPP PA Department, 1992/1993). The number of documented parameters increased from 191 parameters, excluding geometric and stratigraphic positioning of layers, to 1561 documented parameters by 1996.

An important practical problem for parameter uncertainty analysis was determining the number of uncertain parameters to propagate. As the computational capability was increased, the number of uncertain parameters also grew with each assessment: 28 in 1989 (Marietta et al., 1989), 39 in 1990 (Rechard et al., 1990), 46 in 1991 (WIPP PA Division, 1991/1992), 49 in 1992 (WIPP PA Department, 1992/1993), and 57 in 1996 (DOE, 1996a).

\subsection{Sensitivity Analysis}

Sensitivity analysis is the evaluation of aspects of the system that most influence the calculated or observed results. Specifically, a sensitivity analysis ranks in importance the uncertain parameters $\mathbf{X}_{s u}$ (or model forms, e.g., $\left.f_{\alpha}^{m}(\bullet)\right)$ that determine $C\left(\mathbf{x}_{s u}\right)$ and its cumulative distribution function $(C D F)$, i.e., $\operatorname{Pr}\{R \leq r\}=\int \delta\left[r-\mathrm{C}\left(\mathbf{x}_{s u}\right)\right] \mathrm{d} D\left(\mathbf{x}_{s u}\right)$, where $\delta(\bullet)$ is the delta function (whose integral is zero when the argument is negative and one when the argument is positive), $D\left(\mathbf{X}_{s u}\right)$ is the joint probability function for the $\mathbf{X}_{s u}$ model parameters, $r$ is an arbitrary variable, and the integral is evaluated over the space of uncertain parameters. A sensitivity analysis can be conducted after the probability, consequence, or compliance steps.

\subsubsection{LHS Technique}

During the 1940s, the advent of computers allowed new problem-solving techniques to address issues of nuclear weapon design. An important practical tool developed at this time-the Monte Carlo solution technique-was designed to integrate the multidimensional integrals that arose in the study of the physics of weapons (LANL, 1987). But the technique applies to any multidimensional integration such as that determining the distribution of $C\left(\mathbf{X}_{\text {su }}\right)$, i.e., $\operatorname{Pr}\{R \leq r\}=\frac{1}{n K} \sum_{k=1}^{n K} I\left[r-C\left(\mathbf{x}_{s u, k}\right)\right]$, where $I(\bullet)$ is an indicator function equal to zero when the argument is negative 
and one when the argument is positive, $\mathbf{X}_{s u, k}$ is a set of sampled parameters drawn from $D\left(\mathbf{X}_{s u}\right.$ and $n K$ equals the number of Monte Carlo samples. However, using a large number of samples, as is necessary with the crude Monte Carlo method, is impractical when evaluation of the function $C(\mathrm{x})$ is time consuming, as in the WIPP calculations.

Many procedures have been developed to judiciously sample the domain of parameters to reduce the required total number of samples in a Monte Carlo analysis. A simple scheme developed in 1975, Latin Hypercube Sampling (LHS) (McKay et al., 1979), has been frequently used in the United States in PAs and probabilistic risk assessments because sample points are easily selected and there is frequently a good matching of results from more extensive random sampling. The LHS technique for Monte Carlo analysis was developed for a 1975 study to determine the important parameters in a complex code that modeled pipe ruptures in nuclear power plants (McKay et al., 1979). It was also proposed for use in analyses for the geologic disposal of radioactive waste as early. as 1978 (Iman et al., 1978). LHS was later applied to a 1980 examination of important parameters of a geologic disposal system (Iman and Conover, 1980).

The robustness of the procedures, as conjectured in the early 1980s (Iman and Conover, 1980; Iman, 1981) and more thoroughly demonstrated later in the decade (Iman and Helton, 1988; 1991), encouraged the WIPP Project to adopt the LHS technique to propagate parameter uncertainty and determine the distribution of $C(x)$ for comparison with $40 \mathrm{CFR}$ 191. Other techniques for sensitivity uncertainty analysis, such as developing surrogate analytic expressions for the results ("response surface development") or differential analysis with normalized partial derivative of parameters (e.g., "adjoint procedure"), were also proposed in the 1980s (Helton, 1993b). However, these techniques have never been used routinely for large-scale sensitivity analyses with several complex and linked submodels. Because the Monte Carlo technique was used to propagate uncertainty in the WIPP analysis, sensitivity of the results, $C(\mathrm{x})$, to changes in parameter values could be approximated and conveniently determined in several ways, including (1) examining scatterplots or (2) developing a statistical regression model and comparing the size of the standardized regression coefficients or the associated partial correlation coefficient (Helton et al., 1993a, 1996). Details of the application of LHS in the 1996 PA are described further in the stochastic uncertainty article in this special issue (Helton et al., this issue-b).

\subsubsection{Sensitive Parameters}

The 1989 PA used sensitivity analysis, but the method was ad hoc because CAMCON was not yet ready and so there was no easy method to input parameters and results into regression analysis codes. In the 1989 PA and in all subsequent analyses, radioisotope releases occurred only after inadvertent human intrusion. Hence, out of the 28 parameters sampled in the $1989 \mathrm{PA}$, the most important parameters were those associated with the human-intrusion scenario: solubility of radioisotopes, time of intrusion into the repository, and assumed permeability of the resulting but abandoned borehole. The 1989 PA did not evaluate separately the release of radioisotopes from cuttings brought directly to the surface in the drilling operation because it was set at a constant upper bound of three drums of CHTRU waste. Simultaneous with the 1989 PA, a sensitivity analysis was conducted on the importance of alternative 
conceptual models and various modeling techniques for components of the exposure pathway model (Rechard et al., 1990).

In 1990, regression analysis techniques to determine sensitivity were used (Helton, 1993b). The same three parameters (solubility of radioisotopes, time of intrusion, and assumed diameter of the borehole) were again the most important out of the selected 39 uncertain parameters in the 1990 PA (Bertram-Howery et al., 1990). This PA also evaluated release of radioisotopes from cuttings brought directly to the surface; these releases controlled the shape of the CCDF at probabilities greater than 0.5 . Below probabilities of 0.5 , radioisotope releases from the repository by means of groundwater transport through the intrusion borehole into the brine aquifer overlying the repository were important.

In the $1991 \mathrm{PA}$, release of radioisotopes from cuttings was clearly the dominant pathway and again controlled the shape of the CCDF for probabilities greater than 0.5 (Fig. 15). Out of 46 parameters sampled, two were important for this release: the rate constant $(\lambda)$ in the Poisson distribution for modeling the rate of human intrusion and the borehole diameter $\left(d_{b}\right)$. However, because. other parameters-solubility of plutonium, uranium, and americium; permeability of the borehole; permeability of the halite surrounding the repository; and retardation distribution coefficients for radioisotopes during groundwater transport-could markedly vary groundwater transport releases, their ranking in importance was higher than the ranking for the diameter of the intrusion borehole (WIPP PA Division, 1991/1992; Helton et al., 1993b). The sensitivity analysis in 1991 also included an evaluation of alternative conceptual models (Helton et al., 1995).

In the $1992 \mathrm{PA}$ (and also in 1996), releases from cuttings again dominated total radioisotope release for the mid to highest probabilities of the CCDF. Of 49 parameters, the three most important were the rate constant $\lambda$, borehole permeability, and solubility of americium (WIPP PA Department, 1992/1993; Helton et al., 1996). Thus, by 1992 it was evident that regulatory assumptions on the style of modeling, specifically with regard to assumptions about human intrusion, were dominating the results. A separate sensitivity study was also conducted to determine parameters important to migration of gas and brine in the vicinity of the repository, because an evaluation of the potential for migration of volatile organic compounds (VOCs, RCRA hazardous constituents) was still required at this time (Helton et al., 1993a). In the 1996 PA, releases occurred only from directly drilling into the repository. Parameters influencing these releases are described in two articles in this special issue (Helton et al., this issue-c, this issue-d).

\subsubsection{Project Guidance from Sensitivity Analyses}

For the WIPP Project, the sensitivity analyses helped to (1) verify the correctness of the calculations, i.e., errors were occasionally found when unexpected behavior was examined more thoroughly, (2) gain understanding and insight about the system, and (3) evaluate the influence of various options (Rechard, 1995). In addition, sensitivity analysis, in combination with multiple iterations through the PA process, provided some guidance to project managers on how to direct resources for the collection of information about significant model parameter values and

$45-3 / 9 / 99$ Draft 
model forms, based on what was already known about the site or waste. In 1990, 1991, and 1992 some general guidance was provided (Helton et al., 1991; WIPP PA Division, 1991/1992).

Beginning in 1994, an effort was made to combine the PA process directly with decision analysis in order to more definitively determine the best combination of scientific investigations, engineered alternatives, and waste acceptance criteria to support the CCA. The first attempt, called the System Prioritization Methodology (SPM), began in March 1994. The calculations and decision analysis were completed in December (Helton et al., 1997a; 1997b). A second iteration of the methodology was conducted in 1995 (Prindle et al., 1996). The new process produced additional information and thus helped the new DOE management team at the WIPP to allocate resources in 1995. However, the SPM cost much more in time and money than a general sensitivity analysis and the additional information it supplied mainly confirmed earlier sensitivity studies. In addition, basic tenants of decision analysis, such as developing an explicit utility function, were not followed (Lee, 1996). Also, in its practical application, the analysis was not probabilistic because the time needed to run a sufficient simulation would have been excessive. Given these time constraints, only a deterministic simulation of each activity, using an ad hoc combination of mean and median parameter values, could be run.

\subsection{Compliance Assessment and Summary}

An important difference between risk assessments or other large-scale policy analyses, which are usually conducted to gain understanding of the behavior of a system, and the WIPP PA is that the WIPP PA was specifically designed to test compliance to a set of standards so that decisions can be made about safety, rather than just to elucidate understanding.

\subsection{Assessing Compliance of the WIPP}

The focus of the extensive engineering analyses conducted by the WIPP Project over the years was initially the National Environmental Policy Act (NEPA) of 1969 and later the regulations in 40 CFR 191, Subpart B (58 FR 66398) and 40 CFR 194 (61 FR 5224).

\subsubsection{Predicted Doses for EIS}

For each EIS for the WIPP, dose to an individual has been calculated as one of several measures of evaluating the impact of the repository on humans and the natural environment. In all EISs, doses immediately after human intrusion dominated the results. The predicted dose to the geologist examining a 7.6-cm mineral core was estimated to be $1 \mathrm{mrem}$ in 1979 (DOE, 1979); $0.08 \mathrm{mrem}$ in 1989 (Lappin et al., 1989); and $0.01 \mathrm{mrem}$ in 1996, assuming the core extracted CH-TRU waste (DOE, 1996b). The predicted dose to a maximally exposed driller ingesting fragments was $0.37 \mathrm{mrem}$ in 1996. In addition, a separate probabilistic analysis of potential radiation exposure was conducted in 1996 (Helton et al., 1998). The predicted dose (primarily through inhalation) to a farm family $500 \mathrm{~m}$ downwind from the drilling mud pit was 0.036 mrem in 1979 (DOE, 1979); the maximum committed dose equivalent over $50 \mathrm{yr}$.

46- 3/9/99 Draft 
from inhalation to the farm family was $\sim 0.77$ mrem in 1989 (Lappin et al., 1989). No calculations were conducted for the farm family in the 1996 EIS (DOE, 1996b).

\subsubsection{Releases from Preliminary PAs}

Preliminary results in the form of CCDFs from the PAs were compared with the EPA regulations between 19891992 (Fig. 15). Over the years, the predicted cumulative releases immediately after drilling into the repository were similar even as more mechanisms for release were added (i.e., spallings and direct brine release in 1996). The releases have remained similar because the general required assumptions for exploratory drilling were specified in the regulations. However, the cumulative releases from leakage through the intrusion borehole and into the brine aquifer in the Culebra, a pathway much more dependent upon scientific knowledge about the WIPP disposal system, decreased until they became practically nonexistent by 1996 .

Although more scientific knowledge could be acquired about the WIPP disposal system, the results, in the form of cumulative releases, currently are contingent on the modeling assumptions or "style" required by the EPA regulations. That is, the regulations require inclusion of inadvertent human intrusion through exploratory drilling using current technology, and this regulatory requirement now directly determines the maximum releases. Continued collection of information about the disposal system is not likely to change the estimated overall releases substantially (Fig. 16); hence, the EPA requirement that the human intrusion event be included indirectly defines the point at which disposal system characterization is sufficient.

Fig. 16. Changes in the distribution of cumulative releases (normalized by the EPA limits) for (a) direct releases to the surface during drilling and $(b)$ releases via groundwater pathway through Culebra. Since the first full $P A$ in 1990, direct releases to the surface have dominated overall releases to the accessible environment of the WIPP (Rechard, 1999).

\subsubsection{PA for CCA}

In October 1996, the calculations and description of the 1996 PA were completed for the 80,000-page Compliance Certification Application (CCA) (DOE, 1996a). The overall pathway exposure model, $f(\bullet)$, for the 1996 PA was run 100 times with LHS samples. Furthermore, the 100 LHS samples were replicated three times (using new random numbers) to demonstrate the stability of the results. Many of the phenomenological models were run many more times than 300 because of the various pathways (e.g., direct, groundwater, anhydrite beds), scenarios (E0, E1, E2, E2E1), and times of intrusion (e.g., 350 and $1000 \mathrm{yr}$ for BRAGFLO for E1 and E2 scenarios) used in the analysis. In total, the calculations ran on $40 \mathrm{DEC}$ Alpha ${ }^{\mathrm{TM}}$ processors for $37,000 \mathrm{CPU}$ hours; although Tbytes of data were created, $\sim 100$ Gbytes of data were retained in 97,000 files. The releases, which were solely from drill cuttings, cavings, spallings, and direct brine flow immediately after intrusion, showed compliance with 40 CFR 191 (Fig. 16).

Throughout the winter and spring of 1997 (during the first 6 months after submittal), additional PA analysis and documentation, totaling 20,000 pages, were provided to the EPA at its request. For example, the EPA conducted an extensive review of the justifications for the parameter values and mathematical models used in the analysis, some of

47 - 3/9/99 Draft 
which required elaboration. Separate from the formal review of the CCA but as part of the EPA's evaluation, the EPA also directed DOE to run an abbreviated version of the PA in March 1997, varying models and parameters to bolster confidence in the WIPP disposal system. In May, the EPA directed DOE to conduct a PA verification test using the EPA's own selected modeling assumptions together with changes in distributions for 26 parameters (MacKinnon et al., 1997). The EPA declared the DOE's application complete in May 1997. In October 1997, one year after the submission of the CCA, the EPA proposed a rule in the Federal Register to certify operation of the WIPP (62 FR 58792); in May 1998, the EPA certified operation of the WIPP (63 FR 27354).

\subsection{Summary}

Almost immediately after the advent of nuclear weapons research and development, waste disposal became an issue. Over the decades, the United States has progressed from the burial of solid nuclear waste in shallow trenches and augered holes by the Manhattan Engineering District to the concept of deep geologic disposal. The examination of radioactive waste disposal in general and geologic disposal at the WIPP in particular started with the informal generic hazard identification by the NAS in 1955 followed by a selection of the disposal mode (deep geologic) to eliminate or mitigate those identified general hazards in some way. After repeated recommendations by the NAS for disposal in salt, the large salt beds of the Delaware Basin in southeastern New Mexico were selected in 1973 for the WIPP.

After the selection of the Delaware Basin and a specific site, ORNL evaluated the consequences of those hazards that remained, e.g., meteorite impact and catastrophic faulting, in 1974. A more formal hazard identification occurred in conjunction with the Draft and Final EIS of 1979 and 1980. Probabilities and consequences were evaluated only on aspects of the disposal system that were pertinent to the hazard under evaluation, i.e., a "scenario". Hazards such as sabotage or nuclear criticality, with very small subjective estimates of probability or consequences, were eliminated. Then consequences of the remaining hazards, such as exposure to drill cuttings containing TRU waste, were formally estimated to determine whether those remaining hazards were sufficient to disqualify the site. The EIS predicted no significant adverse long-term environmental impacts to human health that would support arguments against construction. Thus in 1979, six years after site selection, Congress authorized the DOE to build the WIPP near Carlsbad, New Mexico, for disposal of waste contaminated with TRU radioisotopes. After an exploratory phase in 1981, full construction of the WIPP began in 1983, was essentially complete 5 years later at the end of 1988, and officially complete by January 1990 .

In 1986, Sandia accepted the task of evaluating the compliance of the WIPP with the EPA regulation and began construction of an analysis system for the required probabilistic simulations in about 1988. An important goal of the analyses was to consistently examine hazards that remained after screening such that individual consequences from each could be combined in an overall distribution, i.e., the entire distribution of consequences was desired not just the expected value. Between 1989 and 1992, Sandia conducted four. preliminary PAs. Each iteration examined the behavior of the WIPP repository, based on current understanding, incorporated uncertainty, and then compared its preliminary results to the regulatory criteria. Because the physical and chemical processes that determine the

$48-3 / 15 / 99$ Draft 
behavior and evolution of the disposal system are complex, many of the models that represented the physical and chemical processes had become technically sophisticated by the 1992 PA and were carried forward for the 1996 PA.

In October 1996, the EPA began its review of the CCA for the WIPP. In 1998, 19 years after authorization and 25 years after site selection, the EPA certified that the WIPP disposal concept complied with its regulations. The EPA's decision was based on the results from the 1996 PA, which is summarized in this special issue of Reliability Engineering and System Safety (Marietta et al., this issue). Pending favorable court rulings on recently filed lawsuits and the issuance by the State of New Mexico of the required RCRA permits for $60 \%$ of the TRU waste that contains hazardous waste contaminants, the opening of the WIPP is very near, the culmination of an assessment process of over 25 years.

\section{Acknowledgments}

This work was supported by the U.S. Department of Energy (DOE) under Contract DE-AC04-94AL85000. This paper is a greatly expanded version of a table of milestones originally prepared for a report by Rechard (1995) and updated in 1999 (Rechard, 1999). The original tables included technical milestones, but emphasized the political and policy forces acting upon the WIPP Project. Although most of the information from those tables is included here, the emphasis in this paper is on the technical aspects of the project and so additional information is presented. The usefulness of this history is due in part to D.E. Munson, M.S. Tierney, and W.D. Weart, all of Sandia National Laboratories, who reviewed the text; F.C. Allan and S. Halliday, librarians at Sandia who assisted with searches; and Tech Reps, Inc. personnel, C.S. Crawford, who verified references; J.M. Chapman, who edited the text, and S.K. Best, who generated the figures.

49 - 3/9/99 Draft 
AEC (Atomic Energy Commission), Environmental Statement, Radioactive Waste Repository, Lyons, Kansas, WASH-1503, United States Atomic Energy Commission, Washington, DC, 1971. (On file in the SWCF as WPO 47929.)

Bachman, G.O., Surficial Features and Late Cenozoic History in Southeastern New Mexico, Open-file report USGS4339-8, United States Department of the Interior, Geological Survey, Denver, 1973.

Bachman, G.O., Johnson, R.B., \& Swenson, F.A., Stability of Salt in the Permian Salt Basin of Kansas, Oklahoma, Texas, and New Mexico, With a Section on Dissolved Salts in Surface Water, Open-file report USGS-43394, United States Department of the Interior, Geological Survey, Denver, 1973.

Barnes, H., Geologic and hydrologic background for selecting site of pilot-plant repository for radioactive waste. Bulletin of the Association of Engineering Geologists, 1974, XI(1), 83-92.

Bartlett, J.W., Burkholder, H.C., \& Winegardner, W.K., Safety assessment of geologic repositories for nuclear waste, in Nuclear Systems Reliability Engineering and Risk Assessment, ed. J.B. Fussell and G.R. Burdick, Society for Industrial and Applied Mathematics, Philadelphia, 1977, pp. 636-660.

Beauheim, R.L., Analysis of Pumping Tests of the Culebra Dolomite Conducted at the H-3 Hydropad at the Waste Isolation Pilot Plant (WIPP) Site, SAND86-2311, Sandia National Laboratories, Albuquerque, 1987.

Bechtel National, Inc., Waste Isolation Pilot Plant Design Validation Final Report, DOE-WIPP-86-010, Bechtel National, Inc., San Francisco, 1986.

Berglund, J.W., Mechanisms Governing the Direct Removal of Wastes from the Waste Isolation Pilot Plant Repository Caused by Exploratory Drilling, SAND92-7295, Sandia National Laboratories, Albuquerque, 1992.

Berglund, J.W. et al., Direct releases to the surface and associated complementary cumulative distribution functions in the 1996 performance assessment for the Waste Isolation Pilot Plant: cuttings, cavings, and spallings. Reliability Engineering and System Safety, this issue. (Since I haven't yet seen this paper, I cannot verify the correctness of this citation.)

Bertram-Howery, S.G., Marietta, M.G., Rechard, R.P., Swift, P.N., Anderson, D.R., Baker, B.L., Bean, Jr., J.E., Beyeler, W., Brinster, K.F., Guzowski, R.V., Helton, J.C., McCurley, R.D., Rudeen, D.K., Schreiber, J.D., \& Vaughn, P., Preliminary Comparison with 40 CFR Part 19I, Subpart B for the Waste Isolation Pilot. Plant, December 1990, SAND90-2347, Sandia National Laboratories, Albuquerque, 1990.

Bingham, F.W. \& Barr, G.E., Scenarios for Long-Term Release of Radionuclides from a Nuclear-Waste Repository in the Los Medaños Region of New Mexico, SAND78-1730, Sandia National Laboratories, Albuquerque, 1979.

Bingham, F.W. \& Barr, G.E., Development of scenarios for the long-term release of radionuclides from the proposed Waste Isolation Pilot Plant in southeastern New Mexico, in Scientific Basis for Nuclear Waste Management, Proceedings of the International Symposium, Boston, MA, November 27-30, 1979, ed. C.J.M. Northrup, Jr., SAND79-0955C, Plenum Press, New York, 1980, 2, pp. 771-778.

Bradshaw, R.L. \& McClain, W.C. (eds.), Project Salt Vault: A Demonstration of the Disposal of High-Activity Solidified Wastes in Underground Salt Mines, ORNL-4555, Oak Ridge National Laboratory, Oak Ridge, 1971.

Breeding, R.J., Helton, J.C., Gorham, E.D., \& Harper, F.T., Summary description of the methods used in the probabilistic risk assessments for NUREG-1150. Nuclear Engineering and Design, 1992, 135(1), 1-27. 
Brush, L.H. \& Storz, L.J., Revised ranges and probability distributions of $\mathrm{K}_{\mathrm{d}} \mathrm{s}$ for dissolved $\mathrm{Pu}, \mathrm{Am}, \mathrm{U}$, Th, and Np in the Culebra for the PA calculations to support the WIPP CCA, Memo to M.S. Tiemey, July 24, 1996, Sandia WIPP Central Files WPO 41561, Sandia National Laboratories, Albuquerque, 1996.

Brush, L.H., Grbic-Galic, D., Reed, D.T., Tong, X., Vreeland, R.H., \& Westerman, R.E., Preliminary results of laboratory studies of repository chemistry for the Waste Isolation Pilot Plant, in Scientific Basis for Nuclear Waste Management XIV, Materials Research Society Symposium Proceedings, Boston, MA, November 2629, 1990, ed. T.A. Abrajano, Jr. and L.H. Johnson, SAND90-1031C, Materials Research Society, Pittsburgh, 1991, 212, pp. 893-900.

Brush, L.H., Molecke, M.A., Westerman, R.E., Francis, A.J., Gillow, J.B., Vreeland, R.H., \& Reed, D.T., Laboratory studies of gas generation for the Waste Isolation Pilot Plant, in Scientific Basis for Nuclear Waste Management XVI, Materials Research Society Symposium Proceedings, Boston, MA, November 30 December 4, 1992, ed. C.G. Interrante and R.T. Pabalan, SAND92-2160C, Materials Research Society, Pittsburgh, 1993, 294, pp. 335-340.

Campbell, J.E., Dillon, R.T., Tierney, M.S., Davis, H.T., McGrath, P.E., Pearson, Jr., F.J., Shaw, H.R., Helton, J.C., and Donath, F.A., Risk Methodology for Geologic Disposal of Radioactive Waste: Interim Report, SAND78-0029, NUREG/CR-0458, Sandia National Laboratories, Albuquerque, 1978.

Campbell, J.E., Longsine, D.E., \& Cranwell, R.M., Risk Methodology for Geologic Disposal of Radioactive Waste: The NWFT/DVM Computer Code Users Manual, SAND81-0886, NUREG/CR-2081, Sandia National Laboratories, Albuquerque, 1981.

Campbell, J.E., Leigh, C.D., \& Longsine, D.E., NEFTRAN-S: A Network Flow and Contaminant Transport Model for Statistical and Deterministic Simulations Using Personal Computers, SAND90-1987, Sandia National Laboratories, Albuquerque, 1991.

Carter, L.J., Nuclear Imperatives and Public Trust: Dealing with Radioactive Waste, Resources for the Future, Inc., Washington, DC, 1987, pp. 60, 64, 186.

Channell, J.K., Calculated Radiation Doses from Radionuclides Brought to the Surface if Future Drilling Intercepts the WIPP Repository and Pressurized Brine, EEG-11, Environmental Evaluation Group, Santa Fe, 1982.

Channell, J.K., Rodgers, J.C., \& Neill, R.H., Adequacy of TRUPACT-I Design for Transporting Contact-Handled Transuranic Wastes to WIPP, EEG-33, Environmental Evaluation Group, Santa Fe, 1986.

Claiborne, H.C. \& Gera, F., Potential Containment Failure Mechanisms and Their Consequences at a Radioactive Waste Repository in Bedded Salt in New Mexico, ORNL-TM-4639, Oak Ridge National Laboratory, Oak Ridge, 1974.

Cranwell, R.M., Campbell, J.E., Helton, J.C., Iman, R.L., Longsine, D.E., Ortiz, N.R., Runkle, G.E., \& Shortencarier, M.J., Risk Methodology for Geologic Disposal of Radioactive Waste: Final Report, SAND81-2573, NUREG/CR-2452, Sandia National Laboratories, Albuquerque, 1987.

Cranwell, R.M., Guzowski, R.V., Campbell, J.E., \& Ortiz, N.R., Risk Methodology for Geologic Disposal of Radioactive Waste: Scenario Selection Procedure, SAND80-1429, NUREG/CR-1667, Sandia National Laboratories, Albuquerque, 1990.

Dawson, P.R., \& Tillerson, J.R., Nuclear Waste Canister Thermally Induced Motion, SAND78-0566, Sandia National Laboratories, Albuquerque, 1978. 
Dillon, R.T., Lantz, R.B., \& Pahwa, S.B., Risk Methodology for Geologic Disposal of Radioactive Waste: The Sandia Waste Isolation Flow and Transport (SWIFT) Model, SAND78-1267, NUREG/CR-0424, Sandia National Laboratories, Albuquerque, 1978.

DOE (US Department of Energy), Draft Environmental Impact Statement, Waste Isolation Pilot Plant, DOE/EIS0026-D, US Department of Energy, Washington, DC, 1979, 1-2.

DOE (US Department of Energy), Final Environmental Impact Statement, Waste Isolation Pilot Plant, DOE/EIS0026, US Department of Energy, Washington, DC, 1980, 1-2.

DOE (US Department of Energy), Draft Supplement, Environmental Impact Statement, Waste Isolation Pilot Plant, DOE/EIS-0026-DS, US Department of Energy, Office of Environmental Restoration and Waste Management, Washington, DC, 1989, 1-13.

DOE (US Department of Energy), Final Safety Analysis Report, WP 02-9, Rev. 0, May, Westinghouse Electric Corporation, Carlsbad, 1990a, 1-3. (On file in the SWCF as WPO 43327.)

DOE (US Department of Energy), WIPP Test Phase Plan: Performance Assessment, DOE/WIPP 89-011, Revision 0, United States Department of Energy, Waste Isolation Pilot Plant, Carlsbad, $1990 \mathrm{~b}$.

DOE (US Department of Energy), Final Supplement, Environmental Impact Statement, Waste Isolation Pilot Plant, DOE/EIS-0026-FS, US Department of Energy, Office of Environmental Restoration and Waste Management, Washington, DC, 1990c, 1-13.

DOE (US Department of Energy), Transuranic Waste Baseline Inventory Report (Revision 2), DOE/CAO-95-1121, US Department of Energy, Carlsbad Area Office, Carlsbad, 1995.

DOE (US Department of Energy), Title 40 CFR Part 191 Compliance Certification Application for the Waste Isolation Pilot Plant, DOE/CAO-1996-2184, US Department of Energy, Waste Isolation Pilot Plant, Carlsbad, 1996a, I-XXI.

DOE (US Department of Energy), Waste Isolation Pilot Plant Disposal Phase Draft Supplemental Environmental Impact Statement, DOE/EIS-0026-S-2, US Department of Energy, Carlsbad Area Office, Carlsbad, 1996b.

DOE (US Department of Energy), Waste Isolation Pilot Plant Disposal Phase, Final Supplemental Environmental Impact Statement, DOE/EIS-0026-S-2, US Department of Energy, Carlsbad Area Office, Carlsbad, 1997.

Dormuth, K.W. \& Sherman, G.R., SYVAC-A Computer Program for Assessment of Nuclear Fuel Waste Management Systems, Incorporating Parameter Variability, AECL-6814, Atomic Energy of Canada Ltd., Whiteshell Nuclear Research Establishment, Pinawa, Manitoba, 1981.

Dosch, R.G., Radionuclide migration studies associated with the WIPP site in southeastern New Mexico, in Scientific Basis for Nuclear Waste Management, Proceedings of the Symposium on Science Underlying Radioactive Waste Management, Boston, MA, November 28-December 1, 1978, ed. G.J. McCarthy, SAND78-1178J, Plenum Press, New York, 1979, 1, pp. 395-398.

Dosch, R.G., Solubility and Sorption Characteristics of Uranium(VI) Associated with Rock Samples and Brines/Groundwaters from WIPP and NTS, SAND80-1595, Sandia National Laboratories, Albuquerque, 1981.

EPA (US Environmental Protection Agency), Background Information Document Final Rule for High-Level and Transuranic Radioactive Wastes, EPA 520/1-85-023, US Environmental Protection Agency, Office of Radiation Programs, Washington, DC, 1985. 
Fanchi, J.R., Kennedy, J.E., \& Dauben, D.L., BOAST II: A Three-Dimensional, Three-Phase Black Oil Applied Simulation Tool, DOE/BC-88/2/SP, K and A Technology, Tulsa, 1987. (On file in the SWCF as WPO 51925.)

Francis, A.J., Gillow, J.B., \& Giles, M.R., Microbial Gas Generation Under Expected Waste Isolation Pilot Plant Repository Conditions, SAND96-2582, Sandia National Laboratories, Albuquerque, 1997.

Froelich, G.K., et al., Quality assurance in the 1996 performance assessment for the Waste Isolation Pilot Plant. Reliability Engineering and System Safety, this issue-a. (Need to list all authors. Since I haven't yet seen this paper, I cannot verify the correctness of this citation.)

Froelich, G.K., et al., Computational environment and logistics of the 1996 performance assessment for the Waste Isolation Pilot Plant. Reliability Engineering and System Safety, this issue-b. (Need to list all authors. Since I haven't yet seen this paper, I cannot verify the correctness of this citation.)

Galson, D.A. \& Swift, P.N., Recent progress in scenario development for the WIPP, in High Level Radioactive Waste Management 1995, Proceedings of the Sixth Annual International Conference, Las Vegas, NV, April 30 - May 5, 1995, SAND95-0117C, American Nuclear Society, Inc., La Grange Park, 1995, pp. 391-396.

Galson, D.A., Swift, P.N., Anderson, D.R., Bennett, D.G., Crawford, M.B., Hicks, T.W., \& Wilmot, R.D., Scenario development for the Waste Isolation Pilot Plant Compliance Certification Application. Reliability Engineering and System Safety, this issue. (Need to list all authors. Since I haven't yet seen this paper, I cannot verify the correctness of this citation.)

Gard, L.M., Geologic Studies, Project Gnome, Eddy County, New Mexico, Professional Paper 589, U.S. Geological Survey, Washington, DC, 1968.

Gilkey, A.P., ALGEBRA-A Program That Algebraically Manipulates the Output of a Finite Element Analysis (Exodus Version), SAND88-1431, Sandia National Laboratories, Albuquerque, 1988.

Guzowski, R.V., Preliminary Identification of Scenarios That May Affect the Escape and Transport of Radionuclides From the Waste Isolation Pilot Plant, Southeastern New Mexico, SAND89-7149, Sandia National Laboratories, Albuquerque, 1990.

Hansen, F., et al., Design and construction of the Waste Isolation Pilot Plant. Reliability Engineering and System Safety, this issue. (Need to list all authors. Since I haven't yet seen this paper, I cannot verify the correctness of this citation.)

Haug, A., Kelley, V.A., LaVenue, A.M., \& Pickens, J.F., Modeling of Ground-Water Flow in the Culebra Dolomite at the Waste Isolation Pilot Plant (WIPP) Site: Interim Report, SAND86-7167, Sandia National Laboratories, Albuquerque, 1987.

Helton, J.C., Risk, uncertainty in risk, and the EPA release limits for radioactive waste disposal. Nuclear Technology, 1993a, 101(1), 18-39.

Helton, J.C., Uncertainty and sensitivity analysis techniques for use in performance assessment for radioactive waste disposal. Reliability Engineering \& System Safety, 1993b, 42(2-3), 327-367.

Helton, J.C., Drilling intrusion probabilities for use in performance assessment for radioactive waste disposal. Reliability Engineering and System Safety, 1993c, 40(3), 259-275.

Helton, J.C., Treatment of uncertainty in performance assessments for complex systems. Risk Analysis, 1994, 14(4), 483-511. 
Helton, J.C., Uncertainty and sensitivity analysis in the presence of stochastic and subjective uncertainty. Journal of Statistical Computation and Simulation, 1997, 57(1-4), 3-76.

Helton, J.C. \& Iuzzolino, H.J., Construction of complementary cumulative distribution functions for comparison with the EPA release limits for radioactive waste disposal. Reliability Engineering and System Safety, 1993, 40(3), 277-293.

Helton, J.C. \& Shiver, A.W., A Monte Carlo procedure for the construction of complementary cumulative distribution functions for comparison with the EPA release limits for radioactive waste disposal. Risk Analysis, 1996, 16(1), 43-55.

Helton, J.C., Garner, J.W., McCurley, R.D., \& Rudeen, D.K., Sensitivity Analysis Techniques and Results for Performance Assessment at the Waste Isolation Pilot Plant, SAND90-7103, Sandia National Laboratories, Albuquerque, 1991.

Helton, J.C., Garner, J.W., Marietta, M.G., Rechard, R.P., Rudeen, D.K., and Swift, P.N., Uncertainty and sensitivity analysis results obtained in a preliminary performance assessment for the Waste Isolation Pilot Plant. Nuclear Science \& Engineering, 1993a, 114(4), 286-331.

Helton, J.C., Bean, J.E., Butcher, B.M., Garner, J.W., Schreiber, J.D., Swift, P.N., and Vaughn, P., Uncertainty and Sensitivity Analyses for Gas and Brine Migration at the Waste Isolation Pilot Plant, May 1992, SAND922013, Sandia National Laboratories, Albuquerque, $1993 \mathrm{~b}$.

Helton, J.C., Anderson, D.R., Baker, B.L., Bean, J.E., Berglund, J.W., Beyeler, W., Garner, J.W., Iuzzolino, H.J., Marietta, M.G., Rechard, R.P., Roache, P.J., Rudeen, D.K., Schreiber, J.D., Swift, P.N., Tierney, M.S., and Vaughn, P., Effect of alternative conceptual models in a preliminary performance assessment for the Waste Isolation Pilot Plant. Nuclear Engineering and Design, 1995, 154(3), 251-344.

Helton, J.C., Anderson, D.R., Baker, B.L., Bean, J.E., Berglund, J.W., Beyeler, W., Economy, K., Garner, J.W., Hora, S.C., Iuzzolino, H.J., Knupp, P., Marietta, M.G., Rath, J., Rechard, R.P., Roache, P.J., Rudeen, D.K., Salari, K., Schreiber, J.D., Swift, P.N., Tierney, M.S., and Vaughn, P., Uncertainty and sensitivity analysis results obtained in the 1992 performance assessment for the Waste Isolation Pilot Plant. Reliability Engineering and System Safety, 1996, 51(1), 53-100.

Helton, J.C., Beyeler, W., \& Hora, S.C., Conceptual basis of a systems prioritization methodology for the Waste Isolation Pilot Plant. Reliability Engineering and System Safety, 1997a, 57(3), 203-222.

Helton, J.C., Anderson, D.R., Baker, B.L., Bean, J.E., Berglund, J.W., Beyeler, W., Blaine, R., Economy, K., Garner, J.W., Hora, S.C., Lincoln, R.C., Marietta, M.G., Mendenhall, F.T., Prindle, N.H., Rudeen, D.K., Schreiber, J.D., Shiver, A.W., Smith, L.N., Swift, P.N., and Vaughn, P., Computational implémentation of a systems prioritization methodology for the Waste Isolation Pilot Plant: a preliminary example. Reliability Engineering and System Safety, 1997b, 57(3), 223-266.

Helton, J.C., Anderson, D.R., Marietta, M.G., \& Rechard, R.P., Performance assessment for the Waste Isolation Pilot Plant: from regulation to calculation for 40 CFR 191.13. Operations Research, 1997c, 45(2), 157-177.

Helton, J.C., Johnson, J.D., Jow, H.-N., McCurley, R.D., \& Rahal, L.J., Stochastic and subjective uncertainty in the assessment of radiation exposure at the Waste Isolation Pilot Plant. Human and Ecological Risk Assessment, 1998, 4(2), 469-526.

Helton, J.C., Anderson, D.R., Jow, H.-N., Marietta, M.G., \& Basabilvazo, G., Conceptual structure of the 1996 performance assessment for the Waste Isolation Pilot Plant. Reliability Engineering and System Safety, this issue-a. (Since I haven't yet seen this paper, I cannot verify the correctness of this citation.) 
Helton, J.C., Davies, F.J., \& Johnson, J.D., Characterization of stochastic uncertainty in the 1996 performance assessment for the Waste Isolation Pilot Plant. Reliability Engineering and System Safety, this issue-b. (Since I haven't yet seen this paper, I cannot verify the correctness of this citation.)

Helton, J.C., Bean, J.E., Economy, K., Garner, J.W., MacKinnon, R.J., Miller, J., Schreiber, J.D., \& Vaughn, P., Uncertainty and sensitivity analysis for two-phase flow in the vicinity of the repository in the1996 performance assessment for the Waste Isolation Pilot Plant: undisturbed conditions. Reliability Engineering and System Safety, this issue-c. (Since I haven't yet seen this paper, I cannot verify the correctness of this citation.)

Helton, J.C., Bean, J.E., Economy, K., Garner, J.W., MacKinnon, R.J., Miller, J., Schreiber, J.D., \& Vaughn, P., Uncertainty and sensitivity analysis for two-phase flow in the vicinity of the repository in the1996 performance assessment for the Waste Isolation Pilot Plant: disturbed conditions. Reliability Engineering and System Safety, this issue-d. (Since I haven't yet seen this paper, I cannot verify the correctness of this citation.)

Hora, S.C., von Winterfeldt, D., \& Trauth, K.M., Expert Judgment on Inadvertent Human Intrusion into the Waste Isolation Pilot Plant, SAND90-3063, Sandia National Laboratories, Albuquerque, 1991.

Howard, et al., Title to be provided, Reliability Engineering and System Safety, this issue.

Hunter, R.L., Events and Processes for Constructing Scenarios for the Release of Transuranic Waste from the Waste Isolation Pilot Plant, Southeastern New Mexico, SAND89-2546, Sandia National Laboratories, Albuquerque, 1989.

Huyakorn, P.S., White, Jr., H.O., \& Panday, S., STAFF2D: Solute Transport and Fracture Flow in 2-Dimensions, Version 3.1, HydroGeologic, Inc., Herndon, 1991. (On file in the SWCF as WPO 7415.)

IAEA (International Atomic Energy Agency), Safety Assessment for the Underground Disposal of Radioactive Wastes, Safety Series No. 56, International Atomic Energy Agency, Vienna, 1981.

IDB (Integrated Data Base), Integrated Data Base for 1990: U.S. Spent Fuel and Radioactive Waste Inventories, Projections, and Characteristics, DOE/RW-0006, Revision 6, Oak Ridge National Laboratory, Oak Ridge, 1990.

Iman, R.L., Statistical methods for including uncertainties associated with the geologic isolation of radioactive waste which allow for a comparison with licensing criteria, in Proceedings of the Symposium on Uncertainties Associated with the Regulation of the Geologic Disposal of High-Level Radioactive Waste, Gatlinburg, TN, March 9-13, 1981, ed. D.C. Kocher, NUREG/CP-0022, CONF-810372, US Nuclear Regulatory Commission, Washington, DC, 1981, pp. 145-157.

Iman, R.L. \& Conover, W.J., Small sample sensitivity analysis techniques for computer models, with an application to risk assessment. Communications in Statistics, 1980, A9(17), 1749-1842.

Iman, R.L. \& Helton, J.C., An investigation of uncertainty and sensitivity analysis techniques for computer models. Risk Analysis, 1988, 8(1), 71-90.

Iman, R.L. \& Helton, J.C., The repeatability of uncertainty and sensitivity analyses for complex probabilistic risk assessments. Risk Analysis, 1991, 11(4), 591-606.

Iman, R.L., Helton, J.C., \& Campbell, J.E., Risk Methodology for Geologic Disposal of Radioactive Waste: Sensitivity Analysis Techniques, SAND78-0912, NUREG/CR-0390, Sandia National Laboratories, Albuquerque, 1978. 
Jones, C.L., Cooley, M.E., \& Bachman, G.O., Salt Deposits of Los Medaños Area, Eddy and Lea Counties, New Mexico, With Sections on Ground Water Hydrology and Surficial Geology, Open-file report USGS-4339-7, United States Department of the Interior, Geological Survey, Denver, 1973.

Knowles, M.K., et al., Review and perspective on spallings releases in the 1996 performance assessment for the Waste Isolation Pilot Plant. Reliability Engineering and System Safety, this issue. (Need to list all authors. Since I haven't yet seen this paper, I cannot verify the correctness of this citation.)

Krieg, R.D., Stone, C.M., \& Key, S.W., Comparisons of the Structural Behavior of Three Storage Room Designs for the WIPP Project, SAND80-1629, Sandia National Laboratories, Albuquerque, 1981.

Lambert, S.J., Dissolution of Evaporites In and Around the Delaware Basin, Southeastern New Mexico and West Texas, SAND82-0461, Sandia National Laboratories, Albuquerque, 1983.

LANL (Los Alamos National Laboratory), Stanislaw Ulam 1909-1984. Los Alamos Science, No. 15, Special Issue, Los Alamos National Laboratory, Los Alamos, 1987.

Lappin, A.R., Summary of Site-Characterization Studies Conducted From 1983 Through 1987 at the Waste Isolation Pilot Plant (WIPP) Site, Southeastern New Mexico, SAND88-0157, Sandia National Laboratories, Albuquerque, 1988.

Lappin, A.R., Hunter, R.L., Garber, D.P., \& Davies, P.B. (eds.), Systems Analysis, Long-Term Radionuclide Transport, and Dose Assessments, Waste Isolation Pilot Plant (WIPP), Southeastern New Mexico; March 1989, SAND89-0462, Sandia National Laboratories, Albuquerque, 1989.

Larson, K.W., et al., Development of the conceptual models for chemical conditions and hydrology used in the 1996 performance assessment for the Waste Isolation Pilot Plant, Reliability Engineering and System Safety, this issue.

LaVenue, A.M. \& RamaRao, B.S., A Modeling Approach to Address Spatial Variability Within the Culebra Dolomite Transmissivity Field, SAND92-7306, Sandia National Laboratories, Albuquerque, 1992.

LaVenue, A.M., Cauffman, T.L., \& Pickens, J.F., Ground-Water Flow Modeling of the Culebra Dolomite: Volume I - Model Calibration, SAND89-7068/1, Sandia National Laboratories, Albuquerque, 1990.

Lee, W.-L., The systems prioritization method for the Waste Isolation Pilot Plant: problems with methodology and results, in Proceedings of the International Topical Meeting on Nuclear and Hazardous Waste Management, Spectrum '96, Seattle, WA, August 18-23, 1996, American Nuclear Society, La Grange Park, 1996, 1, pp. 517-522.

Lipschutz, R.D., Radioactive Waste: Politics, Technology, and Risk, Ballinger Publishing Company, A Division of Harper \& Row, Cambridge, 1980, 144, 199.

Longsine, D.E., Bonano, E.J., \& Harlan, C.P., User's Manual for the NEFTRAN Computer Code, SAND86-2405, NUREG/CR-4766, Sandia National Laboratories, Albuquerque, 1987.

Lynch, A.W., Dosch, R.G., \& Hills, C.R., Migration of Cesium-137 Through a Solid Core of Magenta Dolomite Taken from the Rustler Formation in Southeastern New Mexico, SAND80-1259, Sandia National Laboratories, Albuquerque, 1981.

MacKinnon, R., Freeze, G., \& Jow, H., Summary of EPA-mandated performance assessment verification test (replicate 1) and comparison with the Compliance Certification Application calculations, Technical Data Package, Sandia WIPP Central Files WPO 46674, Sandia National Laboratories, Albuquerque, 1997. 
Marietta, M.G., Bertram-Howery, S.G., Anderson, D.R., Brinster, K.F., Guzowski, R.V., Iuzzolino, H., \& Rechard, R.P., Performance Assessment Methodology Demonstration: Methodology Development for Evaluating Compliance With EPA 40 CFR 191, Subpart B, for the Waste Isolation Pilot Plant, SAND89-2027, Sandia National Laboratories, Albuquerque, 1989.

Marietta et al., Title to be provided, Reliability Engineering and System Safety, this issue.

Markowitz, H. Portfolio section. The Journal of Finance, 1952, VII(1), 77-91.

McKay, M.D., Beckman, R.J., \& Conover, W.J., A comparison of three methods for selecting values of input variables in the analysis of output from a computer code. Technometrics, 1979, 21(2), 239-245.

Meigs, L.C., Beauheim, R.L., McCord, J.T., Tsang, Y.W., \& Haggerty, R., Design, modelling, and current interpretations of the $\mathrm{H}-19$ and $\mathrm{H}-11$ tracer tests at the WIPP Site, in Field Transport Experiments: Role in the Prediction of Radionuclide Migration: Synthesis and Proceeding of an NEA/EC GEOTRAP Workshop, Cologne, Germany, August 28-30, 1996, SAND96-2796C, Nuclear Energy Agency, Organisation for Economic Co-Operation and Development, Paris, 1997, pp. 157-169.

Mercer, J.W., Geohydrology of the Proposed Waste Isolation Pilot Plant Site, Los Medaños Area, Southeastern New Mexico, Open-file report 83-4016, US Department of the Interior, Geological Survey, 1983.

Mercer, J.W. \& Orr, B.R., Interim Data Report on the Geohydrology of the Proposed Waste Isolation Pilot Plant Site, Southeast New Mexico, Water-resources investigations report 79-98, U.S. Department of Interior, Geological Survey, Albuquerque, 1979.

Metlay, D.S., History and interpretation of radioactive waste management in the United States, in Essays on Issues Relevant to the Regulation of Radioactive Waste Management, ed. W.P. Bishop, I.R. Hoos, N. Hilberry, D.S. Metlay, and R.A. Watson, NUREG-0412, Division of Fuel Cycle and Material Safety, Office of Nuclear Material Safety and Safeguards, U.S. Nuclear Regulatory Commission, Washington, DC, 1978, pp. 6-9.

Molecke, M.A., Waste Isolation Pilot Plant Transuranic Wastes Experimental Characterization Program: Executive Summary, SAND78-1356, Sandia National Laboratories, Albuquerque, 1978.

Morgan, H.S., Stone, C.M., \& Krieg, R.D., The use of field data to evaluate and improve drift response models for the Waste Isolation Pilot Plant (WIPP), in Research and Engineering Applications in Rock Masses, Proceedings of the 26th U.S. Symposium on Rock Mechanics, Rapid City, SD, June 26-28, 1985, ed. E. Ashworth, A.A. Balkema, Boston, 1985, 2, pp. 769-776.

. Morgan, M.G., Henrion, M., \& Small, M., Uncertainty, A Guide to Dealing With Uncertainty in Quantitative Risk and Policy Analysis, Cambridge University Press, New York, 1990, 292.

MRSRC (Monitored Retrievable Storage Review Commission), Nuclear Waste: Is There a Need for Federal Interim Storage?, Superintendent of Documents, ÙS Government Printing Office, Washington, DC, 1989, 4.

Munson, D.E., Fossum, A.F., \& Senseny, P.E., Advances in Resolution of Discrepancies Between Predicted and Measured In Situ WIPP Room Closures, SAND88-2948, Sandia National Laboratories, Albuquerque, 1989.

Munson, D.E., Ball, J.R., \& Jones, R.L., Data quality assurance controls through the WIPP in situ data acquisition, analysis, and management system, in High Level Radioactive Waste Management, Proceedings of the International Topical Meeting, Las Vegas, NV, April 8-12, 1990, American Nuclear Society, La Grange Park, 1990, 2, pp. 1337-1350. 
NASARRC (National Academy of Sciences/National Research Council), The Disposal of Radioactive Waste on Land: Report of the Committee on Waste Disposal of the Division of Earth Sciences, Publication 519, National Academy of Sciences/National Research Council, Washington, DC, 1957.

NASARR (National Academy of Sciences/National Research Council), Disposal of Solid Radioactive Wastes in Bedded Salt Deposits, Committee on Radioactive Waste Management, National Academy of Sciences/National Research Council, Washington, DC, 1970.

NAS/NRC (National Academy of Sciences/National Research Council), A Letter Report by the Panel on the Waste Isolation Pilot Plant, Board on Radioactive Waste Management, Commission on Geosciences, Environment, and Resources, National Research Council, Washington, DC, 1992.

NAS/NRC (National Academy of Sciences/National Research Council), Technical Bases for Yucca Mountain Standards, Committee on Technical Bases for Yucca Mountain Standards, Board on Radioactive Waste Management, Commission on Geosciences, Environment, and Resources, National Research Council, National Academy Press, Washington, DC, 1995, 2.

NAS/NRC (National Academy of Sciences/National Research Council), The Waste Isolation Pilot Plant, A Potential Solution for the Disposal of Transuranic Waste, Committee on the Waste Isolation Pilot Plant, Board on Radioactive Waste Management, Commission on Geosciences, Environment, and Resources, National Research Council, National Academy Press, Washington, DC, 1996, 79-80.

Nowak, E.J. \& Stormont, J.C., Scoping Model Calculations of the Reconsolidation of Crushed Salt in WIPP Shafts, SAND87-0879, Sandia National Laboratories, Albuquerque, 1987.

Nowak, E.J., McTigue, D.F., \& Beraún, R., Brine Inflow to WIPP Disposal Rooms: Data, Modeling, and Assessment, SAND88-0112, Sandia National Laboratories, Albuquerque, 1988.

Nowak, E.J., Tillerson, J.R., \& Torres, T.M., Initial Reference Seal System Design: Waste Isolation Pilot Plant, SAND90-0355, Sandia National Laboratories, Albuquerque, 1990.

Papenguth, H.W. \& Behl, Y.K., Test Plan: Evaluation of Dissolved Actinide Retardation at the Waste Isolation Pilot Plant, TP 96-02, Sandia National Laboratories, Albuquerque, 1996. (On file in the SWCF as WPO 31336.)

Perge, A., Historical overview, in Proceedings of Alpha-Contaminated Waste Management Workshop, Gaithersburg, Maryland, August 10-13, 1982, CONF-820845, Oak Ridge National Laboratory, Oak Ridge, 1982, pp. 17-30.

Powers, D.W., Lambert, S.J., Shaffer, S-E., Hill, L.R., \& Weart, W.D. (eds.), Geological Characterization Report, Waste Isolation Pilot Plant (WIPP) Site, Southeastern New Mexico, SAND78-1596, Sandia National Laboratories, Albuquerque, 1978, I-II.

Prindle, N.H., Mendenhall, F.T., Boak, D.M., Beyeler, W., Rudeen, D., Lincoln, R.C., Trauth, K., Anderson, D.R., Marietta, M.G., \& Helton, J.C., The Second Iteration of the Systems Prioritization Method: A Systems Prioritization and Decision-Aiding Tool for the Waste Isolation Pilot Plant, Volume 1: Synopsis of Method and Results, SAND95-2017/1, Sandia National Laboratories, Albuquerque, 1996.

Ramsey, J.L., Wallace, M.G., \& Jow, H.N., Analysis Package for the Culebra Flow and Transport Calculations (Task 3) of the Performance Assessment Calculations Supporting the Compliance Certification Application (CCA), AP-019, Analysis Plan 019, Sandia WIPP Central Files WPO 40516, Sandia National Laboratories, Albuquerque, 1996.

$58-3 / 9 / 99$ Draft 
Ramsey, J.L., Blaine, R., Garner, J.W., Helton, J.C., Johnson, J.D., Smith, L.N., \& Wallace, M., Radionuclide and colloid transport in the Culebra Dolomite and associated complementary cumulative distribution functions in the 1996 performance assessment for the Waste Isolation Pilot Plant. Reliability Engineering and System Safety, this issue. (Since I haven't yet seen this paper, I cannot verify the correctness of this citation.)

Rasmussen, N.C., Reactor Safety Study: An Assessment of Accident Risks in U.S. Commercial Nuclear Power Plants, NUREG-75/014, WASH-1400, US Nuclear Regulatory Commission, Washington, DC, 1975, 1-8.

Rechard, R.P., Review and Discussion of Code Linkage and Data Flow in Nuclear Waste Compliance Assessments, SAND87-2833, Sandia National Laboratories, Albuquerque, 1989.

Rechard, R.P., CAMCON: computer system for assessing regulatory compliance of the Waste Isolation Pilot Plant, in Proceedings of the International Conference on Probabilistic Safety Assessment and Management (PSAM), Beverly Hills, CA, February 4-7, 1991, ed. G. Apostolakis, SAND90-2094C, Elsevier Science Publishers, New York, 1991, 2, pp. 899-904.

Rechard, R.P., An Introduction to the Mechanics of Performance Assessment Using Examples of Calculations Done for the Waste Isolation Pilot Plant Between 1990 and 1992, SAND93-1378, Sandia National Laboratories, Albuquerque, 1995.

Rechard, R.P., Historical Background on Assessing the Performance of the Waste Isolation Pilot Plant, SAND982708, Sandia National Laboratories, Albuquerque, in preparation (1999). (Status? Since I haven't yet seen this paper, I cannot verify the correctness of this citation.)

Rechard, R.P. (ed.), User's Reference Manual for CAMCON: Compliance Assessment Methodology Controller, Version 3.0, SAND90-1983, Sandia National Laboratories, Albuquerque, 1992.

Rechard, R.P., Iuzzolino, H.J., Rath, J.S., Gilkey, A.P., McCurley, R.D., \& Rudeen, D.K., User's Manual for CAMCON, Compliance Assessment Methodology Controller, SAND88-1496, Sandia National Laboratories, Albuquerque, 1989.

Rechard, R.P., Beyeler, W., McCurley, R.D., Rudeen, D.K., Bean, J.E., \& Schreiber, J.D., Parameter Sensitivity Studies of Selected Components of the Waste Isolation Pilot Plant Repository/Shaft System, SAND89-2030, Sandia National Laboratories, Albuquerque, 1990.

Rechard, R.P., Roache, P.J., Blaine, R.L., Gilkey, A.P., \& Rudeen, D.K., Quality Assurance Procedures for Computer Software Supporting Performance Assessments of the Waste Isolation Pilot Plant, SAND901240, Sandia National Laboratories, Albuquerque, 1991.

Rechard, R.P., Trauth, K.M., \& Guzowski, R.V., Quality Assurance Procedures for Parameter Selection and Use of Expert Judgment Panels Supporting Performance Assessments of the Waste Isolation Pilot Plant, SAND91-0429, Sandia National Laboratories, Albuquerque, 1992a.

Rechard, R.P., Rudeen, D.K., and Roache, P.J., Quality Assurance Procedures for Analyses and Report Reviews Supporting Performance Assessments of the Waste Isolation Pilot Plant, SAND91-0428, Sandia National Laboratories, Albuquerque, $1992 \mathrm{~b}$.

Rechard, R.P., Gilkey, A.P., Iuzzolino, H.J., Rudeen, D.K., \& Byle, K.A., Programmer's Manual for CAMCON: Compliance Methodology Controller, SAND90-1984, Sandia National Laboratories, Albuquerque, 1993a.

Rechard, R.P., Trauth, K.M., Rath, J.S., Guzowski, R.V., Hora, S.C., and Tierney, M.S., The use of formal and informal expert judgments when interpreting data for performance assessments, in Scientific Basis for Nuclear Waste Management XVI, Materials Research Society Symposium Proceedings, Boston, MA, 
November 30-December 4, 1992, ed. C.G. Interrante and R.T. Pabalan, SAND92-1148C, Materials Research Society, Pittsburgh, 1993b, 294, pp. 943-950.

Reeves, M., Ward, D.S., Johns, N.D., \& Cranwell, R.M., Theory and Implementation for SWIFT II, The Sandia Waste-Isolation Flow and Transport Model for Fractured Media, Release 4.84, SAND83-1159, NUREG/CR-3328, Sandia National Laboratories, Albuquerque, 1986.

Roache, P.J., The SECO suite of codes for site performance assessment, in High Level Radioactive Waste Management, Proceedings of the Fourth Annual International Conference, Las Vegas, NV, April 26-30, 1993, American Nuclear Society, La Grange Park, 1993, 2, pp. 1586-1594.

Sanchez, L., et al., Radioactive and nonradioactive waste intended for disposal at the Waste Isolation Pilot Plant. Reliability Engineering and System Safety, this issue. (Need to list all authors. Since I haven't yet seen this paper, I cannot verify the correctness of this citation.)

Sandia [National] Laboratories, Waste Isolation Pilot Plant (WIPP) Conceptual Design Report, SAND77-0274, Sandia [National] Laboratories, Albuquerque, 1977.

Sandia [National] Laboratories, Summary of Research and Development Activities in Support of Waste Acceptance Criteria for WIPP, comp. T.O. Hunter, SAND79-1305, Sandia [National] Laboratories, Albuquerque, 1979.

Sandia National Laboratories \& U.S. Geological Survey, Basic Data Report for Drillhole ERDA 6 (Waste Isolation Pilot Plant - WIPP), SAND79-0267, Sandia National Laboratories, Albuquerque, 1983.

Serber, R., The Los Alamos Primer: The First Lectures on How to Build an Atomic Bomb, University of California Press, Berkeley, 1992.

Sjoblom, G., Regulatory policy of the EPA related to alpha-contaminated waste, in Proceedings of AlphaContaminated Waste Management Workshop, Gaithersburg, MD, August 10-13, 1982, CONF-820845, Oak Ridge National Laboratory, Oak Ridge, 1982, pp. 47-58.

Smith, T., Risk and safety analyses for disposal of alpha-contaminated waste in INEL, in Proceedings of AlphaContaminated Waste Management Workshop, Gaithersburg, MD, August 10-13, 1982, CONF-820845, Oak Ridge National Laboratory, Oak Ridge, 1982, pp. 395-436.

Snyder, R.P., Gard, L.M., Jr., \& Mercer, J.W., Evaluation of Breccia Pipes in Southeastern New Mexico and Their Relation to the Waste Isolation Pilot Plant (WIPP) Site, with Section on Drill-Stem Tests, WIPP 31, Openfile report 82-968, U.S. Department of Interior, Geological Survey, Denver, 1982.

State of New Mexico, ex rel., Jeff Bingaman, Attorney General of the State of New Mexico, Plaintiff, $v$. The United States Department of Energy, et al., Defendants, 1981. "Stipulated Agreement." Civil Action No. 81-0363 JB. (United States District Court for the District of New Mexico). July 1, 1981.

Stenhouse, M., Chapman, N., \& Sumerling, T., SITE-94 Scenario Development FEP Audit List Preparation: Methodology and Presentation, SKI Technical Report 93:27, Swedish Nuclear Power Inspectorate, Stockholm, 1993.

Stockman, C., Shinta A., \& Garner, J.W., Analysis Package for the Salado Transport Calculations (Task 2) of the Performance Assessment Analyses Supporting the Compliance Certification Application (CCA), AP-023, Analysis Plan 023, Sandia WIPP Central Files WPO 40515, Sandia National Laboratories, Albuquerque, 1996. 
Stoelzel, D.M. \& O'Brien, D.G., The effects of salt water disposal and waterflooding on WIPP, Summary Memorandum of Record for NS-7a, Sandia WIPP Central Files WPO 40837, Sandia National Laboratories, Albuquerque, 1996.

Stoelzel, D.M., Garner, J.W., Helton, J.C., Johnson, J.D., O'Brien, D.G., \& Smith, L.N., Direct releases to the surface and associated complementary cumulative distribution functions in the 1996 performance assessment for the Waste Isolation Pilot Plant. Reliability Engineering and System Safety, this issue. (Since I haven't yet seen this paper, I cannot verify the correctness of this citation.)

Stone, C.M., SANTOS-A Two-Dimensional Finite Element Program for the Quasistatic, Large Deformation, Inelastic Response of Solids, SAND90-0543, Sandia National Laboratories, Albuquerque, 1997.

Stone, C.M., Krieg, R.D., \& Beisinger, Z.E., SANCHO: A Finite Element Computer Program for the Quasistatic, Large Deformation, Inelastic Response of Two-Dimensional Solids, SAND84-2618, Sandia National Laboratories, Albuquerque, 1985.

Stormont, J.C., Preliminary Seal Design Evaluation for the Waste Isolation Pilot Plant, SAND87-3083, Sandia National Laboratories, Albuquerque, 1988.

Swift, P.N. \& Corbet, T.F., The geologic and hydrogeologic setting of the Waste Isolation Pilot Plant. Reliability Engineering and System Safety, SAND98-2084J, this issue.

Telander, M.R. \& Westerman, R.E., Hydrogen Generation by Metal Corrosion in Simulated Waste Isolation Pilot Plant Environments, SAND96-2538, Sandia National Laboratories, Albuquerque, 1997.

Tierney, M.S., Combining Scenarios in a Calculation of the Overall Probability Distribution of Cumulative Releases of Radioactivity from the Waste Isolation Pilot Plant, Southeastern New Mexico, SAND90-0838, Sandia National Laboratories, Albuquerque, 1991.

Tierney, M.S., Using data and information to form distributions of model parameters in stochastic simulations of performance of the Waste Isolation Pilot Plant (WIPP), in Proceedings of PSAM - II, An International Conference Devoted to the Advancement of System-based Methods for the Design and Operation of Technological Systems and Processes, San Diego, CA, March 20-25, 1994, ed. G.E. Apostolakis and J.S. Wu, SAND93-1302A, 1994, 2, pp. 051-9 through 051-16.

Tierney, M.S. \& Rechard, R.P., Assessing performance of imprecisely characterized systems: a mathematical perspective, in Advances in Safety and Reliability: Proceedings of the ESREL '97 International Conference on Safety and Reliability, Lisbon, Portugal, June 17-20, 1997, ed. C.G. Soares, Pergamon, New York, 1997, 1, 569-576.

Tierney, M.S., Helton, J.C., \& Martell, M.-A., Characterization of subjective uncertainty in the 1996 performance assessment for the Waste Isolation Pilot Plant. Reliability Engineering and System Safety, this issue. (Since I haven't yet seen this paper, I cannot verify the correctness of this citation.)

Trauth, K.M., Rechard, R.P., \& Hora, S.C., Expert judgment as input to Waste Isolation Pilot Plant performance assessment calculations: probability distributions of significant system parameters, in Mixed Waste, Proceedings of the First International Symposium, Baltimore, MD, August 26-29, 1991, ed. A.A. Moghissi and G.A. Benda, SAND91-0625C, University of Maryland, Baltimore, 1991, pp. 4.3.1 through 4.3.9.

Trauth, K.M., Hora, S.C., Rechard, R.P., \& Anderson, D.R., The Use of Expert Judgment to Quantify Uncertainty in Solubility and Sorption Parameters for Waste Isolation Pilot Plant Performance Assessment, SAND920479, Sandia National Laboratories, Albuquerque, 1992. 
Trauth, K.M., Hora, S.C., \& Guzowski, R.V., Expert Judgment on Markers to Deter Inadvertent Human Intrusion into the Waste Isolation Pilot Plant, SAND92-1382, Sandia National Laboratories, Albuquerque, 1993.

Tyler, L.D., Matalucci, R.V., Molecke, M.A., Munson, D.E., Nowak, E.J., \& Stormont J.C., Summary Report for the WIPP Technology Development Program for Isolation of Radioactive Waste, SAND88-0844, Sandia National Laboratories, Albuquerque, 1988.

Vaughn, P., A Numerical Model for Thermal Recovery Processes in Tar Sand: Description and Application, DOE/FE/60177-2219, Western Research Institute for Department of Energy, Morgantown Energy Technology Center, Laramie Project Office, Laramie, 1986. (On file in the SWCF as WPO 51804.)

Vaughn, P., Bean, J.E., Helton, J.C., Lord, M.E., MacKinnon, R.J., \& Schreiber, J.D., Modeling of two-phase flow in the vicinity of the repository in the 1996 performance assessment for the Waste Isolation Pilot Plant. Reliability Engineering and System Safety, this issue. (Since I haven't yet seen this paper, I cannot verify the correctness of this citation.)

Van Sambeek, L.L., Luo, D.D., Lin, M.S., Ostrowski, W., \& Oyenuga, D., Seal Design Alternatives Study, SAND92-7340, Sandia National Laboratories, Albuquerque, 1993.

Voss, C.I., SUTRA (Saturated-Unsaturated Transport): A Finite-Element Simulation Model for SaturatedUnsaturated, Fluid-Density-Dependent Ground-Water Flow with Energy Transport or ChemicallyReactive Single-Species Solute Transport, Water-resources investigations report 84-4369, US Geological Survey, Reston, 1984.

Weart, W.D., WIPP: A bedded salt repository for defense radioactive waste in southeastern New Mexico, in Radioactive Waste in Geologic Storage, 176th Annual Meeting of the American Chemical Society, Miami Beach, FL, September 11-15, 1978, ed. S. Fried, SAND78-0934C, ACS Symposium Series No. 100, American Chemical Society, Washington, DC, 1979, pp. 13-36.

Westinghouse Electric Corporation (WEC), Backfill Engineering Analysis Report, Waste Isolation Pilot Plant, Westinghouse Electric Corporation, Waste Isolation Division, Carlsbad, 1994.

WIPP PA Department, Preliminary Performance Assessment for the Waste Isolation Pilot Plant, December 1992, SAND92-0700/1/2/3/4/5, Sandia National Laboratories, Albuquerque, 1992/1993, 1-5.

WIPP PA Department, User's Manual for FMT, Version 2.00, Sandia WIPP Central Files WPO 28119, Sandia National Laboratories, Albuquerque, 1995.

WIPP PA Division, Preliminary Comparison with 40 CFR Part 191, Subpart B for the Waste Isolation Pilot Plant, December 1991, SAND91-0893/1/2/3/4, Sandia National Laboratories, Albuquerque, 1991/1992, 1-4.

Woolfolk, S.W., Radiological Consequences of Brine Release by Human Intrusion Into WIPP, TME 3151, U.S. Department of Energy, Waste Isolation Pilot Plant, Albuquerque, 1982.

Zimmerman, D.A. \& Gallegos, D.P., A comparison of geostatistically-based inverse techniques for use in performance assessment analyses at the WIPP site: results from test case no. 1, in High Level Radioactive Waste Management, Proceedings of the Fourth Annual International Conference, Las Vegas, NV, April 2630, SAND92-2127C, American Nuclear Society, La Grange Park, 1993, 2, pp. 1426-1436. 


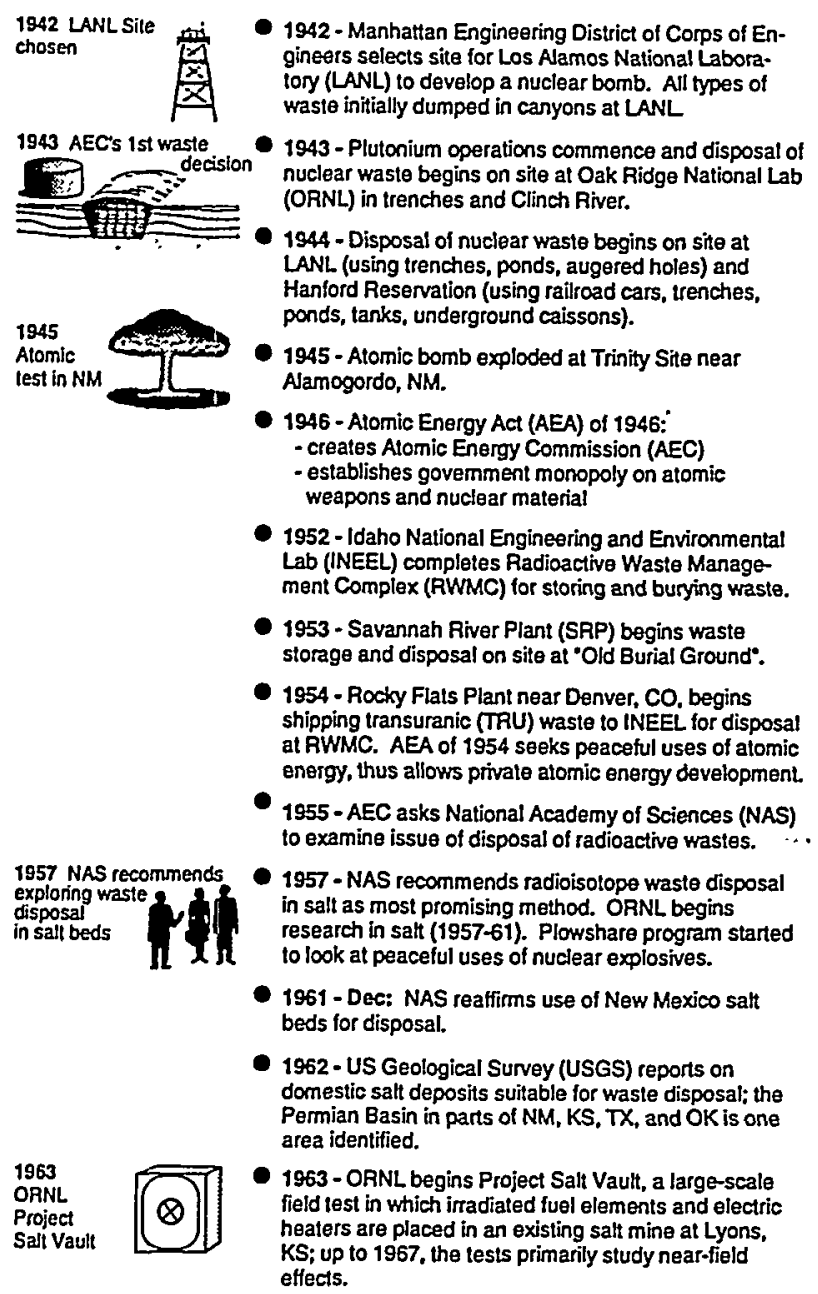

1965 - Savannah River Plant (SRP) begins disposing TRU waste in trenches on site.

- 1966 - NAS reatirms use ol salt beds for disposal and strongly criticizes current disposal practices.

- 1968 - Committee on Radicactive Waste Management established by NAS, later permanent "Board" (BRWM): first task is to reevaluate the use of bedded salt. AEC asks NAS to revisit the issue of nuclear waste disposal. A15 At request of Congress. General Accounting Otfice (GAO) audits AEC waste management practices and finds faults with records and management. AEC forms task force to address criticisms.

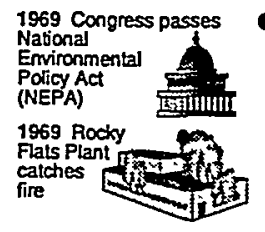

- 1969 - May: Rocky Flats Plant catches fire and cleanup waste sent to idaho for disposal at RWMC; event focuses public attention on AEC nuclear waste problems. Dec: Congress passes National Environmental Policy Act (NEPA):

- requires federal agencies to consider environmental consequences of any major action through environmental impact statement (EIS) - first US environmental law to be applied to the Waste Isolation Pilot Plant (WIPP)

Intemational Atomic Energy Agency (IAEA) forms advisory committeo to categorize nuelear waste; Alpha contaminated waste one category defined.

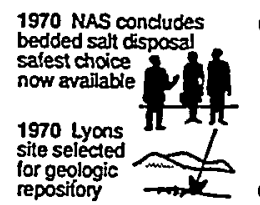

1970 - Jun: AEC tells Sen. Church that the waste from fire stored at INEEL will be removed by 1980 . AEC tentatively selects salt mine in Lyons, KS, as repository. Nov: BRWM of NAS issues report concluding bedded salt satistactory and safest choice available for nuclear waste disposal

lor geologic

1971 - Many drill holes and some solution mining discovered at Lyons, KS. AEC directs HLW be solidified within 5 yr, stored retrievably, and delivered to federal repository within $10 \mathrm{yr}$. Congress directs AEC to stop Lyons project until safety is certified. Appeals coutt re quires AEC to look at all environmental impacts in EIS.

1972 Lyons 1972 - May: AEC abandons Lyons project. AEC ansite judged (LYons) nounces plans for Retrievable Surface Storage Facility (RSSF) for radioactive wastes. EPA and anti-nuclear groups claim RSSF de facto permanenl disposal in RSSF EIS.

TRI-6342-5836-2

Fig. 1. Early history of nuclear waste disposal related to the WIPP (adapted from Fig. 2 in Rechard, 1998, which provides references). 


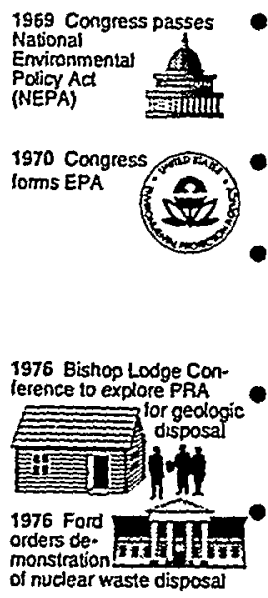

99 - National Environmentai Policy Act (NEPA) - requires foderal agencies to consider environmental consequences of any major action through environmeniafmpact statement (EIS)

first environmental law to be applied to the WIPP

1970 - Congress forms Environmental Protection Agency (EPA) and transfers to it research, monitoring. ment activities.

1974 - AEC promises ldaho that wastes will be shipped out of Idaho in the 1980's. Oct: Energy Reorganization Act splits AEC into Nuclear Regularory Commis sion (NRC) and Energy Research and Development Agency (ERDA) effective January 1975.

1976 -ERDA funds conference on modeling of geologic disposal systems to bring engineers and geologists logether to explore predicting geological features. nis, and processes (FEPs).

1976 - Oet: President Ford orders expansion of ERDA program ro demonstrate disposal for nuclear Wan by 1985 and orders EPA to develop applicable (RCRA) seeks to reduce hazardous waste generation. Dec: EPA announces intent to develop standards for Dec: EPA announ

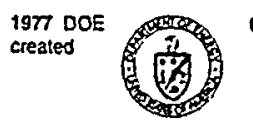

1977- Oct: DOE Organization Act creates Deparment of Energy (DOE) from ERDA Feb: EPA conducts 151 public workshop to understand public concens and technical issues of waste disposal.

1978 Oversight by WIPP panel of NAS and
New Mexico

- 1978 - DOE Deputy Sec. Jetry OL Leary promises NM Congressional delegation "ir NM did not wish to have Congressional delegation "is NM did not wish to have
the WiPP, then it could veto the plan." DOE General the WiPP, then it could veto the plan." DOE Gener Counsels stale O'Leary poweriess to grant "state protection criteria for radioactive wastes. Jun: In response to DOE requesi to review scientific aspects of WIPP Project, WIPP Panel of BAWM of NAS holds first meeting. Nov: EPA publishes "Criteria for Radioactive Wastes" as guidance for federal agencies and seeks comments. DOE contracts with NM to establish Environmental Evaluation Group (EEG) to provide an independent state assessment of WIPP.

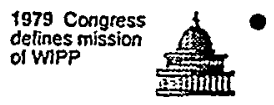

1979 - Dec: Congress delines mission of WIPP: - sets up WPP as a research and development facility for disposal of only DOE TRU waste - exempts WIPP from NRC licensing - requires DOE to sign a "Consultation \& Cooperation" (C\&C) Agreement with NM

- 1980 - NM and DOE begin negotiations on C\&C Agree ment to define procedures and process of cooperation

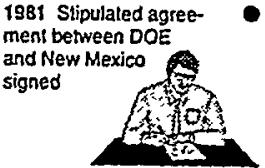

1981 - Jan: DOE decides to proceed with Site and Preliminary Design Validation (SPDV). In response: - Mar: Citizens for Altematives to Radioactive Dumping (CARD) asks for preliminary injunction. - May: NM sues DOE and Department of Interior (DOI) alleging violations of federal and state laws. - Jul: Southwest Research \& Information Center (SWRIC) files lawsuit and begins filing numerous interrogatories to which DOE must respond. in response to lawsuits, DOE Sec. Edwards visits NM to talk 10 Gov. King and accedes in a "Stipulated Agree ment (SA)" for (1) geotectinical experiments. (2) state \& public review of WIPP changes, and (3) creation of a state/federal task lorce to oversee transponation issues (e.g., emergency response and highway upgrades). C\&C Agency response and highway up"Working Agreement" as Appendix B. U.S. Dist. Judge Burciag stays lawsuits. posal criteria for radioactive wastes difficult, thus EPA starts developing standards for each waste type.

- 1982 - EPA publishes working draf 20 as proposed 40 CFR 191. Dec: Supplemental SA signed commitIIng DOE (1) to soek funds for upgrading highways in

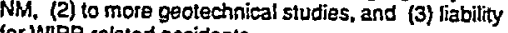
for WiPP

- 1983 - In response to questions by EEG, DOE conciudes draft 40 CFR 191 applies to disposal phase bus not test phase ot WIPP. May: Oak Rioge complex admits releasing $2 \times 10^{6}$ ib of. Hg from $Y-12$ plant be tween 1950 and 1977 . Revelation prompts Natural Resources Delense Council (NRDC) and Legal Environmental Assistance Foundation (LEAF) 10 SUS DOE.

- 1984 - Feb: EPA. Scientific Advisory Board (SAB) en dorses probabilistic approach of 40 CFR 191 but states criteria too restrictive and recommends changes.

- 1984 - (con't) Apr: LEAF vs. Hodel subjects I RCRA requitements though AEA exempled DO human health laws. Nov: Hazardous \& Solid h. Amendments (HSWA) to RCRA ban land dispos hazardous waste without treatment uniess dispo and generator demonstrate "no migration" ol cor ents for as long as waste remains hazardous. Is ification to C\&C Agreement limiting rearous. 1sI (FH) TRU waste amount 10 $5.1 \times 10^{5} \mathrm{Ci}$.

1985 EPA promulgates
$40 \mathrm{CFR} 191$

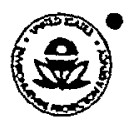

1985 - Feb: NRDC sues EPA to issue 40 CFR 1: mandated in NWPA. Sep: EPA promulgates 40 191 for disposal of SNF, HLW, and TRU:

- probabilistic criteria indirectly based on populat health risk - requires inclusion of all uncertainty Nov: DOE attempts to define "by-product materia include mixed waste and thus exclude EPA regula

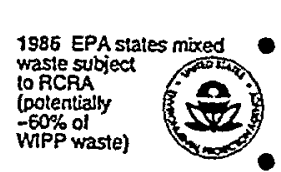

1986 - EPA states that mixed waste (fadioactive wr with hazardous wasto) is subject to RCRA regulatic Mar: NADC and others sue EPA over groundwate individual protection standards in $40 \mathrm{CFR} 191$.

- 1987 - May: DOE defines "by-product material" to exclude everything except radionuclides, and theret TRU waste is subject to RCRA. Jul: in response to NRDC lawsuit, Court of Appeals for ist Circuit in Bos: vacates and remands all of 40 CFA 191. Aug: 2nd modification to C\&C Agreement commits DOE comply with all applicable laws; to use 40 CFR 191 a! comply wh all applicable laws; to use 40 CFR 19 1st issued for evaluating Wis complance until reissued by EPA and apply NRC and Department of Transportalion (DOT) reguiations to ThU transpon. Sep: Coun reinstales Subpart A of 40 CFR 191 in responsa to EPA request.

- 1988 - Oct: ID Gov. Andrus bans shipments of radioa tive waste into state because WIPP not open. With co tinued technical problems (e.g., TRUPACT - II not yet licenseo\%. NM Congressional delegation cannol get cor sensus among themselves and WIPP Land Windrawal Act dies. Dee: ID Gov. Andrus, CO Gov. Romer, and NM Gov. Carsuthers meet in Salt Lake City to discuss WPP and options to avent shutdown ot Rocky Flats Plant from lack of storage imposed by $\mathrm{CO}$, and inabilsy to ship to ID; DOE agrees to pursue both administrative and legislative land withdrawal for WIPP.

- 1989 - Westinghouse completes "no-migration" petition for FCRA variance for WIPP test phase.

- 1990 - EPA issues no migration variance for test phase.

- 1991 - Westinghouse completes Pans A \& B of RCRA permit application to state.

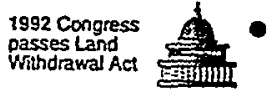

1992 - Oct: WIPP Land Withdrawal Act (LWA): - transfers land from DOI $10 \mathrm{DOE}$ - establishes EPA as regulator tor WIPP - requires recertitying site every 5 yr - reinstates Subpart B of 40 CFR 191 except disputed individual and groundwater requisements - requires DOE cooperation with EEG.

1953 EPA 1993 - Dec: in response to court remand and WPP repromulgates 10 LWA. EPA repromulgates 40 CFR 191 - no intluentia changes for WIPP.

- 1995 - Jan: EPA proposes compliance criteria lor WIPP in 40 CFR 194.

1996 EPA states Finat 1996 - Fab: EPA promulgates final 40 CFR 194 how to imple- 2 -requires analysis and peer review of waste characterization, engineered bartier evaluation in 40 CFR 194 and conceptual models - requires a monitoring system - specifies requirements on quality assurance (OA), peer review, and expen juogment - requires potash mining to be considered Sep: Congress amends WPP LWA and relieves WIPP of need to comply with land disposal restrictions of RCRA, but other requirements of RCRA still apply.

- 1997 - Oct: EPA issues dratt rule to approve WPP With conditions: requires use of panel seals used in PA. design requires $\mathrm{QA}$ for waste generalors; lists requirements for using process knowledge to characterize wastes; requires schedule for installing passive controls: denies any protective credit for passive controls; and 120-day public comment period begins.

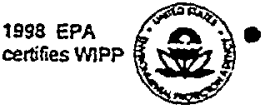

1998 - May: EPA certifies WIPP. Jul: NM AG sue EPA alleging insuticient time to cornment on CCA. CARD and SWRIC also file law suits.

TRI-6342-5837-2

Fig. 2. Development of performance goals for the WIPP (adapted from Fig. 3 in Rechard, 1998, which provides references). 


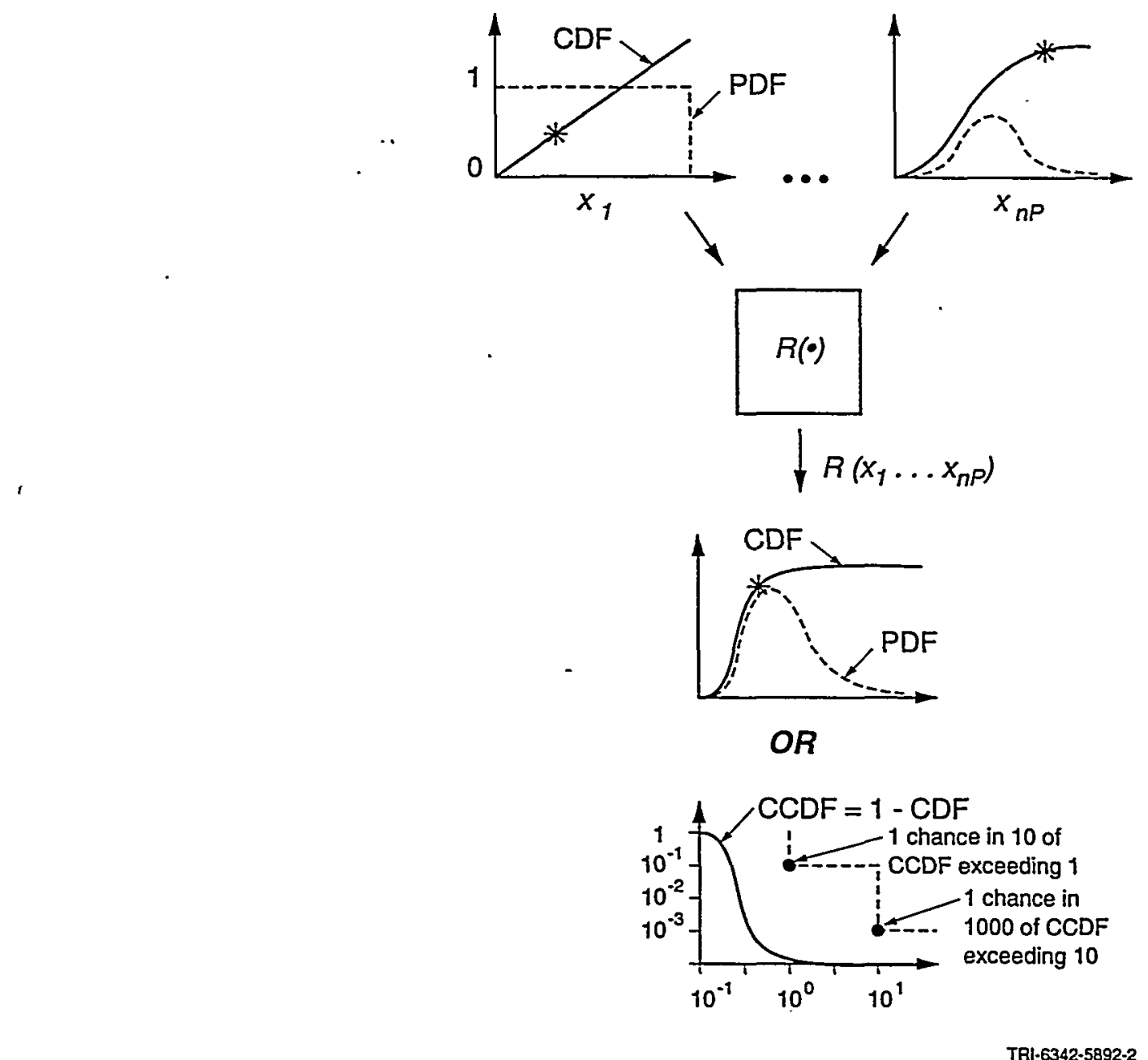

Fig. 3 Uncertainty in model parameters $x$ (expressed as a probability density function [PDF], $d$, or cumulative distribution function [CDF], $D$ ) results in uncertainty in the results $C\left(x_{1} \ldots x_{n P}\right)$. This uncertainty (expressed as a complementary distribution function CCDF or 1-CDF) is compared to the limits in 40 CFR 191. 


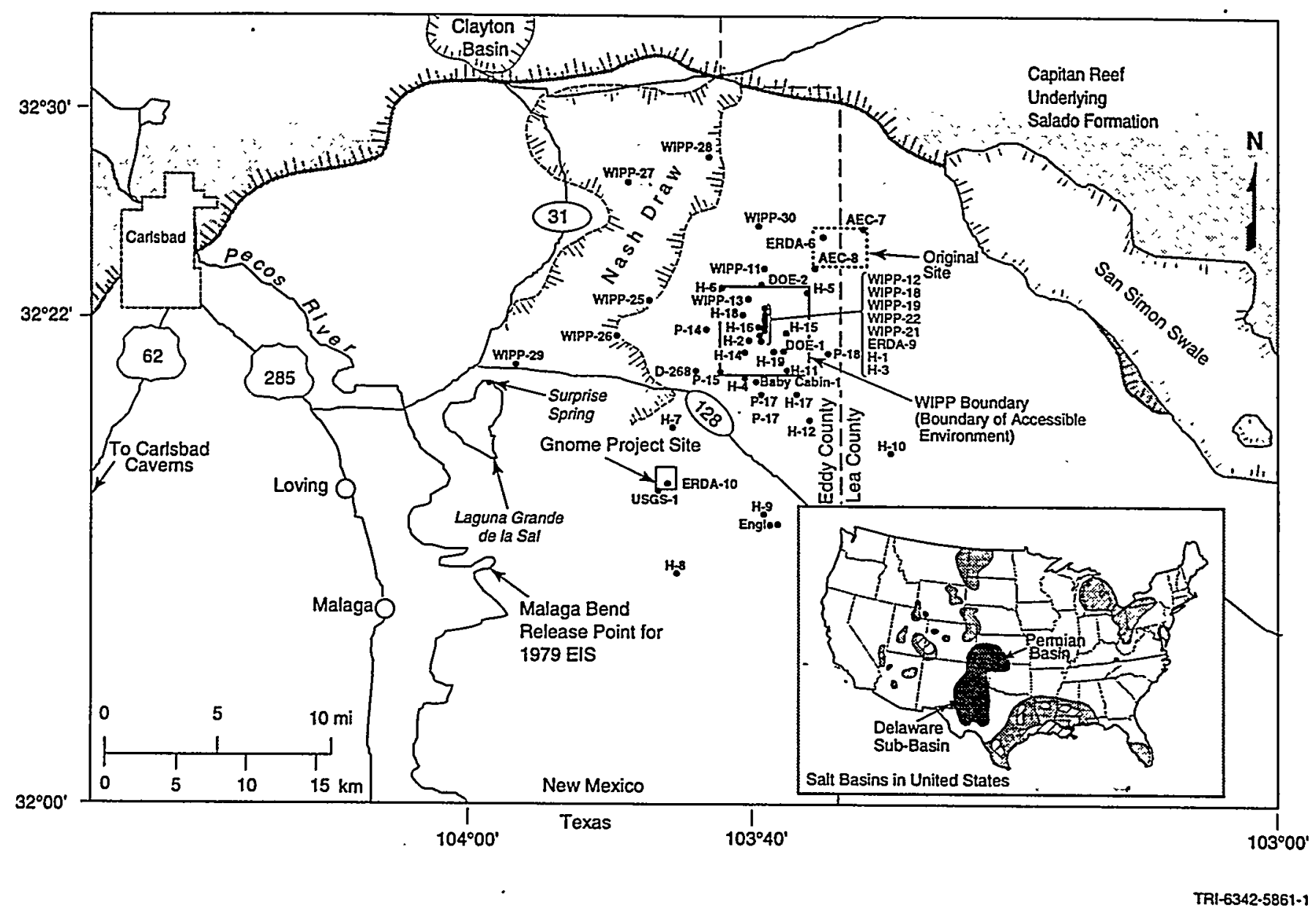

Fig. 4. Physical setting of the WIPP in Delaware Basin (after Rechard, 1995, Figure 2.1-1) 


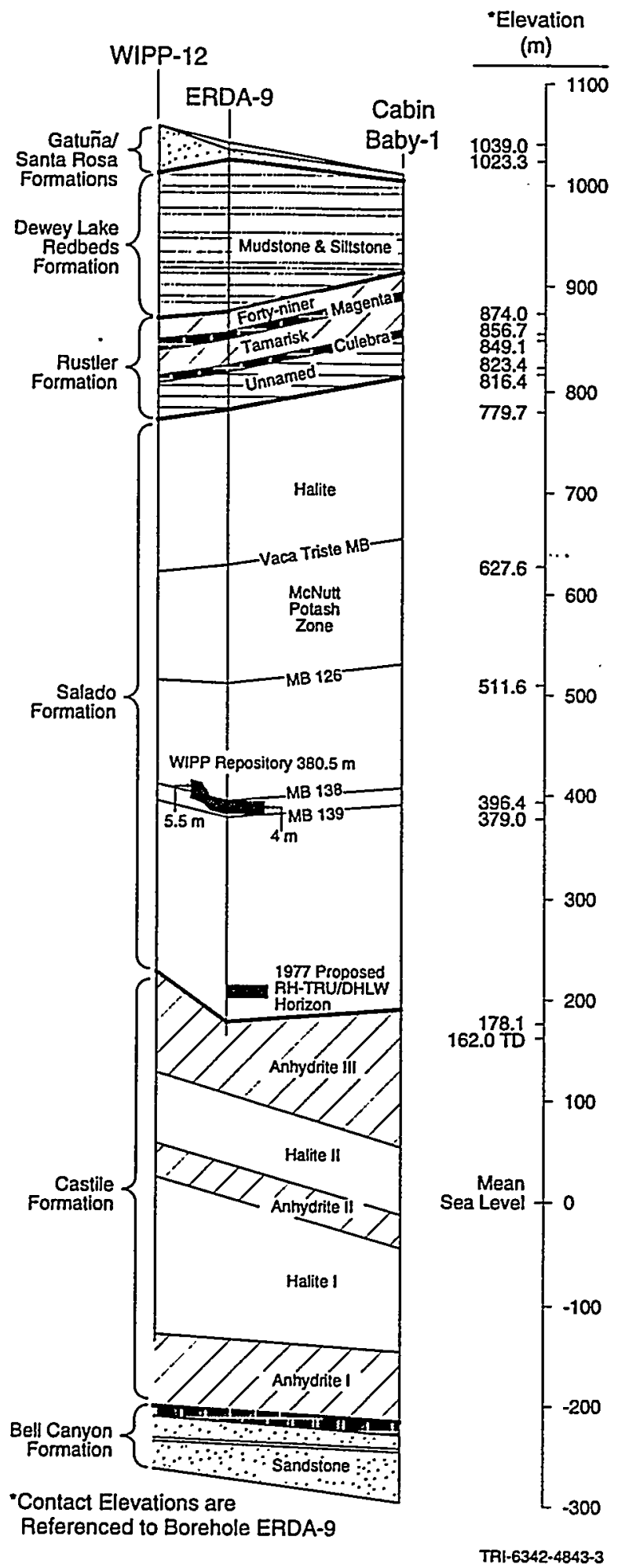

Fig. 5. Stratigraphy above and below the WIPP repository (after Rechard, 1995, Figure 2.1-2) 
$\therefore$

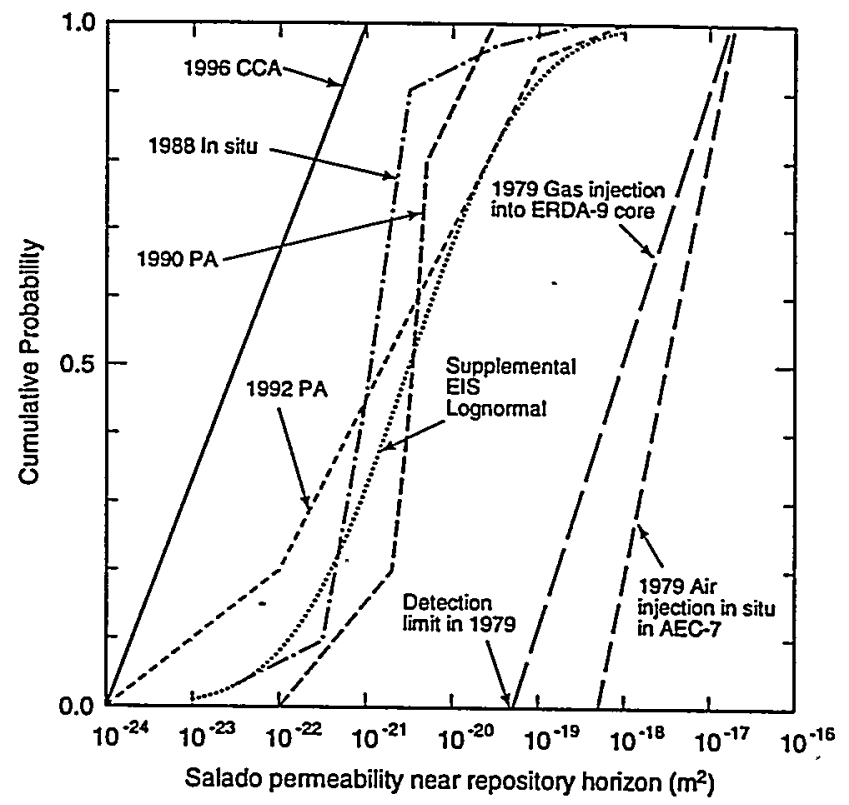

TRI-6342-5845-0

Fig. 6. Estimated permeability of Salado Formation near repository horizon continued to decrease over the years (Rechard, 1998). 


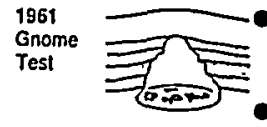

1961 - USGS evaluates stratigraphy and AEC mines into Salado Fm at Gnome site near Carlsbad, NM, fo Gnome test as part of Plowshare program.

1971 - USGS tests permeability of strata around Gnome site (Plowshare program) for closure studies by AEC.

1973 Los Medanos

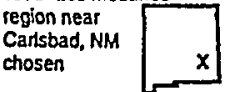

1973 - Nationwide search for suitable salt site resumed. With tacit approval of Gov. King, local political leaders and potash mine operators invite AEC to southeastem NM. USGS and ORNL recommend southeastem NM (lack of boreholes 2 miles from site important selection criterion but relaxed to 1 mile in 1975).

- 1974 - Mar: ORNL begins field investigations for the Bodded Salt Pilot Plant (BSPP) by drilling AEC-7 and AEC-8. May: WIPP work suspended until 1975 because AEC wished to emphasize RSSF and AEC Chaiman Ray would not withdraw land from oil exploration because of oil embargo.

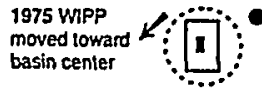

1975 - Jan: ERDA asks Sandia National Laboratories (SNL), located in NM, to oversee investigations rather than ORNL and suggests an opening date of 1982. Mar: SNL receives lunding and starts four tasks: selecting site and characterizing, producing cohceptual design, drafting EIS, initiating scientific studies. May: ERDA-6 drilled at NW comer of original ORNL site; encounters delormed salt beds and hits brine and $\mathrm{H}_{2} \mathrm{~S}$. SNL recommends relocation and project moves site $-11 \mathrm{~km}(7 \mathrm{mi})$ toward center of Delaware Basin to avoid delomed salt beds as indicated by oil well logs.

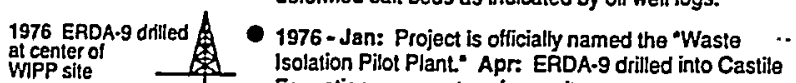
at center of
WiPP site Formation near center of new site.

1978 SNL publishes 1978 - Aug: SNL completes geologic characterization supporting character- report supporting Dratt EIS on WIPP; transmissivity

documents
lor EIS

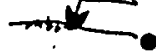

1979 - 1st in-situ permeability measurement of Salado Formation salt from AEC-7 well (values 1000 times larger than found when measured within repository in 1988). Laboratory measurements made of permeability on ERDA-9 core.

- 1981 - Nov: Project strikes pressured brine reservoir while deepening WIPP-12 north of the repository (as part of Stipulated Agreement [SA]). Extensive tests and analysis continue on WIPP-12 through 1983.

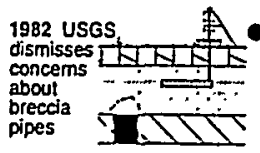

1982 - Jul: Drilling of DOE-1 started and completed to top of Anhydrite I in Castile Fm. Dec: SNL completes interim report on dissolution of evaporates in and around the Delaware Basin (part of SA). USGS completes breccia pipe report (part of SA) and dismisses concems.

- 1983-Mar: SNL, USGS, and contractors complete most reports required by SA (e.g., USGS reports Culebra transmissivity at 20 locations; SNL reports on groundwater flow in Rustler Frn. and delormation of evaporates near WPP; technical support contractor. Westinghouse, reports on brine reservoirs in the Castile Fm.).
- 1983 - (con't) May: After reviewing results from SPDV program, EEG concludes that "...the Los Medanos site has been characterized in sufficient detail to warrant confidence in the validation of the site for permanen em- placement of approximately 6 million $\mathrm{ft}^{3}$ $\left(1.75 \times 10^{5} \mathrm{~m}^{3}\right)$ of defense TRU waste." but also recommends additional studies to resolve outstanding geotechnical issues such as evaluation of potential for brine reservoirs. Aug: Deepening of Cabin Baby started and completed to Bell Canyon Fm.; geophysica logs run and deep sandstones in Bell Canyon hydrologically tested.

- 1984 - Pumping tests at DOE-1 suggest fracture flow in Culebra. First in situ gas flow measurement conducted around underground dritt. Aug: SNL drills and tests DOE-2.

1985 - With the definition of a 5-km boundary to the disposal system in 40 CFR 191. project begins to focus more on near-field hydrologic modeling rather than regional modeling.

1986 - First in situ injected brine flow measurement to determine permeability around drifts.

1987 Brine 1987 - SNL finds possibility of a pressurized brine res ervoir below the TRU disposal area cannol be ruled out. Dec: Environmental groups raise concem of brine seepage into repository. 1988 Brine seepage 1988 - Jan: EEG issues report on potential brine big issue reservoirs under WIPP. NM Congressional delegation asks NAS BRWM to study brine inllow controversy. Sop: SNL reports on in situ permeability (1000 times lower than 1979) and small potential brine intlow. Members of NAS BRWM (not WIPP Panel) study brine inflow, conclude no problem but suggest more brine inflow tests. SNL completes pumping tests at $\mathrm{H}-11$ and begins using results to calibrate regional flow model.

- 1989 - SNL reports on reevaluation of Culebra permeability at AEC-7 and D-268 wells; Culebra transmissivity available at 41 locations. Jan - Aug: $Q$ tunnel mined and instrumented for brine inflow experiment.

- 1993 - Brine inflow to Q tunnel can be explained as either dewatering of disturbed rock zone or darcy flow through salt.

1994 - Aug: SNL seeks permits to drill new wells for 1995 Tracer test tracer test in Culebra.

begins ln Culebra 1995 - Fob: Drilling of wells for tracer tests begin.

1906 - 5 - 1996 - Apr: SNL completes tracer test in Culebra dual porosity modet $F$ results suggest dual porosity reasonable and single dual porosity modet porosity transport could be ruled out. Jul: SNL reports

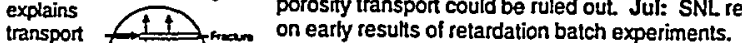
in Culebra

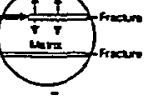

TRI-6342-5838-2

Fig. 7. Site characterization studies at the WIPP (adapted from Fig. 7 in Rechard, 1998, which provides references). 
- 1966 - Jan: B52 collides with relueling tanker at $30,500 \mathrm{ft}$; three nuclear weapons crash into Spanish soil; fourth weapon parachutes into ocean. (Question raised as to how much plutonium contaminated soil to relum to Savannah River Plant).

1970 AEC begins storing 1970 - Mar: AEC directs TAU waste be stored retriev TRU waste ably at all DOE facilities rather than disposed with low above ground level waste. AEC conservatively bounds TRU waste as waste contaminates with transuranic radioisoptopes with activity greater than $10 \mathrm{Cl} / \mathrm{g}$.

- 1975 - ERDA removes WIPP from commercial repository program.

- 1976 - Laboratory tests on TRU waste behavior and HLW packages intiated.

- 1977 - Apr: Carter announces plan to defer indelinitely reprocessing of commercial SNF. Nov: Athough role of NRC at WPP unctear, DOE telis NRC it plans to seek license to build and operate WIPP based on policy from Carter administration.

1978 SNL tests gas generation potenlial of TAU waste

- 1978 - SNL raises concern about gas generation and contracts with Los Alamos to do laboratory tests. Oct Deutch (Massachusetts Institute of Technology [MIT] chem. prof.) report written for DCE recommends (1) disposing TRU waste at WIPP without planning for retrieval, and (2) demonstrating spent nuclear fuel (SNF). HLW, and TRU disposal at WIPP. DOE Deputy Sec. J. O'Leary presses on with 2nd recommendation until 1979 enabling law for WIPP as a way to satisty Califomia law banning nuclear power plants until SNF disposal demonstrated. Nov: Lab studies focus on -. titanium alloys for HLW canisters.

1979 Draft EIS on 1979 - Mar: Interagency Review Group (IRG), formed WIPP has option by President Carter (in response to Deutch report). for commercial SNF $\&$ recommends disposal of SNF, HLW, and TRU in mined 1979 Congress passes bill to build WPP for TRU waste only

geologic repositories in final report. Report also suggests making WIPP candidate for commercial SNF repository. Apr: DOE defines project as a combination military/commercial repository in Dratt EIS. May: House Armed Services Committee cuts WIPP funding in response to DOE's expansion of the project to a repository for commercial SNF and thus requiring NRC licensing. Dec: Congress defines mission of WIPP: - sets up WIPP as a research and development facility for disposal of only TRU radioactive waste from DOE facilities

- exempts WIPP from NAC licensing

- requires DOE to sign a "Consultation \& Cooperation (C\&C) Agreement with NM. Based on salt permeability tests in AEC-7 well, DOE cancels all gas generation and some backfill experiments. EPA defines TRU waste as waste with activity greater than $100 \mathrm{n} \mathrm{CVg}$.

- 1980 - Feb: Carter orders SNF reprocessing to stop. Mar: Carter rescinds 1980 funds for WIPP becaus unlicensed repository for defense waste only and announces interim strategy to set aside money for other waste disposal projects at WIPP. Jul: House Armed Services Committee disagrees with Carter poliey: therelore, rescinded funds are retumed to WIPP in mid year. Dct: DOE issues final EIS eliminating SNF \& year. Oct: DOE issues final EIS eliminating SNF \&
HLW disposal and thereby reinstates WPP mission defined by Congress in 1979
1981 - Jun: WIPP Project Mgr. McGough rekindles disagreements between DOE and New Mexico by stating HLW could be placed by 1983 and remain stating HLW could be placed by 1983 and remain
during the operating phase of WIPP. Dratt (but not during the operating phase of WIPP. Dratt (but not
final) Nuclear Waste Policy ACt (NWPA) defines TRU waste as waste contaminated with transuranic radioisotopes with hall-life grater than $20 \mathrm{yr}$ and activity greater than ioon Civg.

- 1985 - Apr and Oct: SNLtums on heat for simulated OHLW canister experiments. Sep: In 40 CFR 191. EPA defines TRU waste as wasle with activity greater than $100 \mathrm{nCi} / \mathrm{g}$ and halt-life greater than $20 \mathrm{yr}$.

- 1987 - Dec: Nuclear Waste Policy Amendment Act (NWPAA) selects Yucca ML, NV, 10 undargo site characterization for potential SNF and HLW disposal; (bedded salt not being considered for SNF and HLW).

- 1988 - Dec: DOE abruptly cancels SNF and HLW experiments at WPP because of NWPAA (no tunds available to remove simulated disposal containers).

1989 Draft supple- 1989 - Mar: SNL completes report to suppont Draft mental EIS identifies Suppiemental EIS; report identifies generation of gases gas generation $\quad 4$ from container and waste corrosion as issue because salt permeability factor of 1000 lower than thought in 1989 Berin wall falts 1979 . Based on initial analysis results in February. DOE funds SNL to conduct new studies of gas generation. Nov: Berlin Wall falls signaling the end of
the Cold War and greatty changing future demands for the Cold War and greatly changing future demands for nuclear weapon material and, thus, amount and composition of TRU waste going to WIPP.

1990 - SNL and Westinghouse complete report on the pilot test phase of WIPP suggesting that $0.5 \%$ of waste capacity be brought to WIPP for gas generation experiments.

1992 NAS questions need 1992 -SNL \& Westinghouse complete work necessary tor in situ gas 3 to modity Test Phase Plan for gas generation tests.

generation ? Westinghouse completes work necessary tor moditying test Westinghouse completes work necessary tor modifying
Waste Retrieval Plan. Jun: NAS WIPP Panel sends letter to DOE questioning scientific need tor in-situ waste tests at WIPP.

1993 DOE 1993 - Oct: DOE concurs with NAS and decides not to

decides not to 3 emplace waste in a pilot phase at WIPP - lab tests

lest waste at if instead. DOE decides to make draft Compliance Certification Application (CCA) to EPA. Because actual waste not coming to WIPP. "bin tests"canceled.

1995 - Sep: Gas generation studies completed and results used to establish rates for CCA. Det: DOE 1996 Tests on
solubility reported publishes updated revision of WIPP inventory.

Fig. 8. Project goal and characterization of waste properties (adapted from Fig. 8 in Rechard, 1998, which provides references). 


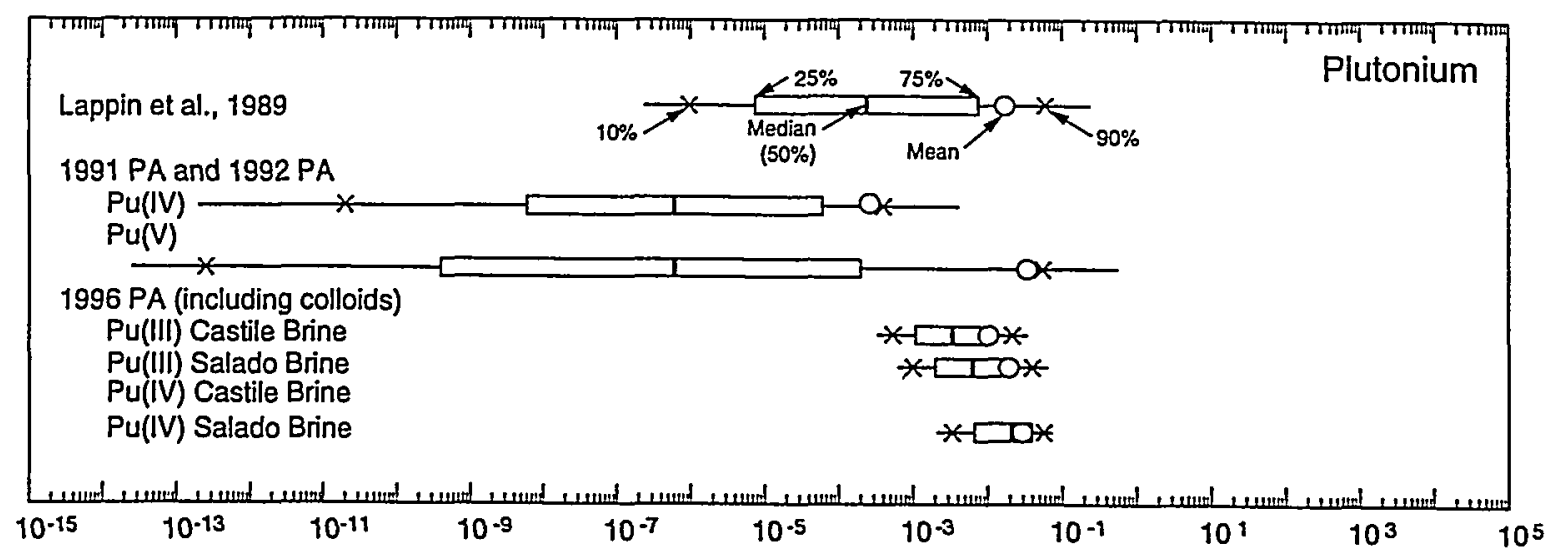

(a) Plutonium Solubility ( $\mathrm{mM}$ or moles $/ \mathrm{m}^{3}$ )

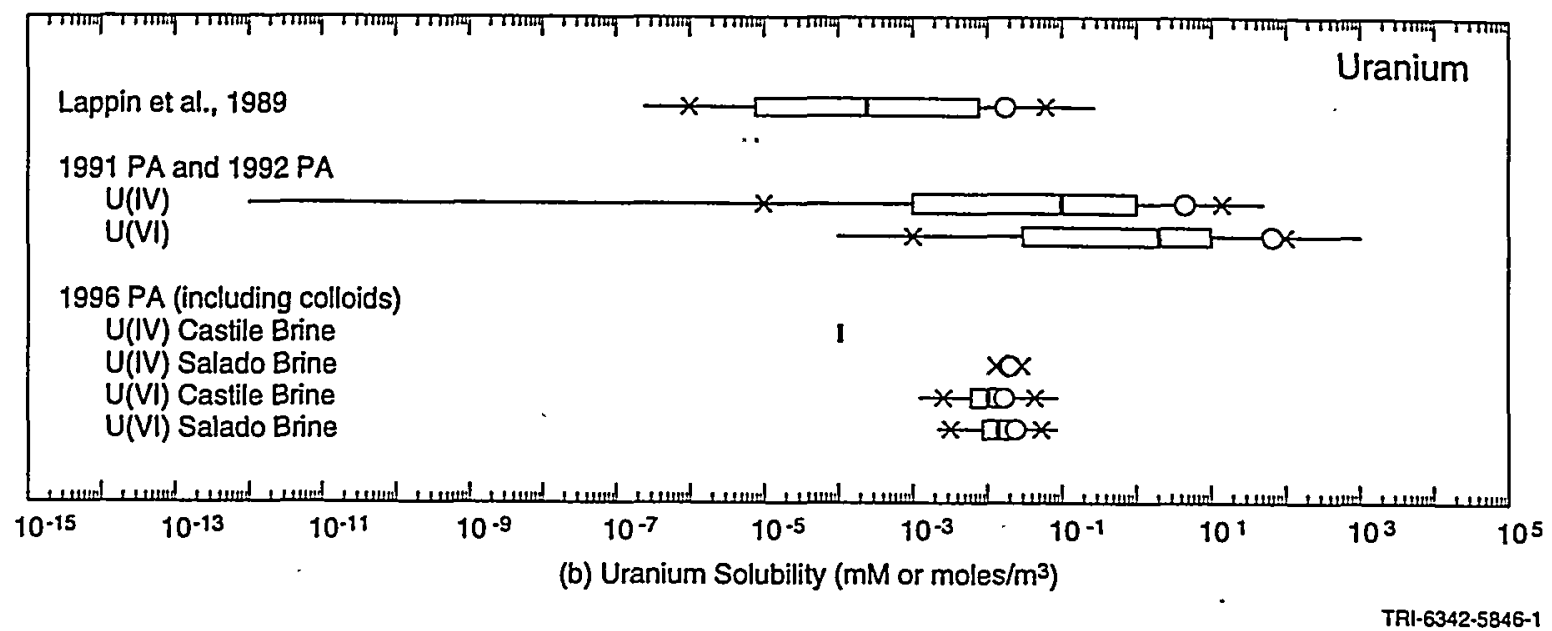

Fig. 9. Solubility of radioisotopes used in calculations between 1989 and 1996 for (a) plutonium and (b) uranium (Rechard, 1998). 


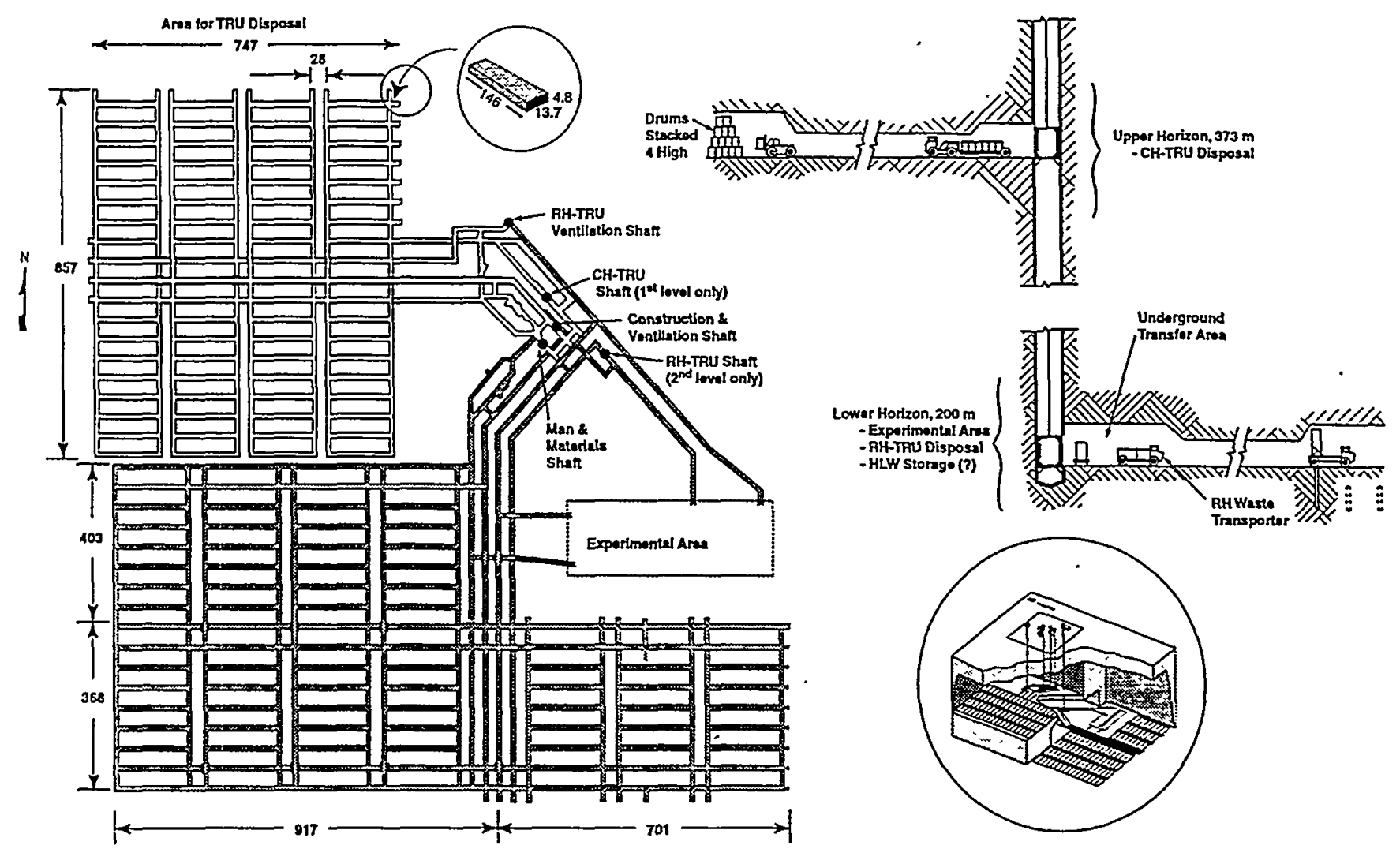

(a) 1977 conceptual design

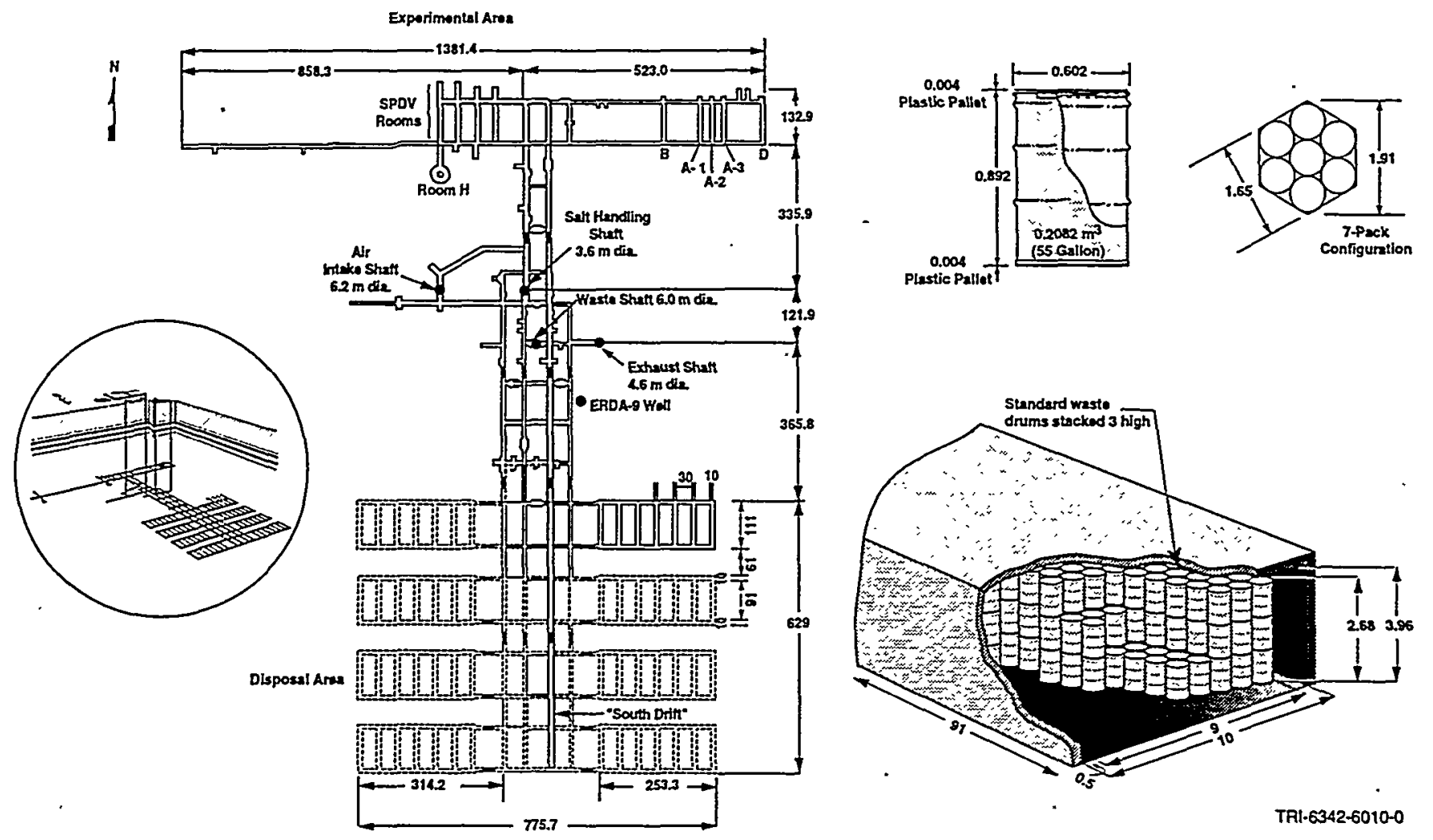

(b) Final construction plans for WIPP repository

Fig. 10. Designs for WIPP repository (a) 1977 conceptual design (Sandia, 1977) and (b) final construction plans (Rechard, 1995). 
1975 - ERDA suggests opening date of 1982 when assigning task to SNL to characterize site and make conceptual design of repository. SNL begins screening grouts to use for plugging boreholes.

- 1976 - Various natural backfilis such as apatite or sat bentonite considered for use in repository. Parsons, Brinckemotf, Quade, and Douglas, Inc. describe hypothetical HLW repository in bedded salt for Office of Nuclear Waste Isolation of ERDA.

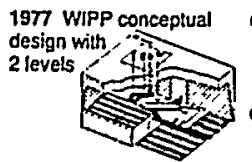

- Jun: SNL issues conceptual design report of WIPP repository with two levels. SNL plugs ERDA-10 to test plugging boreholes in salt.

1978 - Jan: Bechtel National starts as WPP ArchitectEngineer (AVE). Jun: Westinghouse Electric Corp. starts as Technical Support Contractor. Opening date of 1985 suggested.

- 1979 - To develop necessary predictive capability SNL begins 3-yr preliminary test programs on thermaVstrucfural effects in nearby potash mine, and Louisiana dome salt. Consolidation of enushed salt studied. Bechtel identifies 7 potential horizons for WIPP. Jul Preliminary Title 1 design of WPP completed. DOE buys oil and gas leases around site for $\$ 19$ million.

1980 - Westinghouse completes ist Safety Analysis Report (SAR)

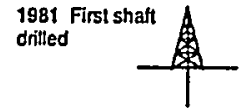

1981 - Jan: DOE publishes Record of Decision to proceed with Site and Preliminary Design Validation (SPDV) phase. Ess Fob: After reviewing preliminary design, DOE okays detailed (Title li) design phase. May: Fenix \& Scisson, SPDV construction contractor, ". begins augering 1st shatt (this exploratory shaft later called construction and salt handling shaft and then satt handling shaft). Jun: Drilling of $2 \mathrm{nd} 3.6 \mathrm{~m}$ shaft begins (this waste shatt initially called ventilation shaft). Oct: 1 st $3.6 \mathrm{~m}$ shaft completed

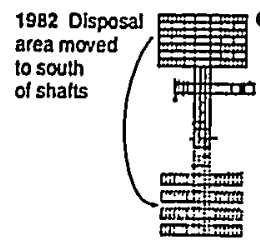

1982 - Mar: 2nd $1.8 \mathrm{~m}$ shaft complated (-80 m [270 ft] of drilling fluid left in the shaft). Westinghouse suggests eliminating 4th shaft along with other cost saving measures. May: Repository level selected. Jun: Army Corps of Engineors assumes responsibility for all phases of construction management. Oct: Underground excavation started to connect the two shafts. Nov: Excavations connect the two existing shafts. Following evaluation of WIPP-12. TRU disposal area moved $-1800 \mathrm{~m}(6000 \mathrm{~h})$ south (experimental area left in original area). Schodule calls for opening WIPP in April 1989. First shatt sealing concepts presented.
1983 1983
Full construction 1983 - Mar: DOE gives Site and Proliminary Design
begins Validation (SPDV reports to NM and allows 60-day comment period. Excavation of experimental rooms begins and Bechtel begins final (Title ItI) design. Apr: NAS WIPP Panel tours WIPP underground to examine SPDV lests. Jul: DOE announces oecision to proceed with construction. Sep: DOE sets Oct 1988 as WIPP opening date. Oct: Drilling of pilol hole for 3rd shaft

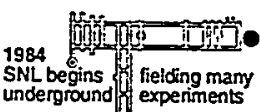

1984 - Feb: Raised bore reeming completed of 3rd shaft. Apr: As rooms excavaled SNL begins thermaVstructural and waste (e.g., defense HLW) tests defined in 1982. Jun: 2nd shatt enlarged from $1.8 \mathrm{~m}$ to $6 \mathrm{~m}$

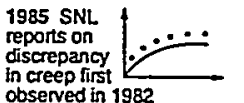

1985 - Jan: Blasting of 3rd shaft to final $4.6 \mathrm{~m}$ diameter completed. Excavation begins for circular room $\mathrm{H}$. SNL reports on discrepancy between measured and predicted salt creep first observed in south drith in 1982.

1986 - Feb: Pillar creep test begins in circular room $\mathrm{H}$ Heated (accelerated) tests of CH.TRU and RH-TRU container behavior start. Oct: In preparation for operations, Westinghouse awarded Management \& . Operation (M\&O) contract. Army Corp. of Engineers relieved of construction management duties.

- 1987 - Wet salt compaction tests concluded, constitu tive equation for consolidation developed. and shaft consofidation modeled (effective cansolidation predicted in $<100 \mathrm{yr}$ ).

- 1988 - May: WPP begins drilling pilot hole for 4 th shat (air intake shaft) after reevaluating 1982 decision to eliminate it Sep: DOE announces that WIPP won' open as scheduled in Oct.

- 1989 - Jan: DOE files request for administrative withdrawal of $16 \mathrm{mi}^{2}$ with DOl (less than hall of land allowed by 40 CFR 191). Feb: SNL resolves discrepancies between measured and predicted salt creep. Mar: Watkins creates 'Blue Ribbon Panel' to examine WIPP readiness. Jun: Watkins announces an indefinite delay in opening of WIPP.

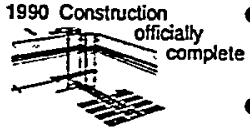

1990 - Jan: Construction officially complete. May: Westinghouse completes "Final" Safety Analysis Report.

1991 - Apr and Aug: To extend life of room 1, panel 1 for gas generation tests, internal and extemal panels meet to recommend roof support. Sep: Westinghouse completes construction of roof support.

- 1995-Oct: IT Corp. completes costbenefit study for Westinghouse and DOE of engineered barrier alterna. tives required by 40 CFR 194.

TR1-6342-5840-2

Fig. 11. Events associated with design, construction, and modeling of the WIPP repository (adapted from Fig. 11 in Rechard, 1998, which provides references). 
Drilling penetrates Upper Aquifer, Repository, Lower Aquifer (4 different intrusion times, $10^{3}, 10^{4}, 10^{5}$, and $10^{6} \mathrm{yr}$ )

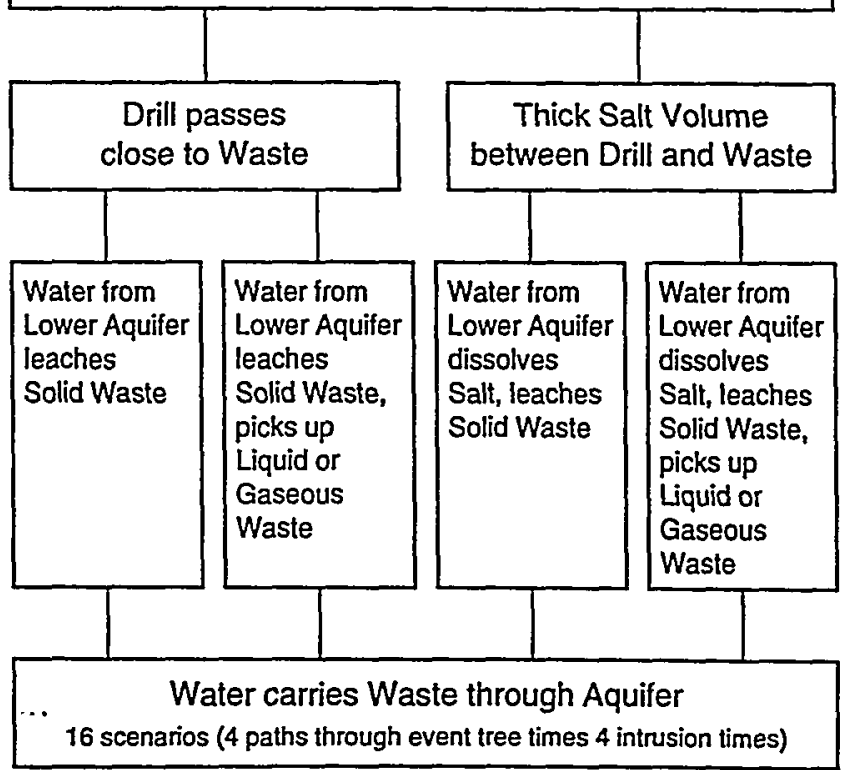

(a) Event tree approach used for scenarios in WIPP EIS in 1979 (after Bingham and Bar, 1980).

\section{Events}

$T S=$ Subsidence resulting from solution mining of potash

$E 1=$ One or more boreholes pass through waste and into a brine pocket

$E 2=$ One or more boreholes pass through waste without penetrating a brine pocket

Combinations and nomenclature

$$
\begin{aligned}
& S_{1}=\overline{T S} \overline{E 1} \overline{E 2}=\text { "EO" (base case - undisturbed performance) } \\
& S_{2}=\overline{T S} \overline{E 1} E_{2}={ }^{-E 2} \text { " (assumed bound by E1) } \\
& S_{3}=\overline{T S E 1} \overline{E 2}=\text { "E1" } \\
& S_{4}=\overline{T S} E 1 \text { E2 = "E1E2" } \\
& S_{5}=T S \overline{E_{1}} \overline{E_{2}}=\text { "TS" } \\
& S_{6}=T S \overline{E 1} E 2=\text { "TSE2" } \\
& S_{7}=\text { TSE1 } \overrightarrow{E 2}=\text { "TSE1" } \\
& S_{B}=\text { TS E1 E2 = "TSE1E2" } \\
& \text { nS } \\
& \sum_{j=1} P\left(S_{j}\right)=1
\end{aligned}
$$

(b) Combination (order unimportant) of events for scenarios in 1990 - 1992 performance calculations (after Rechard, 1995).

TRI-6342-5851-1

Fig. 12. Technique to construct scenarios from various features, events and processes changed between WIPP EIS and PA calculations after 1989. 


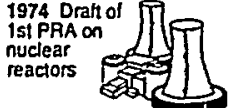

1974 ORNL conducts scenario develop. ment and consequence analysis of WIPP
1974 - Aug: Draft of first major Probabilistic Risk Assessment (PRA) published on two reactors by $60 \mathrm{mem}$ bor team for Nuclear Regulatory Commission (NRC): method uses fault trees to synthesize probability of to tal system tailure. Oct: ORNL conducts first scenario development and deterministic analysis for WIPP. Probability of meteorite impact, probability of lault (and volcanism) and exploratory drilling intersecting disposal area estimated.

1976-Dec: NRC funds panel of earth scientists to identify events and processes that could disrupt a generic repository.

- 1977 - Apr: Second meeting of NRC panel of earth scientists occurs to identify events and process. INEEL begins risk analysis of altematives for TRU waste stored and buried at Radioactive Waste Management Complex (RWMC) over next 4 years. Los Alamos, Savannah River, and Hartord begin similar studies as woll. Human intrusion event significan contributor to consequences in these studies. 1978 SNL adapts
PRA for reactors PAA for reactors to nutear 250,000 yr ( 10 hath lives of $200 \mathrm{Pu}$ ) using large, 3-D Swift tlow model. NRC funds SNL to work on probabilistic PA and apply to hypothetical bedded salt repository.

1979 Dratt EIS on WIPP conducts transport analysis of Pu ou 1979 - Apr: Draft EIS on WIPP published. SNL completes development of scenarios for release radioisolopes from WIPP (part of ElS; process resulting method abandons fault trees and uses simple event trees). 3 major classes of scenarios identified (connec- tion between Culebra aquifers above and below repository, Bell Canyon aquiters, U-tube connection to Culebra, and stagnant pool connection to Culebra) plus drilling intrusion. (Later U-lube split into catastrophic connection and standard U-tube connection.) Probabilities of scenanios assigned based on qualitative reasoned arguments.

1981 SNL reports

- 1981 - Draft of final report to NRC on performance on PA of hypo-
salt site codes, precursors to SWIFT_II (fluid flow code recommends procedure for $\mathrm{PA}$ and potential list of events and processes for scenarios. Jut: Stipulated Agreement (SA) between New Mexico and DOE describes disruptive scenarios (e.g., breccia pipe, salt dissolution, and salt delormation) that are to be dismissed through further site characterization.

1986 - Jul: DOE asks SNL to assess performance of WIPP against 40 CFR 191 criteria. Aug: SNL accepts PA task.

- 1987 - Mar: SNL finds that porous-media flow assumption adequately models flow in Culebra at $\mathrm{H}-3$ but that transport is best modeled as a dual porosity media (though roughly approximated as equivalent porous media). Modeling with variable brine densities suggest Culebra acting as leaky confined aquifer; subsequent models ignored suggestion until 1997. Also model suggests highly transmissive zone in the Culebra to the south of $H-11$ and DOE-1. SNL finds possibility of a pressurized brine reservoir below the TRU disposal area cannot be ruled out.

- 1988 - SNL begins work of CAMCON to link detailed consequence models in probabilistic PA. SNL also simultaneously begins work on prototype of CAMCON to meet Dec. 1989 deadline. SNL completes pumping tests at $\mathrm{H}-11$ and begins using results to calibrate regional flow model.
1989 Draft supplemental EIS identifies gas generation as issue

1989 Demo D 促 of WiPP used CAMCON
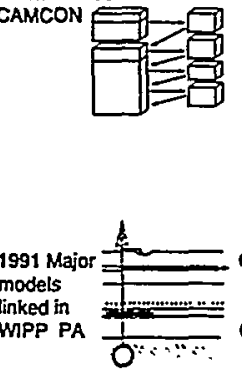
1992 Pefineme lields) in WPP PA
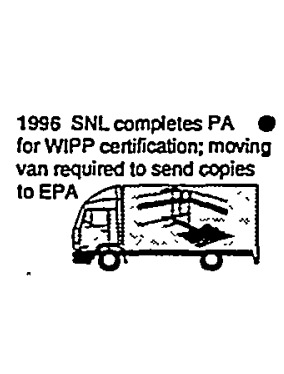

tis each and took $37,000 \mathrm{CPU}$ Def page, $400 \mathrm{lb}$. CCA to EPA. Nov: NAS reports tha WIPP site "excellent choice" geologically. DOE issues 84,000-page 2nd supplemental draft EIS. Dec: EPA begins detailed evaluation of CCA and supporting information at SNL and elsewhere including PA conceptual models, computer coctes, model parameters, $O A$ records, and specific technical issues (e.g. MgO backfill and passive institutional control).

- 1997 - Jan: Conceptual Model Peer Review Group (formed in response to 40 CFR 194) concludes 22 of 24 conceptual models adequate. Spallings model must be redone and $\mathrm{MgO}$ backtill description improved. Mar: SNL conducts misi PA for EPA 10 do parametric sensitivity analysis of PA model parameters lacking "ironclad' defense. Apr: Conceptual Model Peer Review Group reports that with additional inlormation provided by SNL, they are satisfied that the new model of spallings and the model of the $\mathrm{MgO}$ backfill are adequate. May: SNL explains apparent discrepancy between geohydrology and geochemistry by viewing flow in Culebra as a 30 regional system. As part ol EPA eval uation of CCA. SNL runs EPA-mandated PA calculations using EPA-selected values tor 26 parameters and EPA-selected model assumptions, based on results from parameter review team comments in December and sensitivity analysis in March. In letter to DOE secretary. EPA Administrator Browner decrees DOE application "complete"; starting the 1yr clock for review of CCA.

TRI-6342-5841-2

Fig. 13. Engineering analysis of the illustrated behavior of the disposal system (adapted from Fig. 13 in Rechard, 1998, which provides references). 
1989
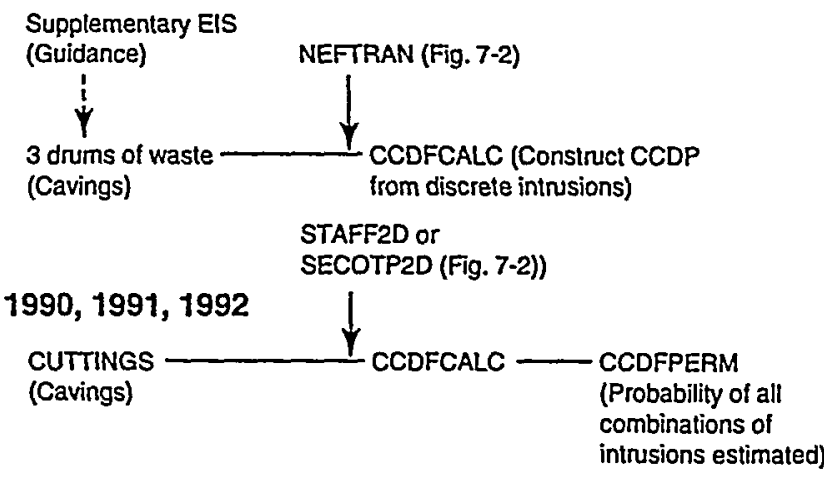

1996

SECOTP2D (Fig. 7-2)

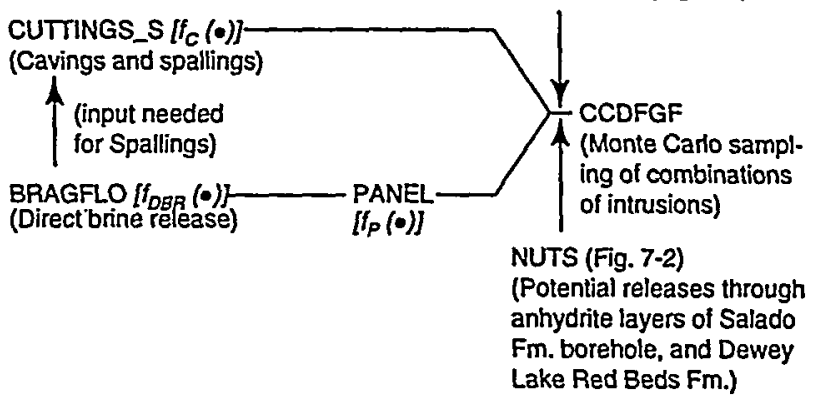

TRI-6342-5857-1

Fig: 14. Changes in code component of the exposure pathway model for immediate releases after exploratory drilling for evaluating compliance of with WIPP (Rechard, 1998).

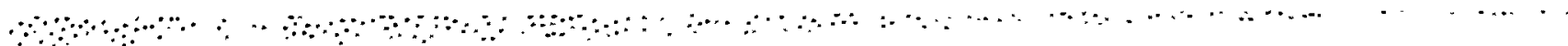




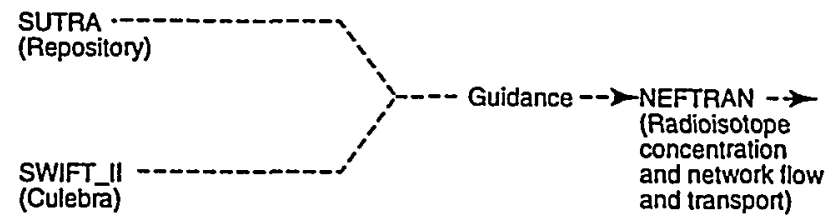

1990

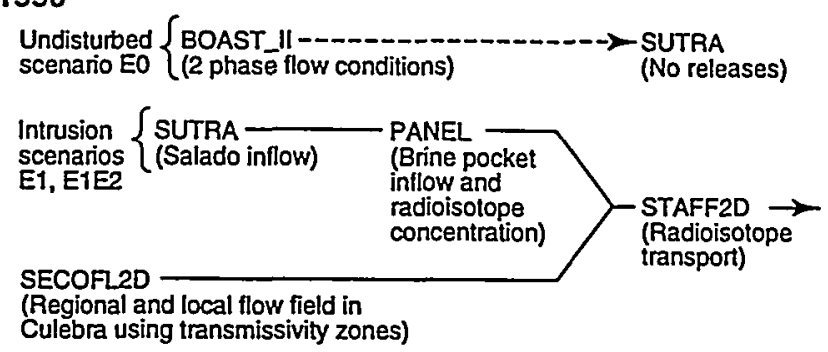

\section{1}

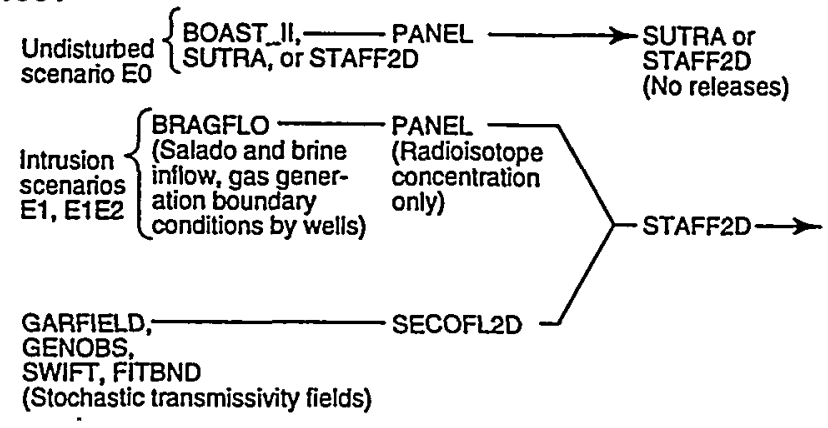

1992

SANCHO

(Salt creep and porosity reduction averaged over repository)

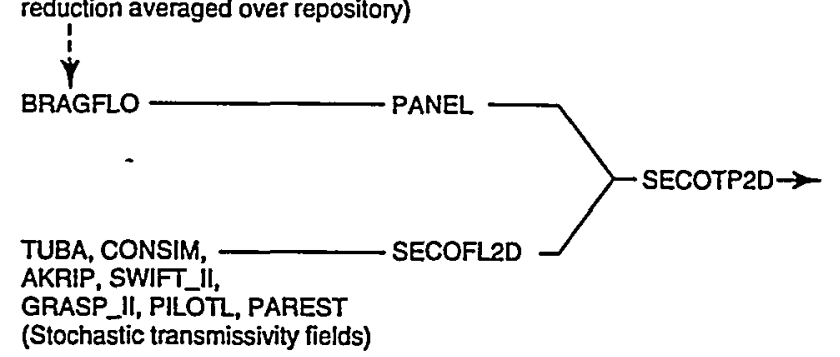

1996

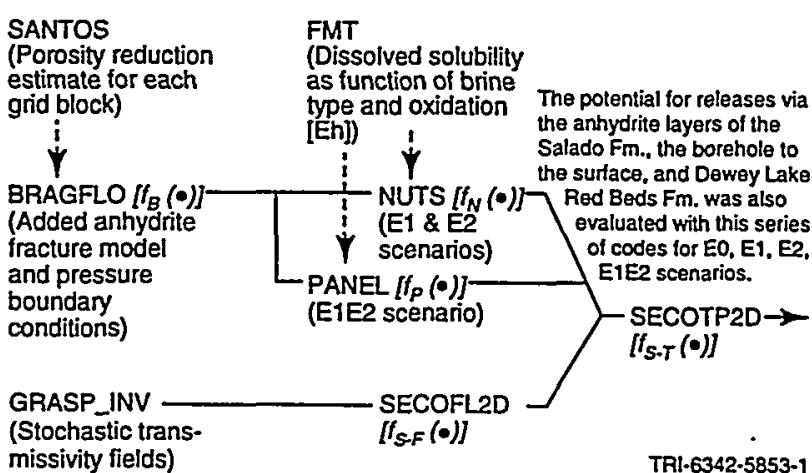

Fig. 15. Changes in components of the exposure pathway model for long-term release via leaking borehole and Culebra brine aquifer (Rechard, 1998). 


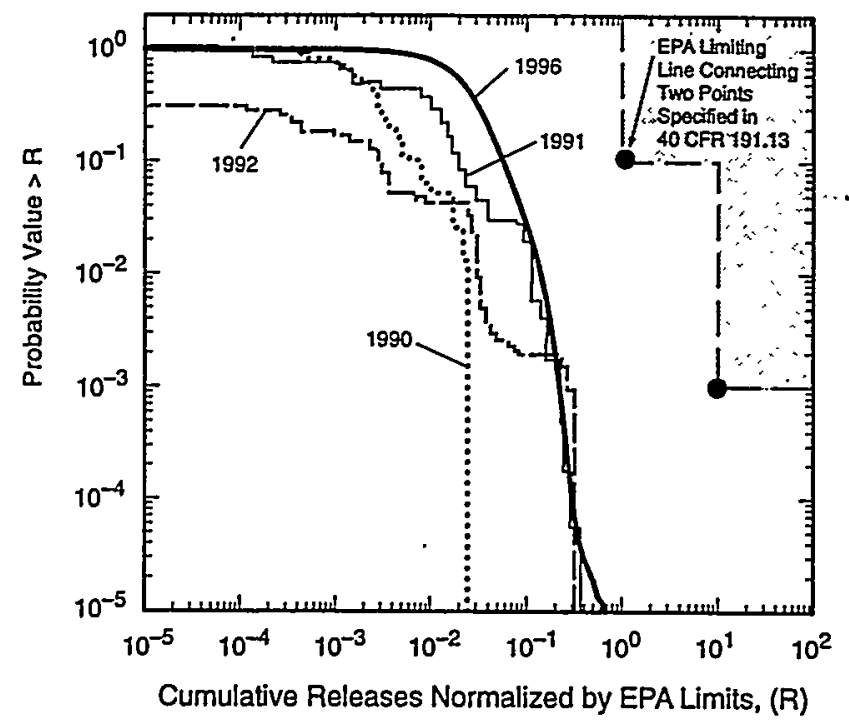

(a) Direct Releases to the Surface during Drilling

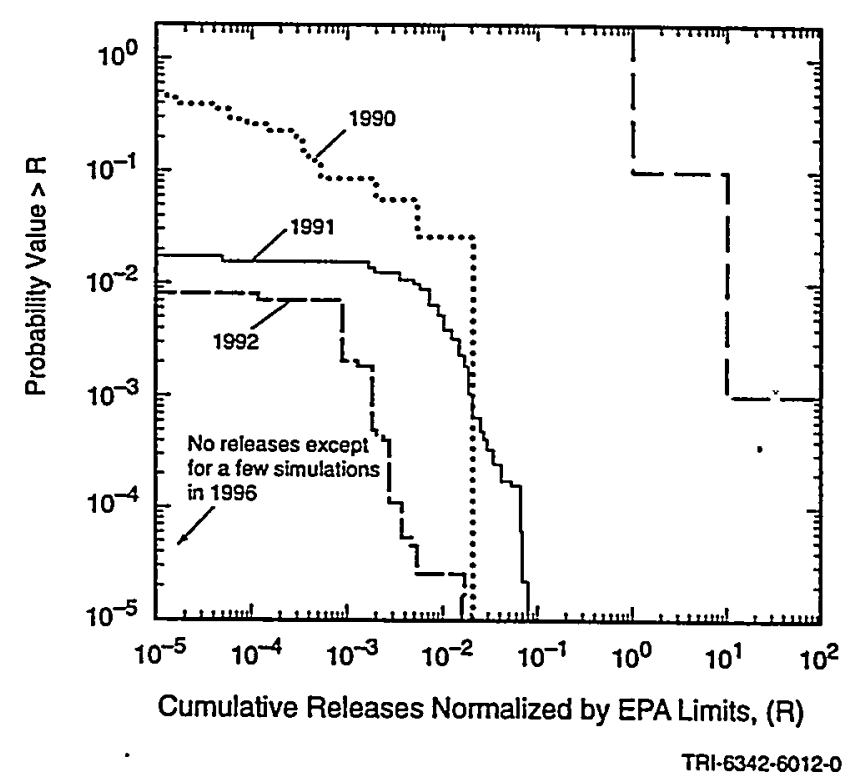

(b) Releases via Groundwater Pathway through Culebra

Fig. 16. Changes in the distribution of cumulative releases (normalized by the EPA limits) for (a) direct releases to the surface during drilling and (b) release via groundwater pathway through Culebra. Since the first complete performance in 1990 , direct releases to the surface have dominated overall releases to the accessible environment of the WIPP (Rechard, 1998). 


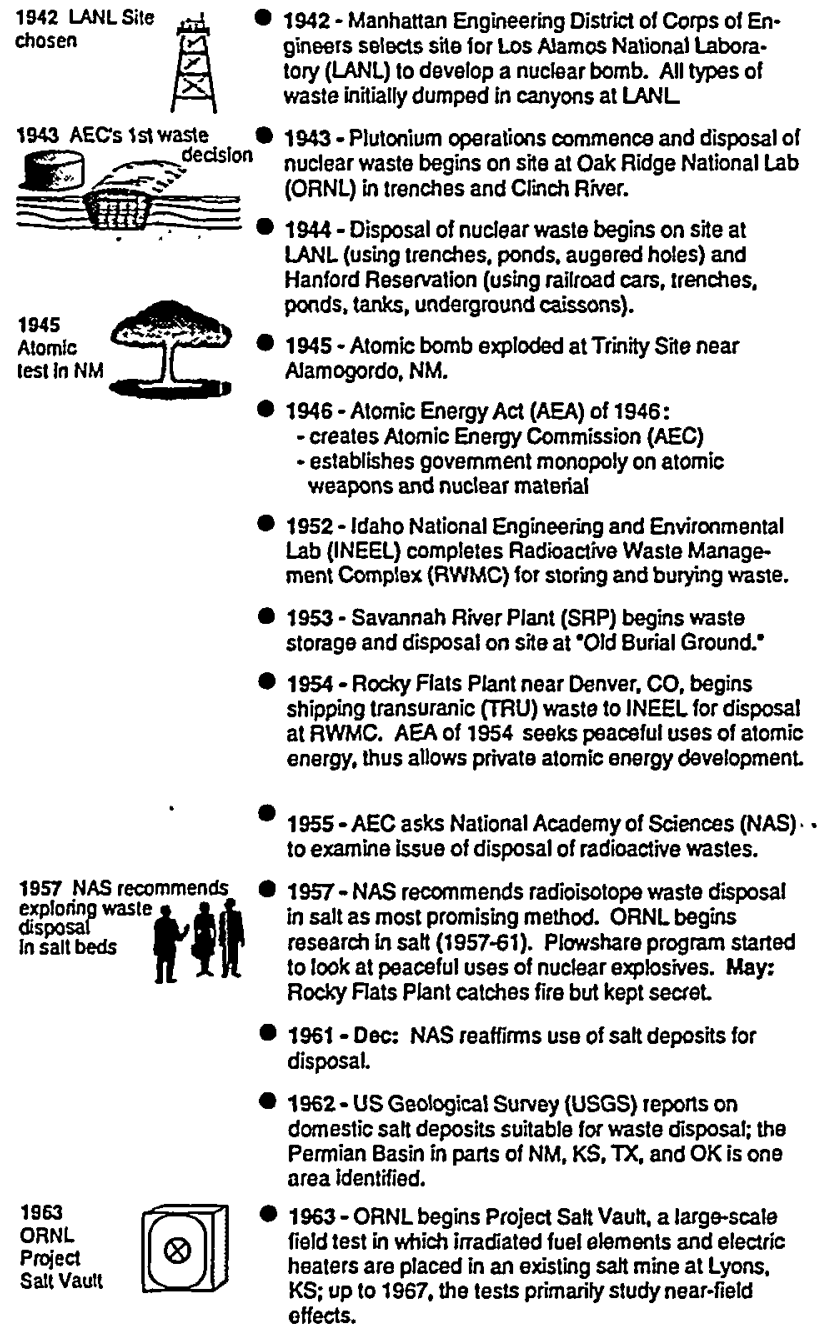

1965 - Savannah River Plant (SRP) begins disposing TRU waste in trenches on site.

- 1966 - NAS reaffirms use of salt beds for disposal and strongly criticizes current disposal practices.

- 1968 - Committee on Radioactive Waste Management established by NAS, later pemanent "Board" (BRWM); first task is to reevaluate the use of bedded salt. AEC asks NAS to revisit the issue of nuclear waste disposal. At request of Congress, General Accounting Otfice (GAO) audits AEC waste management practices and linds laults with records and management. AEC forms task torce to address criticisms.

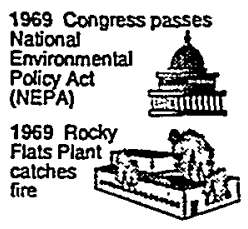

1969 - May: Rocky Flats Plant catches fire and cleanup waste sent to Idaho for disposal at RWMC: event focuses public attention on AEC nuclear waste problems. Dec: Congress passes National Environmental Policy Act (NEPA):

- requires federal agencies to consider environmental consequences of any major action through environmental impact statement (EIS) - first US environmental law to be applied to the Waste Isolation Pilot Plant (WIPP) International Alomic Energy Agency (IAEA) forms advisory committee to categorize nuclear waste; Alpha contaminated waste one category defined.

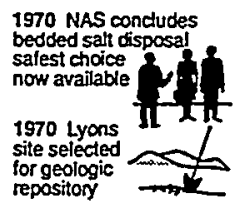

1970 - Jun: AEC tells Sen. Church that the waste from fire stored at INEEL will be removed by 1980 . AEC tentatively selects salt mine in Lyons, KS, as repository. Nov: BRWM of NAS issues report concluding bedded salt satisfactory and salest choice available for nuclear waste disposal.

- 1971 - Many drill holes and some solution mining discovered at Lyons, KS. AEC directs HLW be soliditied within $5 \mathrm{yr}$, stored retrievably, and delivered to federal repository within 10 yr. Congress ditects AEC to stop Lyons project until salety is certified. Appeals court requires AEC to look at all environmental impacts in EIS.

1972 Lyons 1972 - May: AEC abandons Lyons project AEC ansite judged (yodus nounces plans for Retrievable Surface Storage Faciliny unacceptable (LYoNS) MSSF for radioactive wastes. EPA and anti-nuclear (RSSF) for radioactive wastes. EPA and anti-nuclear groups claim

TRI-6342.5836-2

Fig. 1. Early history of nuclear waste disposal related to the WIPP (adapted from Fig. 2 in Rechard, 1998, which provides references). 


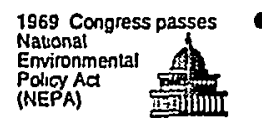

1969 - National Environmental Policy Act (NEPA) - requires federal agencies to consider environmental consequences of any major action through environmental impact statement (EIS)

- first environmental law to-be applied to the WIPP

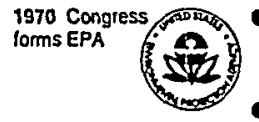

- 1970 - Congress forms Environmental Protection Agency (EPA) and transfers to in research, monitoring. standard setting, and enforcement activities.

1974 - AEC promises Idaho that wastes will be shipped out of Idaho in the 1980's. Oct: Energy Reorganiza tion Act splits AEC into Nuclear Regulatory Commission (NRC) and Energy Research and Development Agency (ERDA) effective January 1975.

1976 Bishop Lodge Conerence to explore PRA for geologic ic disposal systems to bring on modeling of goolog together to explore predicting geological features. resident Ford orders expansion of ERDA program to demonstrate disposal for nuclear waste by 1985 and orders EPA to develop applicable standards. Resource, Conservation and Recovery Act (RCRA) seeks to reduce hazardous waste generation. DeC: EPA announces intent to develop standards for HLW disposal.

1977 DOE

1977 - Oct: DOE Organization Act creates Department of Energy (DOE) from ERDA. Feb: EPA conducts 1st public workshop to understand public concems and technical issues of waste disposal.

1978 Oversight by WIPP panel of NAS and
New Mexico
EEG begins

1978 - DOE Deputy Sec. Jerry O'Leary promises NM Congressional delegation "if NM did not wish to have the WiPP. then it could veto the plan:" DOE General Counsels state O'Leary powerless to grant "state veto." Jan: EPA announces public forum to develop * protection criteria for radioactive wastes. Jun: In response to DOE request to review scientific aspects of WIPP Project, WIPP Panel ol BRWM of NAS holds first meeting. Nov: EPA publishes 'Criteria tor Radioactive Wastes" as guidance for federal agencies and seeks comments. DOE contracts with NM to establish Environmental Evaluation Group (EEG) to provide an independent state assessment of WIPP.

1979 Congress 0 1979-Dec: Congress defines mission of WIPP: defines mission
of WIPP - exempts WIPP from NRC licensing - requires DOE to sign a "Consultation \& Cooperation" (C\&C) Agreement with NM.

- 1980 - NM and DOE begin negotiations on C\&C Agreement to define procedures and process of cooperation.

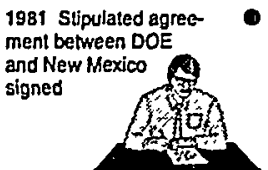

- 1981 - Jan: DOE decides to proceed with Site and Preliminary Design Validation (SPDV). In response: - Mar: Citizens for Altematives to Radioactive Dumping (CARD) asks for preliminary injunction. - May: NM sues DOE and Department of Interior (DOi) alleging violations of tederal and stato laws. Jul: Southwest Research \& Information Center (SWRIC) files lawsuit and begins filing numerous interrogatories to which DOE must respond. In response to lawsuits, DOE Sec. Edwards visits NM to talk to Gov. King and accodes in a "Stipulated Agreement (SA)" for (1) pootechnical experiments, (2) state \& public roview of WIPP changes, and (3) creation of a state/federal task force to oversee transportation issues (e.g., emergency response and highway upgrades). C\&C Agreement attached as Appendix A; 'Working Agreement' as Appendix B. U.S. Dist. Judge Burciaga stays lawsuits. Mar: Developing generic disposal criteria for radioactive wastes difficult, thus EPA stants developing standards for each waste type.

1982 - EPA publishes working draft 20 as proposed 40 CFR 191. Dec: Supplemental SA signed committing DOE (1) to seek funds for upgrading highways in $N M_{1}$ (2) to more geotechnical studies, and (3) liability for WiPP-selated accidents.

- 1983 - In response to questions by EEG. DOE concludes dratt 40 CFR 191 applies to disposal phase but not test phase of WIPP. May: Oak Ridge complex admits releasing $2 \times 10^{8} \mathrm{~b}$ of $\mathrm{Hg}$ from $Y-12$ plant between 1950 and 1977 . Revelation prompts Natural Resources Defense Council (NRDC) and Legal Envitonmental Assistance Foundation (LEAF) to sue DOE

- 1984 - Feb: EPA Scientific Advisory Board (SAB) endorses probabilistic approact of 40 CFR 191 but states criteria too restrictive and reconmends changes. Apr: LEAF vs. Hodel subjects DOE to RCAA requirements though AEA exempted DOE from human health laws.
- 1984 - (con't) Nov: Hazardous \& Solid Waste Amendments (HSWA) to RCRA ban land disposal of hazardous waste without treatment unless disposal ste and generator demonstrato "no migration" of constluenc for as long as waste remains hazardous for as (imiting remote handled (RH) TRU waste amount $105.1 \times 10^{\circ} \mathrm{Ci}$.

1985 EPA promulgates
40 CFR 191

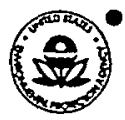

1985 - Feb: NRDC sues EPA to issue 40 CFR 19 as mandated in NWPA. Sep: EPA promulgates 40 CFR 191 for disposal of SNF. HLW, and TRU: - probabilistic criteria indirectly based on population heath risk

- requires inclusion of all uncertainty

Nov: DOE attempts to define "by-product malerial" to include mixed waste and thus exclude EPA regulation. 1986 EPA states mixed
waste subject
toRCFA
(polentially
-60\% of
WiPP waste)

986 - EPA states that mixed waste (radioactive waste with hazardous wast $\theta$ ) is subject to RCRA regulations. Mar: NRDC and others sue EPA over ground- water and individual protection standards in 40 CFR 191.

1987 - May: DOE defines "by-product materiar" to exclude everything except radionuclides, and thereby TRU waste is subject to RCRA. Jul: in response to NRDC lawsuit. Court of Appeals for Ist Circuil in Boston vacales and remands all of 40 CFR 191. Aug: 2nd modification to C\&C Agreement commits DOE to comply with all applicable laws; to use 40 CFR 191 as 1 st issued for evaluating WIPP compliance unlil reissued by EPA; and apply NRC and Department of Transportation (DOT) regulations to TRU transport. Sep: Court reinstates Subpart A of 40 CFR 191 in response to EPA request.

- 1988 - Oct: ID Gov. Andrus bans shipments of radioactive waste into state because WIPP not open. With continued technical problems (e.g. TRUPACT-li not yet licensed), NM Congressional delegation cannot get consensus among themselves and WIPP Land Withdrawal Act dies. Congressman Richardson insisted upon full compliance of WIPP with 40 CFR 191 betore receipt of any waste and funding for roads attached to bin. Dor ID Gov. Andrus, CO Gov Pomer, and Gov. Carruthers meet in Salt Lake City to discuss WIPP and options to avert shutdown of Rocky Flats Plant from lack of storage imposed by $\mathrm{CO}$, and inability to ship to ID; DOE agrees to pursue both administrative and legislative land withdrawal for WIPP.

1989 - Westinghouse completes "no-migration" petition for RCRA variance for WIPP test phase.

- 1990 - EPA issues no migration variance for test phase.

- 1991 - Westinghouse completes Parts A \& B of RCRA permit application to state.

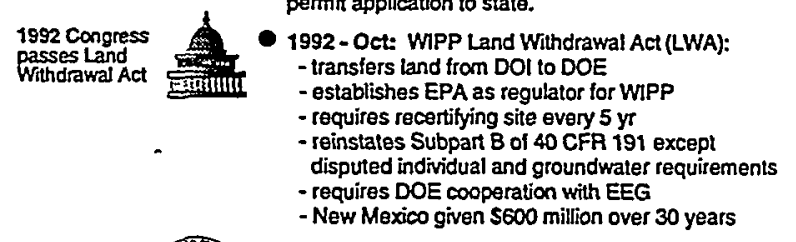

1993 EPA 1993 -Dec: In sesponse to cout temand and WPP

repromulgates 2 LWA, EPA repromulgates 40 CFR 191 - no influential changes for WIPP.

1995 - Jan: EPA proposes compliance criteria for WPP in 40 CFR 194

1996 EPA states 1996 - Feb: EPA promulgates final 40 CFR 194. how to inple- 1 - requires analysis and peer review of wasto ment radioactive ( SWE characterization, engineered barrier ovaluation. waste standard and conceptual models

in 40 CFR $194 \quad-$ requires a monitoring system

- specifies requirements on quality assurance

(QA), peer review, and expert judgment

(QA), peer review, and expert judgment - requires potash mining to be considered
Sep: Congress amends WIPP LWA and relieves WIPP of need to comply with land disposal restrictions of RCRA, but other requirements of RCRA still apply.

1997 - Oct: EPA issues dratt rule to approve WPP with conditions: requires use of panel seals used in PA: design requires $O A$ for waste generators; lists requirements for using process knowledge to characterize wastes; requires schedule for installing passive conwastes; requires schedule for installing passive controls; denies any protective credit for passive

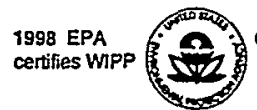

1998 - May: EPA certifies WPP. Jul: NM AG sues EPA alleging insutficient time to comment on CCA CARD and SWRIC also file law suits.

TRI-6342-5837-2

Fig. 2. Development of performance goals for the WIPP (adapted from Fig. 3 in Rechard, 1998, which provides references). 

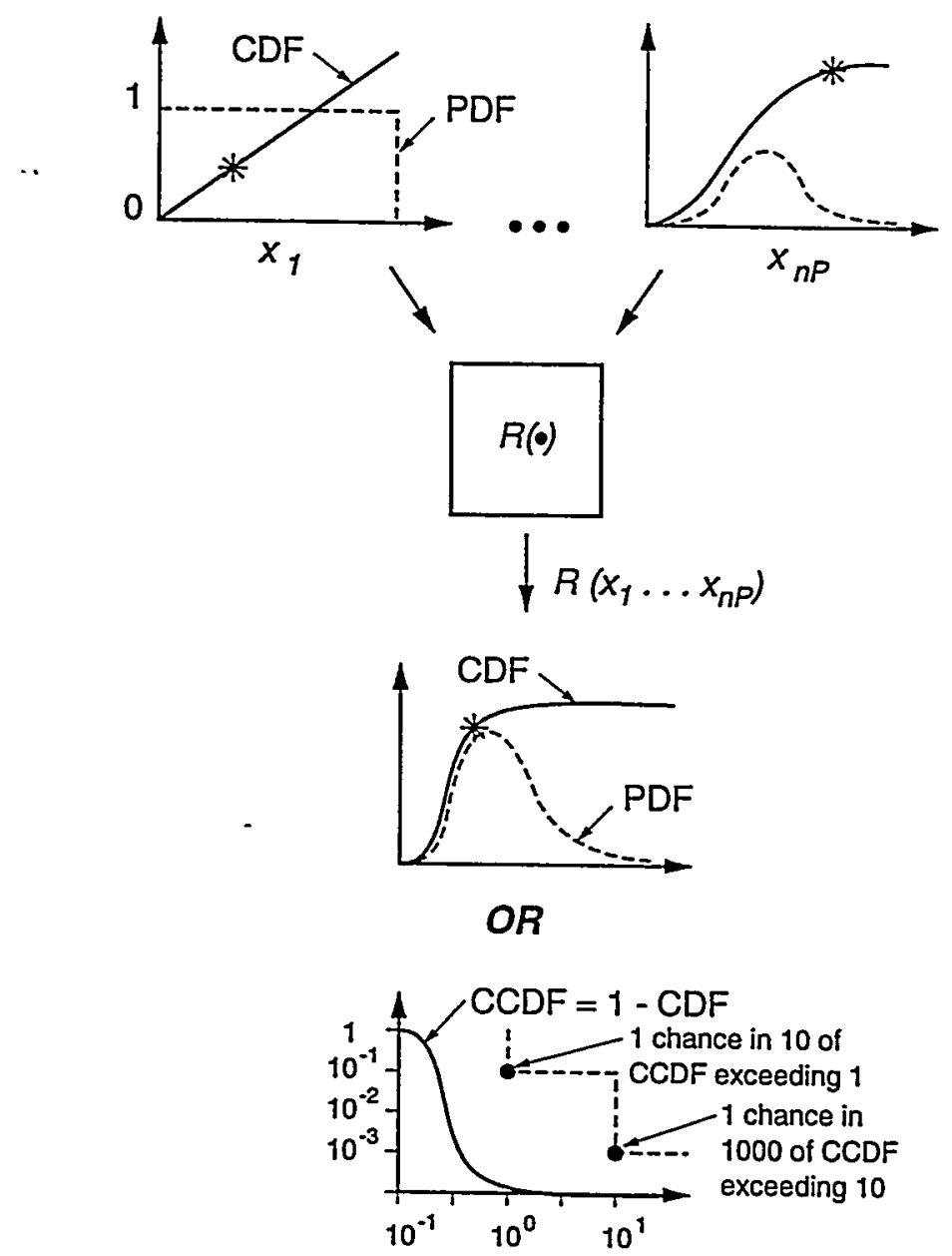

TRI-6342-5892-2

Fig. 3 Uncertainty in model parameters $x$ (expressed as a probability density function [PDF], $d$, or cumulative distribution function $[C D F], D)$ results in uncertainty in the results $C\left(x_{1} \ldots x_{n P}\right)$. This uncertainty (expressed as a complementary distribution function $\mathrm{CCDF}$ or 1-CDF) is compared to the limits in 40 CFR 191. 


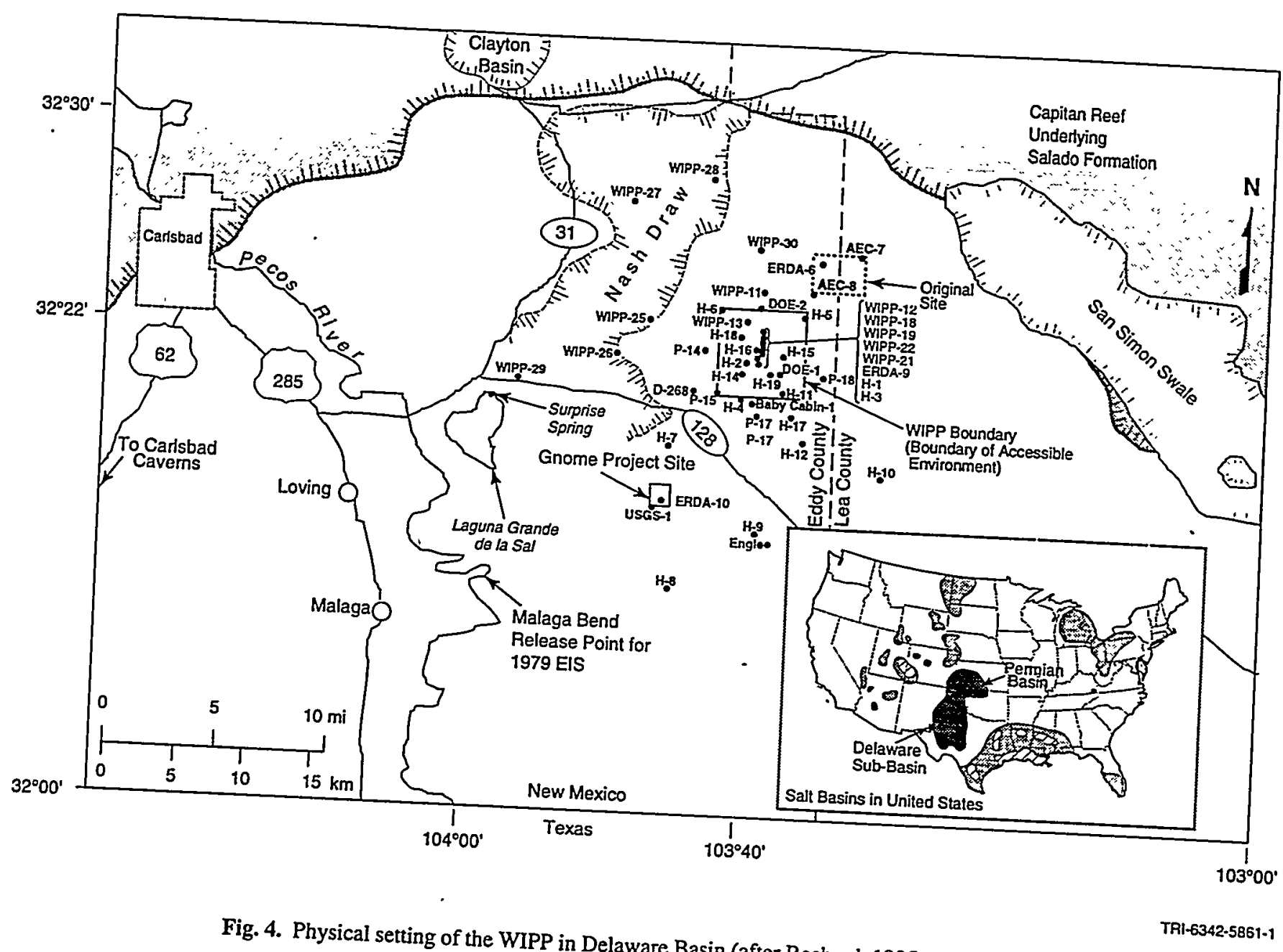




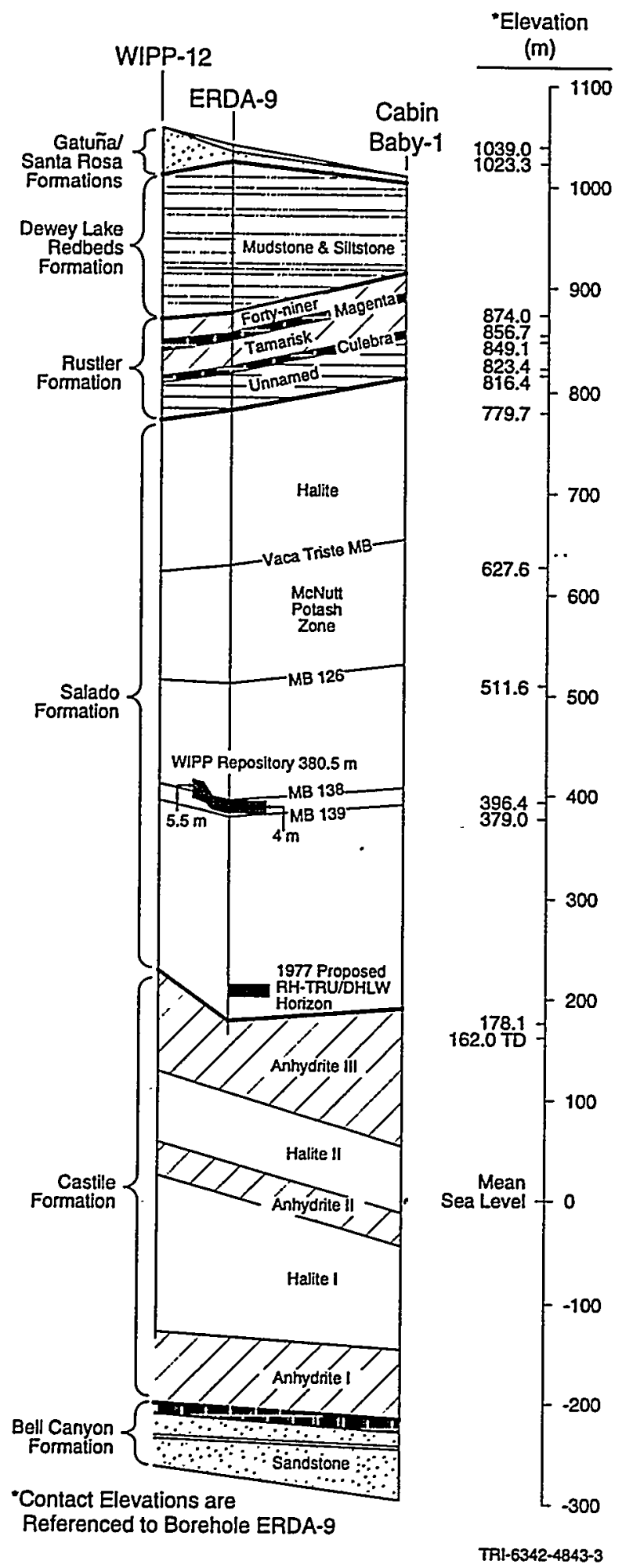

Fig. 5. Stratigraphy above and below the WIPP repository (after Rechard, 1995, Figure 2.1-2) 


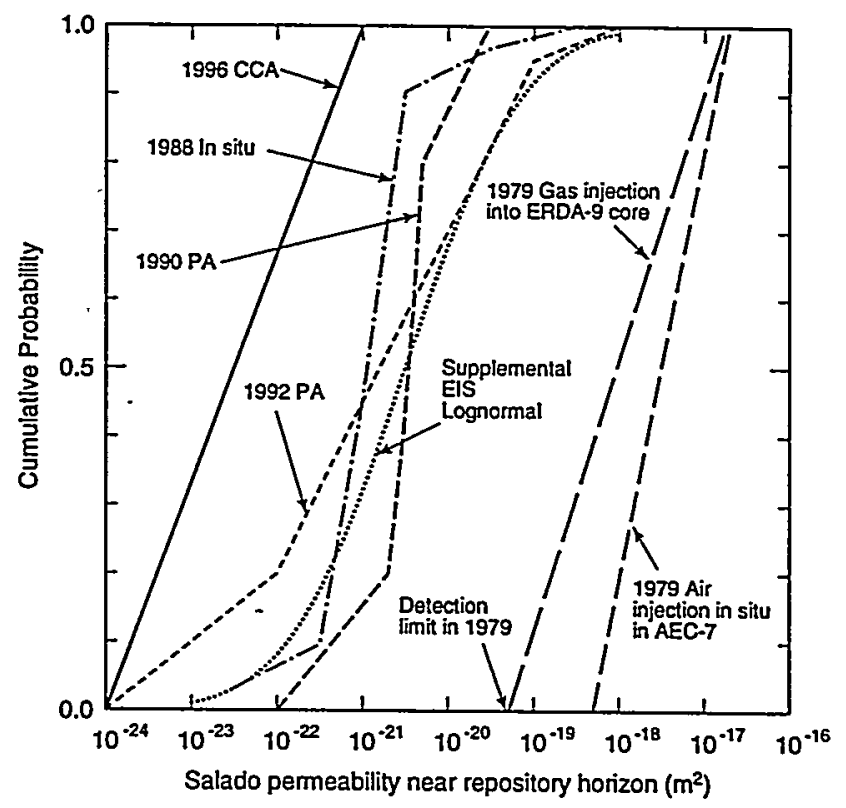

TRI-6342-5845-0

Fig. 6. Estimated permeability of Salado Formation near repository horizon continued to decrease over the years (Rechard, 1998). 


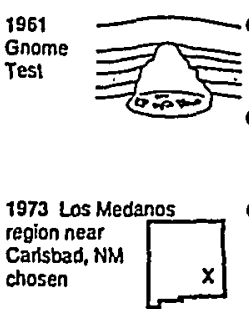

region near
Cartsbad, NM
chosen $\left[\begin{array}{l} \\ \end{array}\right.$

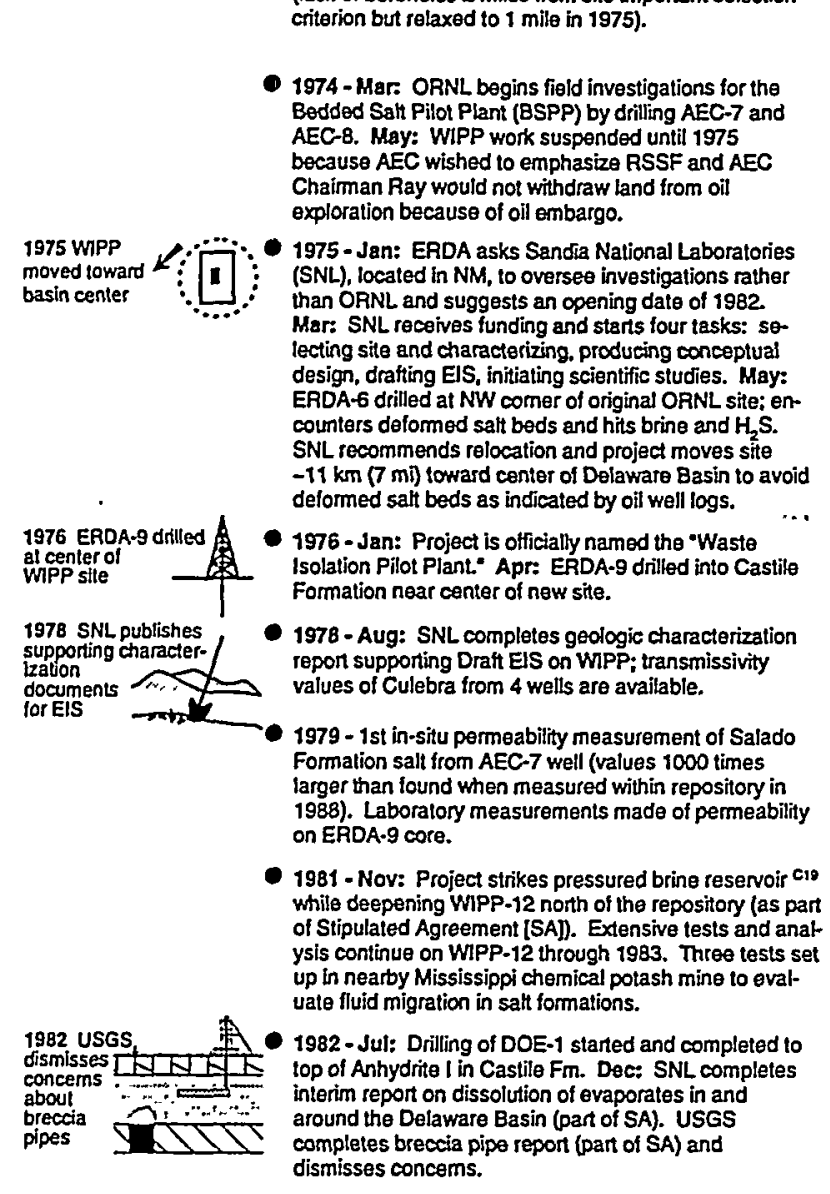

1974 - Mer: ORNL begins field investigations for the IOAd Salt Pilot Plant (BSPP) by drilling AEC-7 and AEC-8. May: WIPP work suspended until 1975 because AEC wished to emphasize RSSF and AEC exploration because of oil embargo.

1973 - Nationwide search for suitable salt site resumed. What tacit approval of Gov. King, local political leaders and potash mine operators invite AEC to southeastern NM. USGS and ORNL recommend southeastem NM (lack of boreholes 2 miles from site important selection 1961 - Dec: USGS evaluates stratigraphy and AEC NM, for Gnome test as part of Plowshare program.

1971 - USGS tests permeability of strata around Gnome site (Plowshare program) for closure studies
1983 - Mar: SNL USGS, and contractors complete most reports required by SA (e.g., USGS reports Culebra transmissivity at 20 locations; SNL reports on groundwater flow in Rustler Fm. and delormation of evaporates near WIPP; technical support contractor. Westinghouse, reports on brine reservoirs in the Castile Fm.). May: After reviewing results irom SPDV program, EEG concludes that :...the Los Medanos site has been characterized in sutficient detait to wamant confidence in the validation of the site for permanent emplacement of approximately 6 million $t^{3}\left(1.75 \times 10^{5} \mathrm{~m}^{3}\right)$ of delense TRU waste," but also recommends additional studies to resolve outstanding geolechnical issues such as evaluation of polential for brine reservoirs. Aug: Deepening of Cabin Baby started and completed to Bell Canyon Fm.; geophysical logs run and deep sandstones in Bell Canyon hydrologically tested.

- 1984 - Pumping tests at DOE-1 suggest fracture flow in Culebra. First in situ gas flow measurement conducted around underground drith. Aug: SNL drills and tests DOE-2.

- 1985 - With the definition of a $5-\mathrm{km}$ boundary to the disposal system in 40 CFR 191. project begins to focus more on near-field hydrologic modeling rather than regional modeling.

1986 - First in situ injected brine flow measurement to determine permeability around dritts.

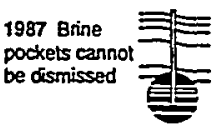

1988 Brine seepage into repository big issue surs up. reservoir below the TRU disposal area cannot be ruled out. Dec: Environmental groups raise concem of brine seepage into repository.

1988 - Jan: EEG issues report on potential brine reservoirs under WIPP. NM Congressional delegation asks NAS BRWM to study brine inllow controversy. Sep: SNL reports on in situ permeabity (100 pilot phase.

1989 - SNL reports on reevaluation of Culebra perme-

1993 - Brine inflow to Q tunnel can be explained as either dewatering of disturbed rock zone or darcy flow

1994 - Aug: SNL seeks permits to drill new wells for tracer test in Culebra.

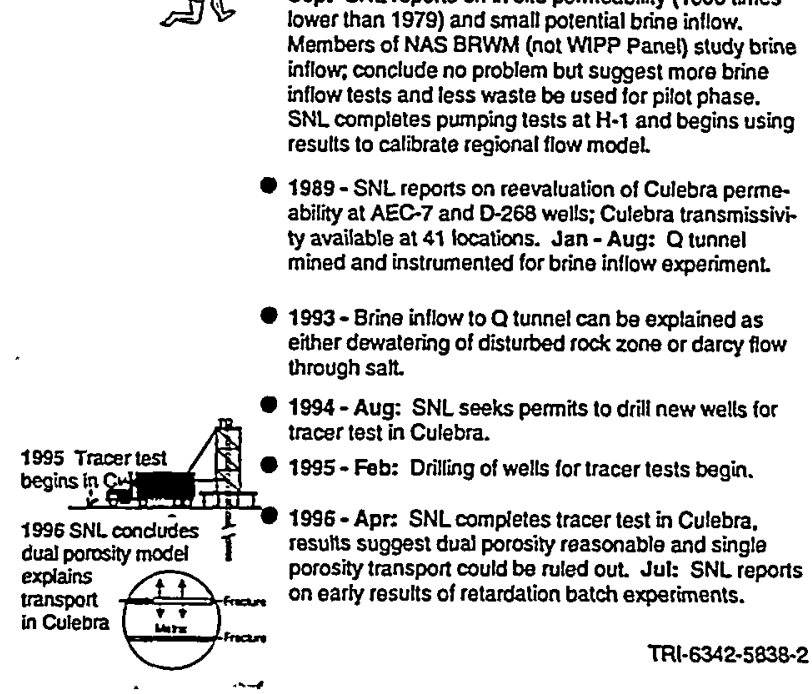

Fig. 7. Site characterization studies at the WIPP (adapted from Fig. 7 in Rechard, 1998, which provides references). 
- 1966 - Jan: B52 collides with refueling tanker at $30,500 \mathrm{tt}$; three nuclear weapons crash into Spanish soil; fourth weapon parachutes into ocean. (Question raised as to how much plutonium contaminated soil to relum to Savannah River Plant).

1970 AEC begins storing 1970 - Mar: AEC directs TRU waste be stored retrievTRU wasto above ground 1970 - Mar: AEC directs TRU waste be stored retriev-
ably at all DOE facilties rather than disposed with low lovel waste. AEC conservatively bounds TAU waste as waste contaminales with transuranic radioisoptopes with activity greater than $10 \mathrm{nCi} / \mathrm{g}$.

- 1975 - ERDA removes WIPP from commercia! repository program.

- 1976 - Laboratory tests on TRU waste behavior and HLW packages initiated.

- 1977 - Apr: Carter announces plan to defer indefinitely reprocessing of commercial SNF. Nov: Atthough role of NRC at WIPP unclear, DOE tells NRC it plans to seek license to build and operate WIPP based on policy from Carter administration.

1978 SNL tests gas generation potential o

- 1978 - SNL raises concem about gas generation and contracts with Los Alamos to do laboratory tests. Oct: TRU waste Deutch (Massachusetts Institute of Technology [MIT] chem. prof.) report written for DOE recommends (1) disposing TRU waste at WIPP without planning for retrieval, and (2) demonstrating spent nuclear fuel (SNF. HLW. and TRU disposal at WIPP. DOE Deputy Sec. J. O'Leary presses on with 2nd recommendation until 1979 onabling law for WPP as a way to satisfy Califomia law banning nuclear power plants until SNF disposal demonstrated. Nov: Lab studies focus on -.. thanium alloys for HLW canisters.

1979 Draft EIS on 1979 - Mar: Interagency Roview Group (IRG), formed WIPP has option by President Carter (in response to Deutch report) lor commercial SNF fi recommends disposal of SNF, HLW, and TRU in mined 1979 Congress passes bill to build s. geologic repositories in final report. Report also sug gests making WIPP candidate for commercial SNF tion military/commercial repository in Draft EIS. May: House Amed Senvices Committee cuts WIPP funding in response to DOE's expansion of the project to a repository for commercial SNF and thus requiring NRC licensing. Dec: Congress defines mission of WIPP - sels up WIPP as a research and development facility for disposal of only TRU radioactive waste from DOE facilities

- exempls WIPP from NRC licensing

- requires DOE to sign a "Consultation Cooperation" (C\&C) Agreement with NM. Based on salt permeability tests in AEC-7 well, DOE cancels all gas generation and some backill experiments. EPA defines TRU waste as waste with activity greater than $100 \mathrm{nCi} / \mathrm{g}$

1980 - Feb: Carter orders SNF reprocessing to 5top. Mar: Carter rescinds 1980 funds for WIPP because unlicensed repository for defense waste only and announces interim strategy to set aside money for other waste disposal projects at WIPP
1980 - (con't) Jul: House Amed Services Committee disagrees with Carter policy, therefore, rescinded funds are relumed to WPP in mid year. Oct: DOE issues final EIS eliminating SNF \& HLW disposal and thereby reinstates WIPP mission defined by Congress in 1979.

1981 - Tests begun in nearby potash mine Mississippi Chemical Mine Co., to evaluate corrosion of potential waste canisters and overpack alloys. Jun: WIPP Project Mgr. McGough rekindles disagreements between DOE and New Mexico by stating HLW could be placed by 1983 and remain during the operating phase of WIPP. Draft (but not final) Nuclear Waste Policy Act (NWPA) defines TRU waste as waste contaminated with transuranic radioisotopes with half-lite greater than $20 \mathrm{yr}$ and activity greater than $100 \mathrm{nCi} / \mathrm{g}$.

- 1985 - Apr and Oct: SNL turns on heat for simulated DHLW canister experiments. Sep: In 40 CFR 191. EPA defines TRU waste as waste with activity greater than $100 \mathrm{nCi} / \mathrm{g}$ and half-life greater than $20 \mathrm{yr}$.

- 1987 - Dec: Nuclear Waste Policy Amendment Act (NWPAA) selects Yucca ML. NV. to undergo site characterization for potential SNF and HLW disposal; (bedded salt nol being considered lor SNF and HLW).

- 1988-Dec: DOE abruptly cancels SNF and HLW experiments at WPP because of NWPAA (no tunds available to remove simulated disposal containers).

1989 Draft supple - 1989 - Mar: SNL completes report to support Draf mental EIS identifies Supplemental EIS; report identifies generation of gases gas generation from container and waste corrosion as issue because salt permeability factor of 1000 lower than thought in 1989 Berin wall fals 1979. Based on initial analysis results in Februany. DOE funds SNL to conduct new studies of gas the Cold $W$ ar and greatly changing future demands for nuclear weapon material and, thus, amount and composition of TRU waste going to WIPP.

1990 - SNL and Westinghouse complete report on the pilot test phase of WMPP suggesting that $0.5 \%$ of waste capacity be brought to WIPP for gas generation experiments.

1992 NAS questions need 1992 -SNL \& Westinghouse complete work necessary for in situ gas 23 lo modify Test Phase Plan for gas generation tests.

generation 2., ? Westinghouse completes work necessary for modifying tests letter to DOE questioning scientific need for in-situ waste tests at WIPP.

1993 DOE 1993 - Oct: DOE concurs with NAS and decides not to decides not to emplace waste in a pilot phase at WIPP - lab tests test waste at 17 instead. DOE decides to make dratt Compliance Certification Application (CCA) to EPA. Because actual waste not coming to WPP, "bin tests" canceled.

1995 - Sep: Gas generation studies completed and results used to establish rates for CCA. Dec. DOE

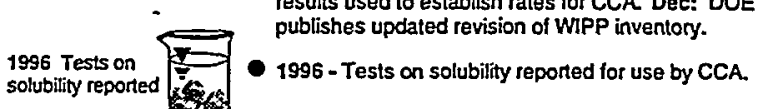

TRI-6342-5839-2

Fig. 8. Project goal and characterization of waste properties (adapted from Fig. 8 in Rechard, 1998, which provides references). 


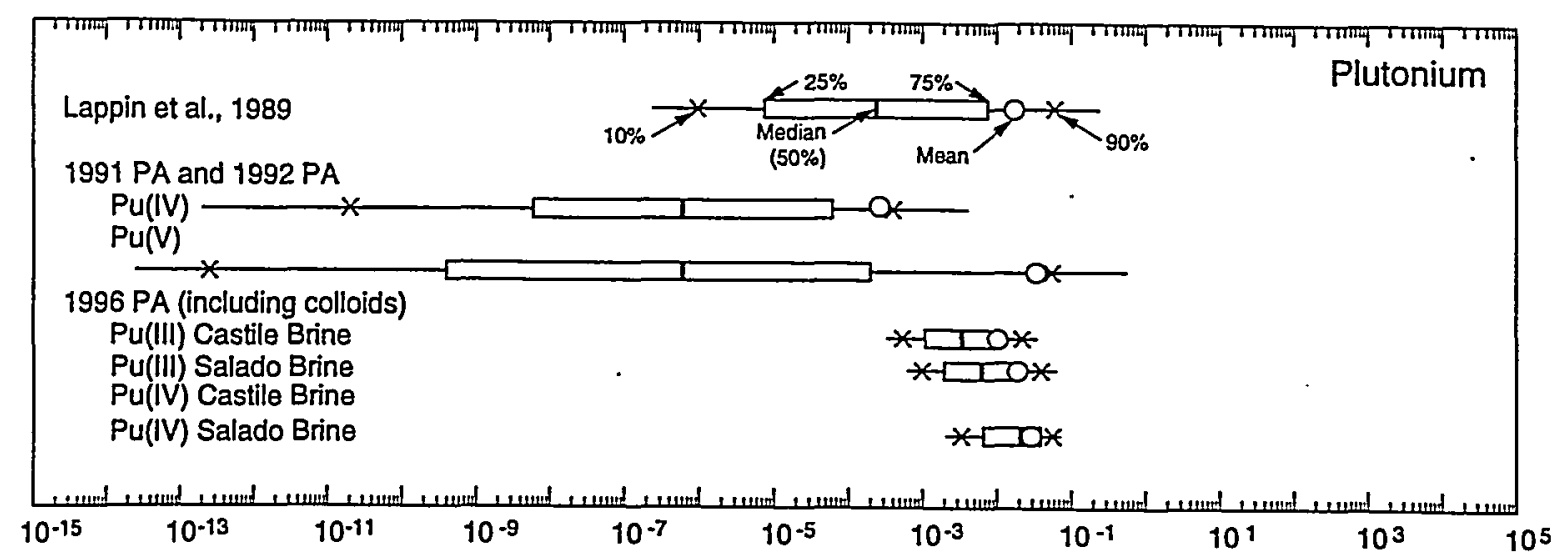

(a) Plutonium Solubility ( $\mathrm{mM}$ or moles $/ \mathrm{m}^{3}$ )

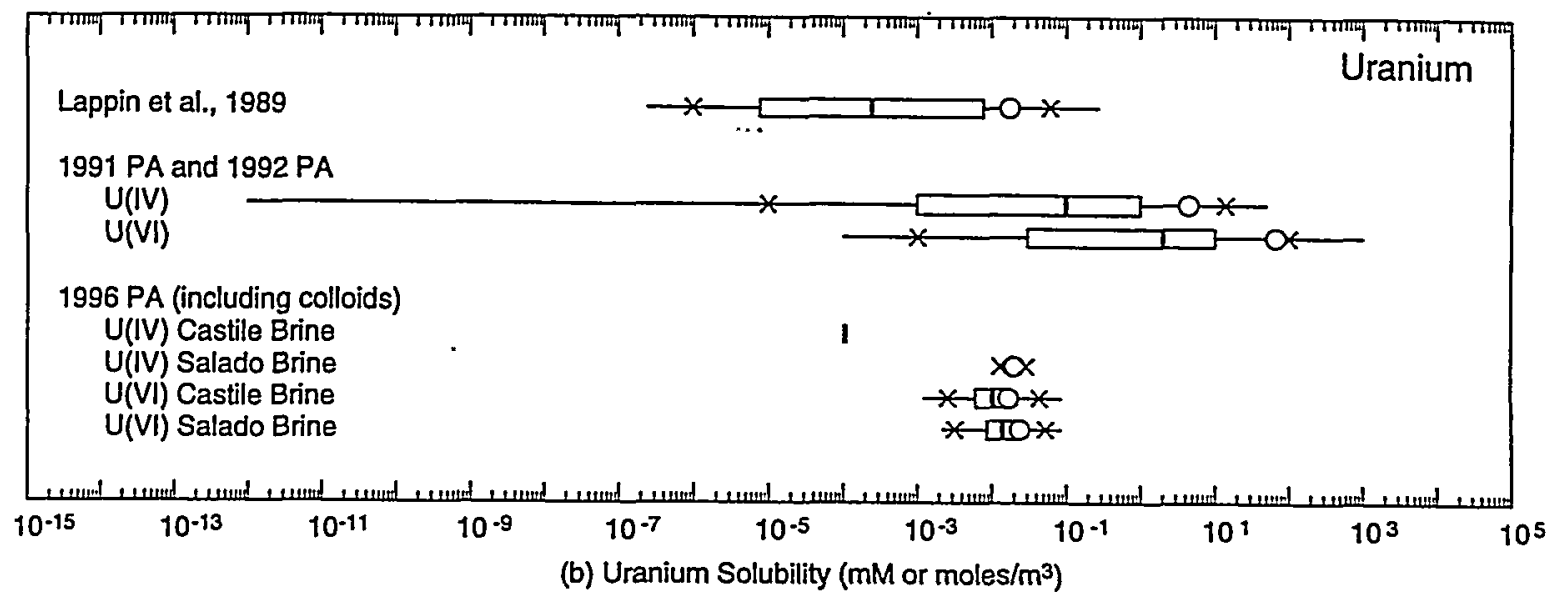

TRI-6342-5846-1

Fig. 9. Solubility of radioisotopes used in calculations between 1989 and 1996 for (a) plutonium and (b) uranium (Rechard, 1998). 


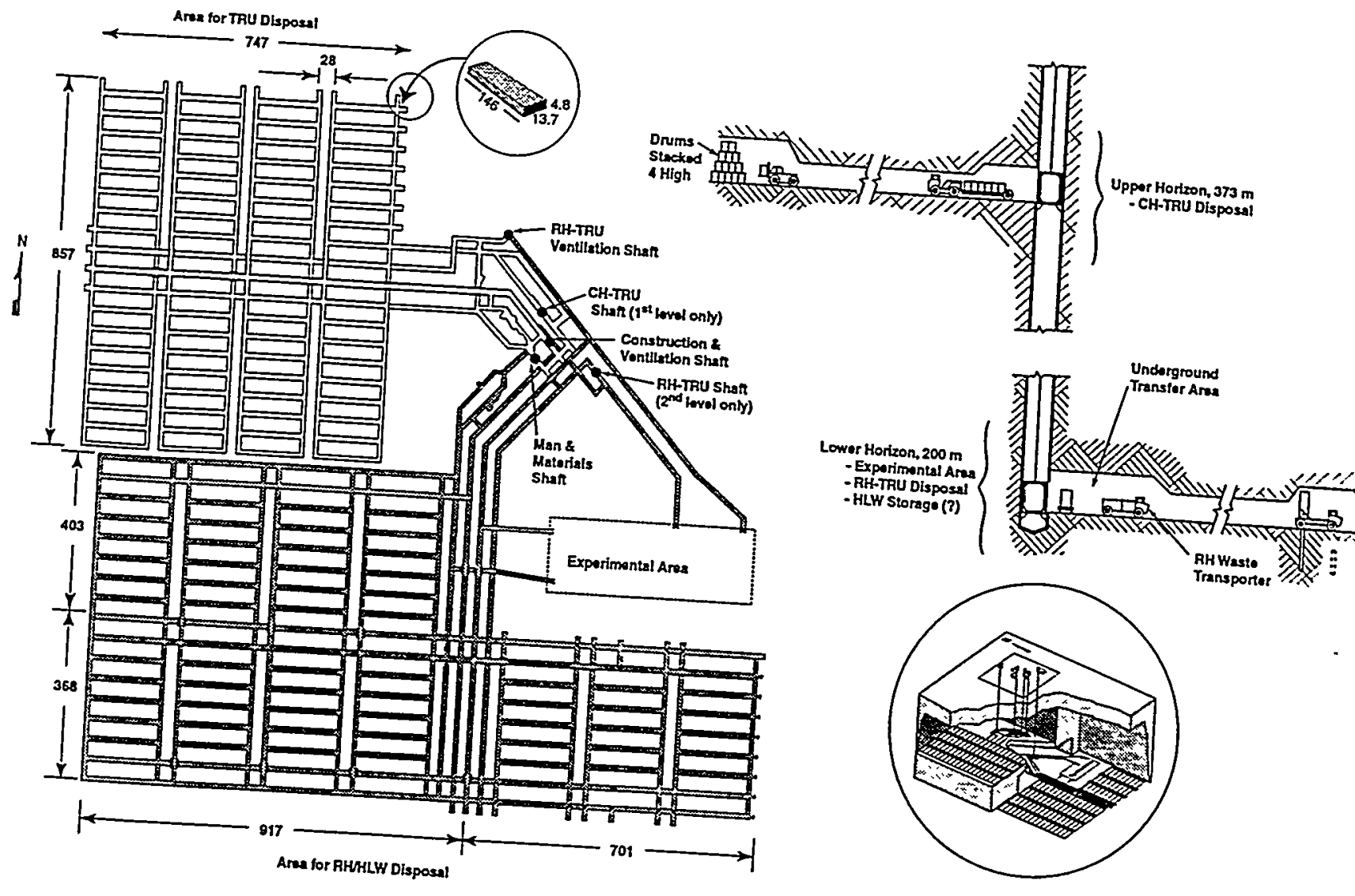

(a) 1977 conceptual design

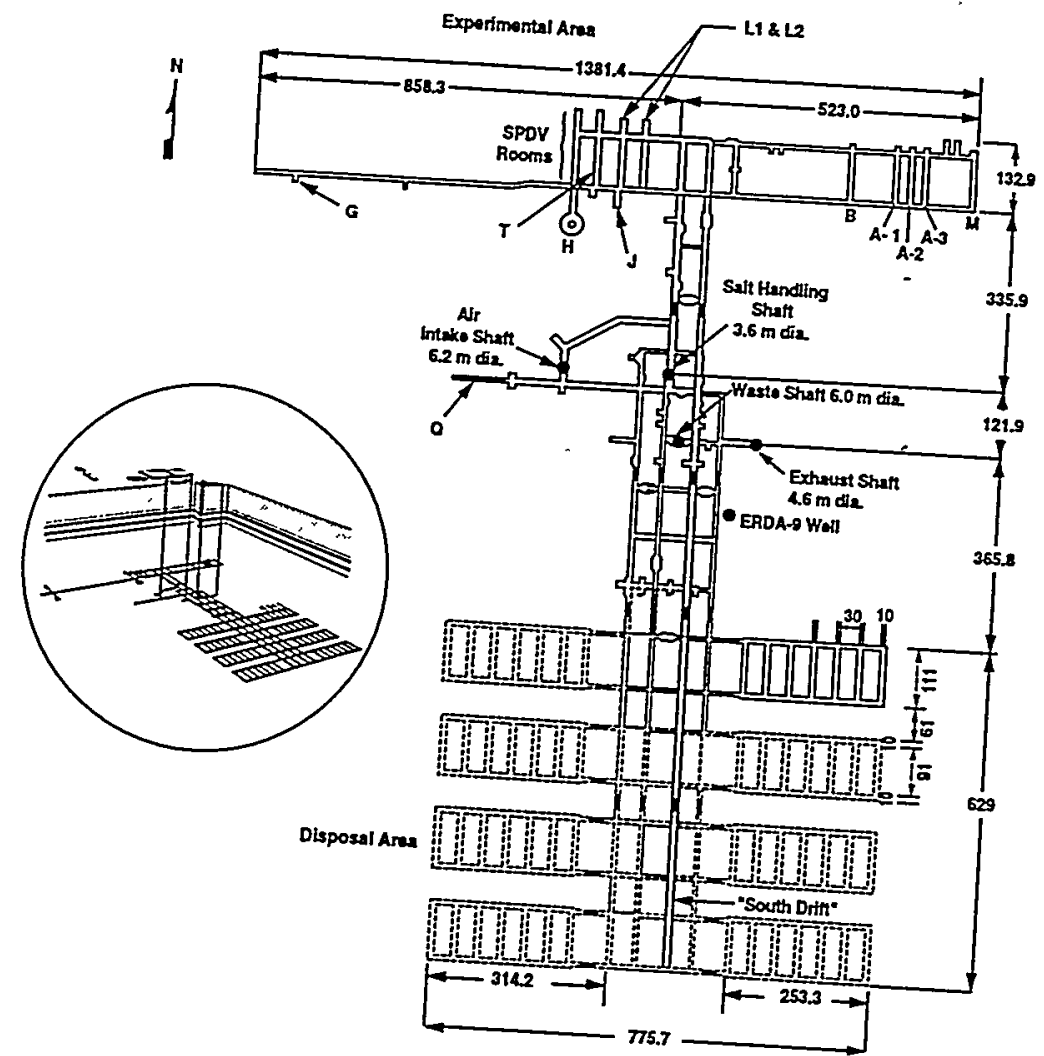

(b) Final construction plans for WIPP repository
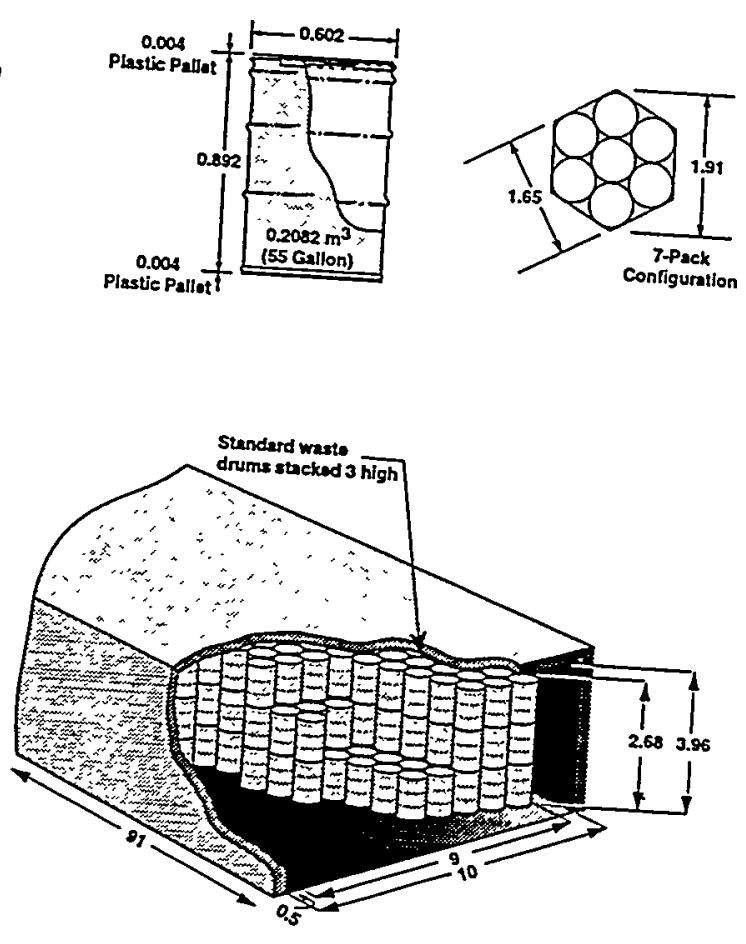

Fig. 10. Designs for WIPP repository (a) 1977 conceptaldesign (sandia 1977 ) and

TR1-6342-6010-0

(a) 1977 conceptual design (Sandia, 1977) and (b) final construction plans (Rechard, 1995). 


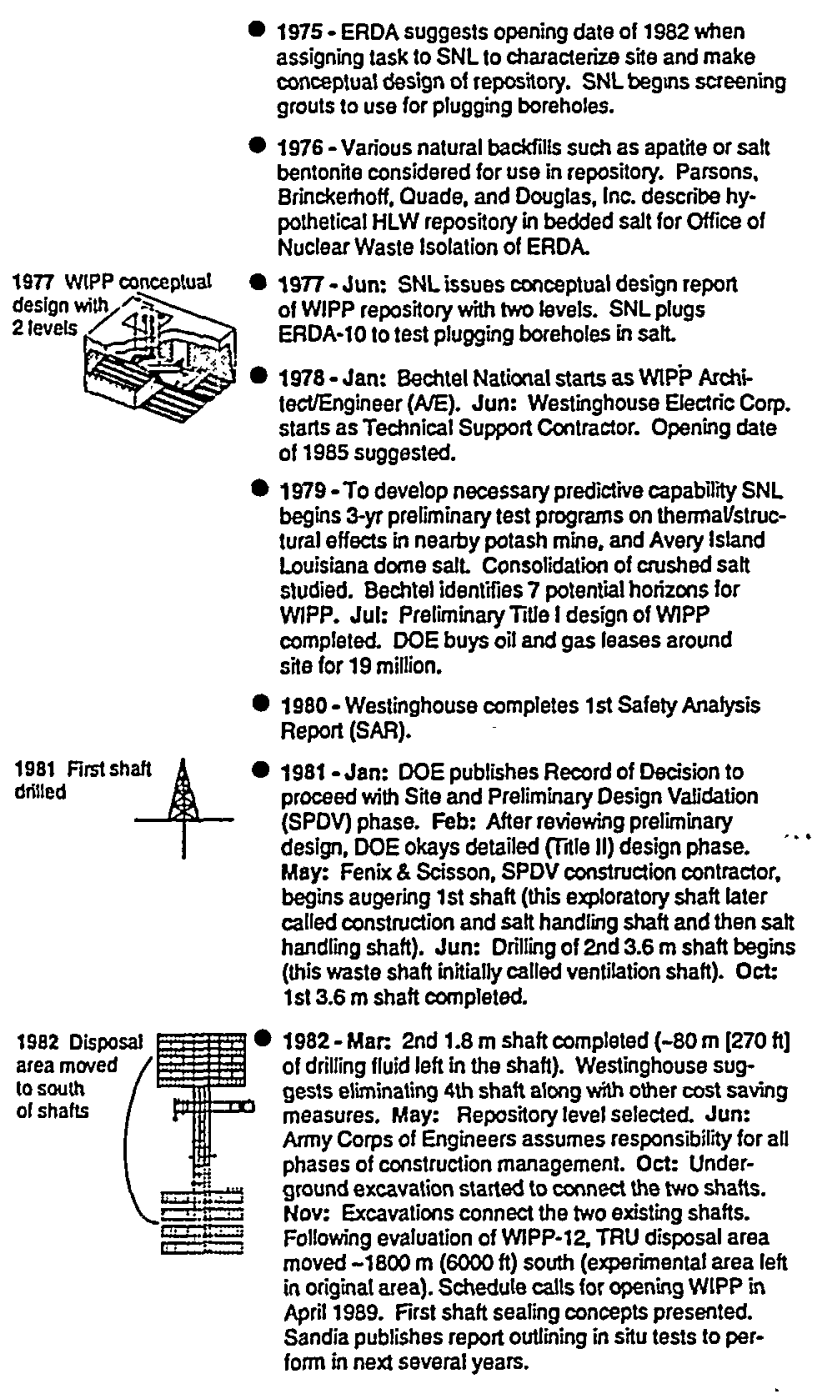

1983

begins

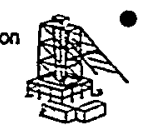

1983 - Mar: DOE gives Site and Preliminary Design Validation (SPDV) reports to NM and allows 60-day comment period. Excavation of experumental rooms begins and Bechtel begins final (Title III) design. Apr: NAS WIPP Panel tours WIPP underground to examine SPDV tests. Jul: DOE announces decision to proceed with construction. Sep: DOE sets Oct 1988 as WIPP opening date. Oct: Drilling of pilot hole for 3 rd shatt begins (exhaust shaft) and is completed in December.

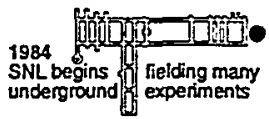

1984 - Feb: Raised bore reeming completed of 3rd shat. Apr: As rooms excavated, SNL begins thermalstructural and waste (e.g., defense HLW) tests defined in 1982. Jun: 2nd shaft enlarged from $1.8 \mathrm{~m}$ to $6 \mathrm{~m}$.

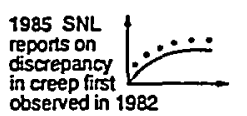

- 1985 - Jan: Blasting of 3rd shatt to final $4.6 \mathrm{~m}$ diameter completed. Excavation begins for circilar room $\mathrm{H}$. SNL reports on discrepancy between measured and prodicted salt creep first observed in south drit in 1982.

1986 - Feb: Pillar creep test begins in circular room $\mathrm{H}$ Heated (accelerated) tests of CH-TRU and RH-TRU container behavior start. Oct: In preparation for operations, Westinghouse awarded Management \& Operation (M\&O) contract. Army Corp. of Engineers relieved of construction management duties.

- 1987 - Wet salt compaction tests concluded, constitutive equation for consolidation developed, and shaft consolidation modeled (effective consolidation predicted in $<100 \mathrm{yr}$ ).

- 1988 - May: WPP begins drilling pilot hole for 4th shat (air intake shaft) after reevaluating 1982 decision to eliminate it. Sep: DOE announces that WIPP wont open as scheduled in Oct

- 1989 - Jan: DOE files request for administrative withdrawal of $16 \mathrm{mi}^{2}$ with DOI (less than halt of land allowed by 40 CFR 191). Fob: SNL resolves discrepancies between measured and predicted salt creep. Mar: Watkins creates "Blue Ribbon Panel" to examine WiPP readiness. Jun: Watkins announces an indefinite delay in opening of WPP.

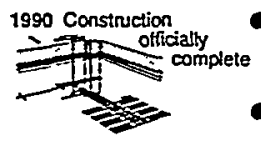

- 1990-Jan: Construction officially complete. May: Westinghouse completes "Final" Safety Analysis Report.

1991 - Apr and Aug: To extend lite of room 1, panel 1 tor gas generation tests, intemal and extemal panels meet to recommend roof support. Sep: Westing. house completes construction of rool support.

1995 - Oct: IT Corp. completes costbenefit study for Westinghouse and DOE of engineered barrier altema tives required by 40 CFR 194.

TRI-6342-5940-2

Fig. 11. Events associated with design, construction, and modeling of the WIPP repository (adapted from Fig. 11 in Rechard, 1998, which provides references). 


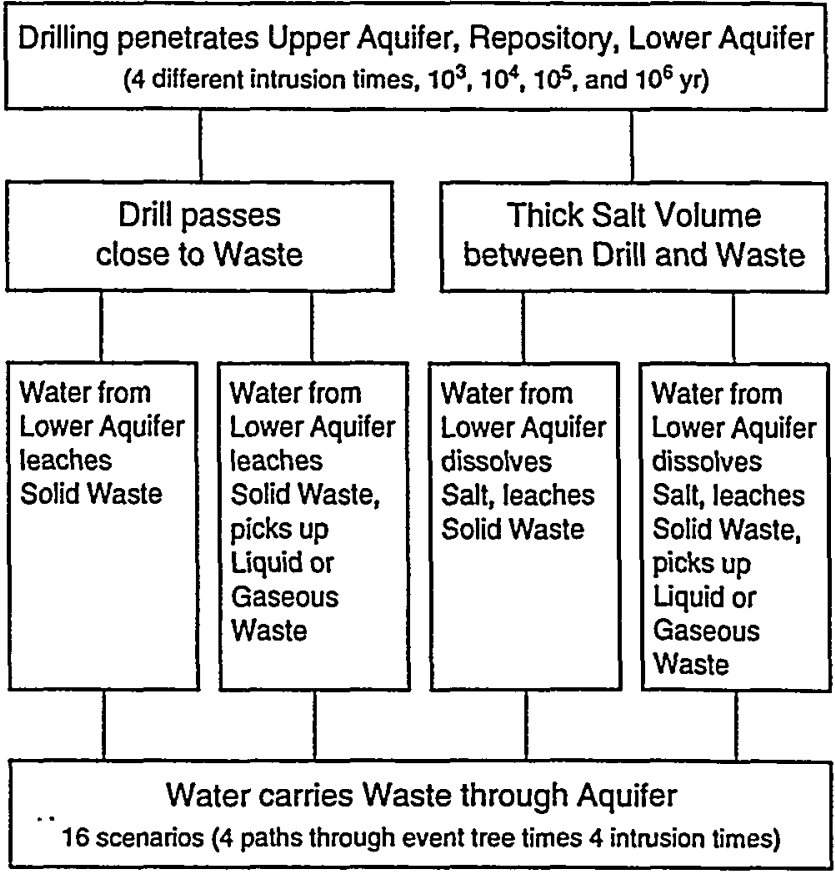

(a) Event tree approach used for scenarios in WIPP EIS in 1979 (after Bingham and Barr, 1980).

\section{Events}

$T S=$ Subsidence resulting from solution mining of potash

$E 1=$ One or more boreholes pass through waste and into a brine pocket

E2 = One or more boreholes pass through waste without penetrating a brine pocket

\section{Combinations and nomenclature}

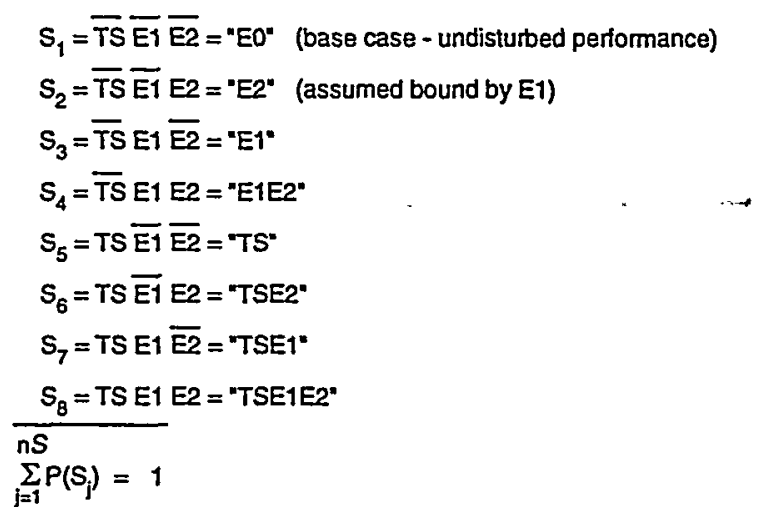

(b) Combination (order unimportant) of events for scenarios in 1990 - 1992 performance calculations (after Rechard, 1995).

TRI-6342.5851-1

Fig. 12. Technique to construct scenarios from various features, events and processes changed between WIPP EIS and PA calculations after 1989. 


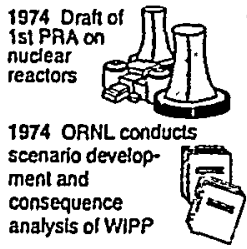

1974 - Aug: Draft of first major Probabilistic Risk Assessment (PRA) published on two reactors by $60 \mathrm{mem}$. ber team for Nuclear Regulatory Commission (NRC): method uses fault trees to synthesize probability of total system failure. Oct: ORNL conducts first scenario development and deterministic analysis for WIPP. Probability of meteorite impact, probability of faut (and volcanism) and exploratory ơriling intersecting disposal area estimated.

- 1976 - Dec: NRC funds panel of earth scientists to identify events and processes that could disrupt a generic repository.

- 1977 - Apr: Second meeting of NRC panel of earth scientists occurs to identify events and process. INEEL begins risk analysis of attematives for TRU waste stored and buried at Radioactive Wasto Management Complex (RWMC) over nex 4 years. Los Alamos. Savannah River, and Harford begin similar sludies as well. Human intrusion event significant contributor to consequences in these studies.

1978 SNL adapts 1978 - Hydrologic and radioisotope transport modeling PRA for reactors
to nuclear
waste repositories

1979 Drat EIS on WIPP conducts transpon analysis ol Pu out 10250,000 yr for draft EIS is primarily regional and extends for 250,000 yt ( 10 half-lives of ${ }^{20} \mathrm{Pu}$ ) using large, 3-D Switt flow model. NRC funds SNL to work on probabilistic PA and apply to hypothetical beoded sant repository.

- 1979 - Apr: Draft EIS on WIPP published. SNL completes development of scenarios for release radioisolopes from WIPP (part of EIS; process resulting method abandons fault trees and uses simple event trees). 3 major classes of scenarios identified (con-... nection between Culebra aquifers above and below repository, Bell Canyon aquifers, U-tube connection to Culebra, and stagnant pool connection to Culebra) plus drilling intrusion. (Later U-tube split into catastrophic connection and standard U-tube connection.) Probabilities of scenarios assigned based on qualitative reasoned arguments.

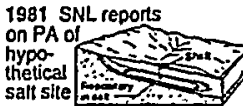

1981 - Draft of final report to NAC on performance assessment (PA) of hypothetical bedded salt repository readily available - uses a set of loosely connected codes, precursors to SWIFT II (iluid flow code), and NEFTRAN (network transport code). IAEA recommends procedure for PA and potential list of events and processes for scenarios. Jul: Stipulated Agreement (SA) between Now Mexico and DOE describes disruptivo scenarios (e.g., breccia pipe, satt dissolution, and salt deformation) that are to be dismissed through further site characterization.

- 1986 - Jul: DOE asks SNL to assess performance of WIPP against 40 CFR 191 criteria. Aug: SNL accepts PA task.

1987 - Mar: SNL finds that porous-media flow assumption adequately models flow in Culebra at $\mathrm{H}-3$ but that transport is best modeled as a dual porosity media (though roughly approximated as equivalent porous media). Modeling with variable brine densities suggest Culebra acting as leaky confined aquifer. subsequent models ignored suggestion until 1997. Aiso model suggests highly transmissive zone in the Culebra to the south of $\mathrm{H}-11$ and DOE-1. SNL finds possibility of a pressurized brine reservoir below the TRU disposal area cannot be ruled out

- 1988 - SNL bogins work of CAMCON to link detailed consequence models in probabilistic PA. SNL also simultaneously begins work on prototype of CAMCON to meet Dec. 1989 deadline. SNL completes pumping tests at $\mathrm{H}-11$ and begins using results to calibrate regional flow model.

1989 Draft supple 1989 - Mar: SNL completes report to support Draft mental EIS identifies $\rightarrow$ Supplemental EIS; report identifies generation of gase
gas generation gas generation salt permeability lower than thought in 1979. Also, ditferent flow direction in past during wet climate hypothesized to explain discrepancy between geochemical analysis and current hydrologic flow in Culebra. DOE issues Draft Supplemental EIS.

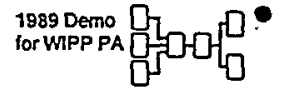

1989 - (con't) Dec: SNL reevaluates release scenarios and issues WPP PA demonstration outlining process for future PAs. No release without hurnan inlrusion; out of 26 parameters, solubility, intrusion time, and borehole permeability most important; cuttings from direct drilling set at 3 drums.

1990 First full PA 1990 - Jan: DOE issues Final Supplemental EIS. of WiPP used CAMCON Jun: DOE issues "Record of Decision" on WIPP Final Supplemental EIS stating construction is officially complete, testung phase ( $-5 \mathrm{yr})$ should proceed, and then another Supplemental Eis should be prepared before going to full operation. SNL refines FEP screening and analyzes four scenarios (E0, E1. E2, E1E2). Dec: SNL issues 1st full PA highlighting use of CAMCON modeling system. (e.g. Secondary parameter catabase completed): coupling of code demonstrated, which allowed better evaluation such as sensitivity anahysis. PA includes both scenano and parameter uncenainty: out of 3 parameters, solubility, intrusion time, and borehole pemeability important; cuttings from direct drilling important release pathway.

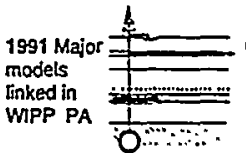

1991 - Dec: SNL issues 2nd PA highlighting major components of the PA process and documents. (e.g., rigorous use of scenarios and geostatistics for transmissivity fields); 46 paramelers sampled; cuttings most important release pathway.

1992 - Dec: SNL issues 3rd PA refining models and data used in the PA, uncertainty in transmissivity fields refined, 49 parameters sampled, evaluated time dependent $\lambda$ parameter in Poisson intrusion model: direct cuttings most important pathway.

- 1994 - Mar: SNL explores possibility of linking PA with decision analysis in System Prioritization Methodology (SPM): results form basis of Dratt Compliance Certification Application (DCCA). to models fe.g transmissivity
fields) in WPP PA

- 1995-Mar: DOE submits DCCA to EPA for review. Computer specialists hired to modify CAMCON implementation to enforce software configuration management and control runs for PA calculations. NAS provides guidance on new regulation for polential Yusca Mt. repository. suggests reporting risk from human intrusion separately. Second attempt at SPM.

1996 SNL completes PA 1996-Oct: SNL completes PA for Compliance for WIPP certification; moving Certification Application (CCA) of WIPP that includes van required to send copies $\mathrm{MgO}$ backfill, potash mining and subsidence scenario and greater intrusion rate: except for few vectors, drill parameters sampled. Calculation was run 3 times with 100 samples each and took 37,000 CPU hrs on 40 DEC alpha processors and tetained $100 \mathrm{GBytes}$ of data in 97,000 files. DOE sends 80,000 page, $400 \mathrm{lb}$. CCA to EPA. Nov: NAS reports that WIPP site "excellent choice" geologically. DOE issues 84,000-page 2nd Supplemental Dratt EiS. Dec: EPA begins detailed evaluation of CCA and supporting information at SNL and elsewhere including PA conceptual models, computer codes, model parameters, $O A$ records, and specific technical issues (e.g. MgO backfill and passive institutional control).

- 1997 - Jan: Conceptual Model Peer Review Group (formed in response to 40 CFR 194) concludes 22 of 24 conceptual models adequate. Spallings model must be redone and $\mathrm{MgO}$ backill description improved. Mar: SNL conducts mini PA for EPA to do parametric sensitivity analysis of PA model parameters lacking "ironclad" defense. Apr: Conceptual Model Peer Review Group reports that with additional information provided by SNL, they are satisfied that the new model of spallings and the model of the $\mathrm{MgO}$ backfill are adequate. May: SNL explains apparent discrepancy between geohydrology and geochemistry by viowing flow in Culebra as a 3D regional system. As part of EPA eval. uation of CCA, SNL runs EPA-mandated PA calculations using EPA-selected values for 26 paramelers and EPA-selected model assumptions, based on results from parameter review team comments in December and sensitivity analysis in March. In letter to DOE secretary. EPA Administrator Browner decrees DOE application "complete"; starting the 1yr clock for review of CCA.

$\operatorname{TRI}-6342-5841-2$

Fig. 13. Engineering analysis of the illustrated behavior of the disposal system (adapted from Fig. 13 in Rechard, 1998, which provides references). 

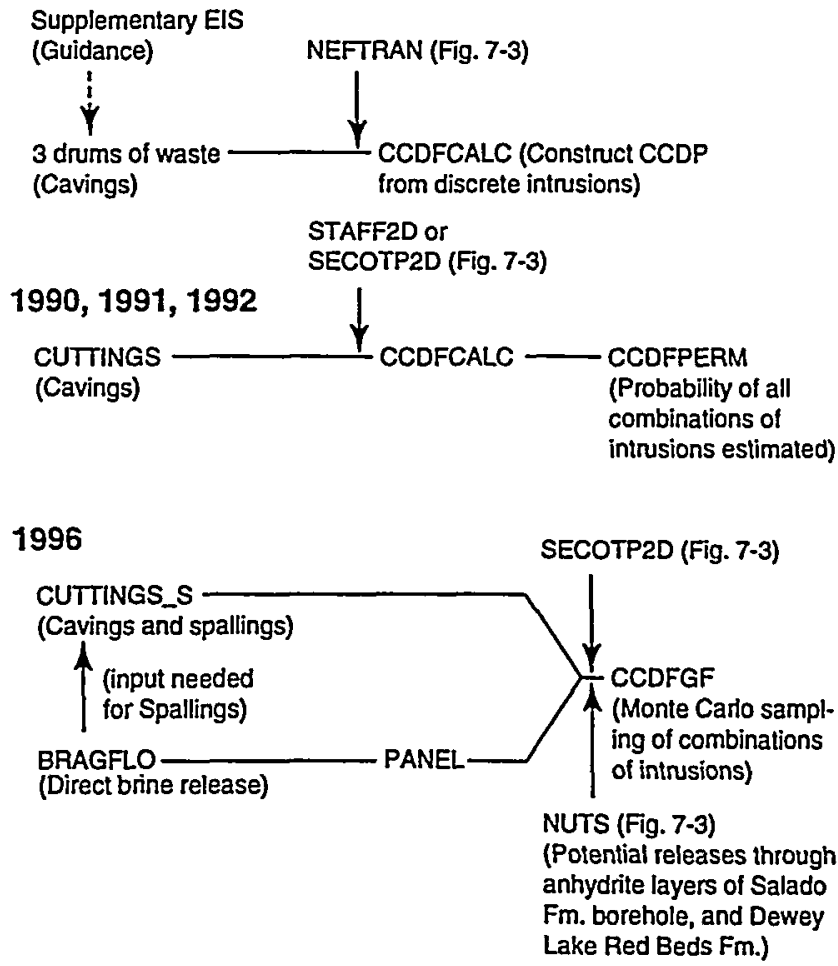

TRI-6342-5857-1

Fig. 14. Changes in code component of the exposure pathway model for immediate releases after exploratory drilling for evaluating compliance of with WIPP (Rechard, 1998). 


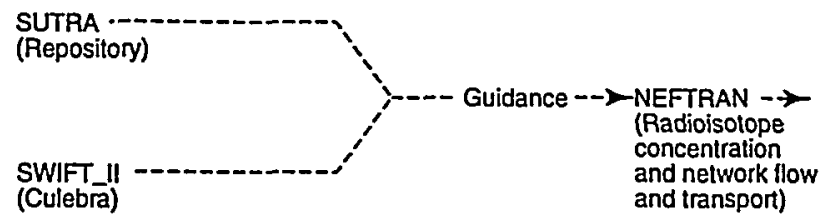

\section{0}

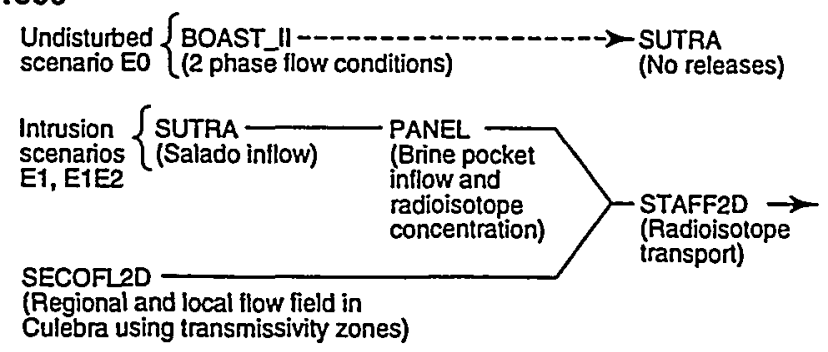

1991

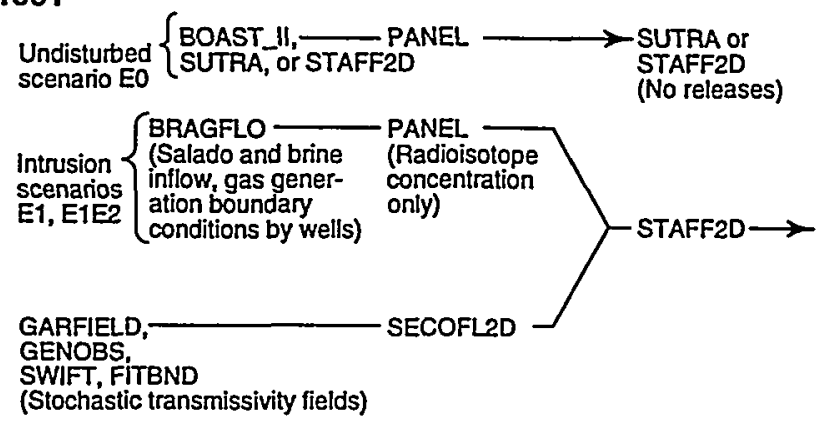

1992

SANCHO

(Salt creep and porosity

reduction averaged over repository)
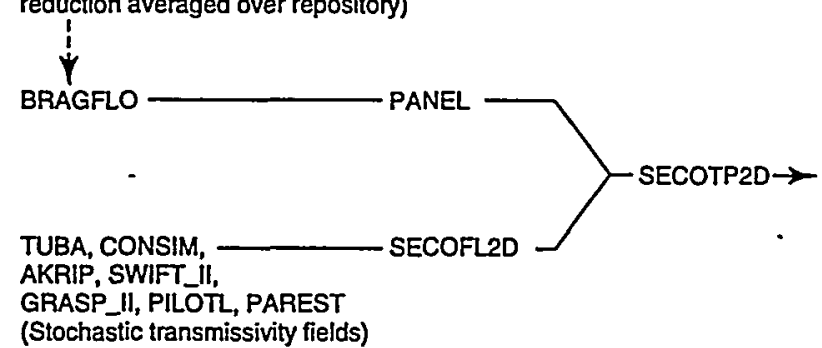

\section{6}

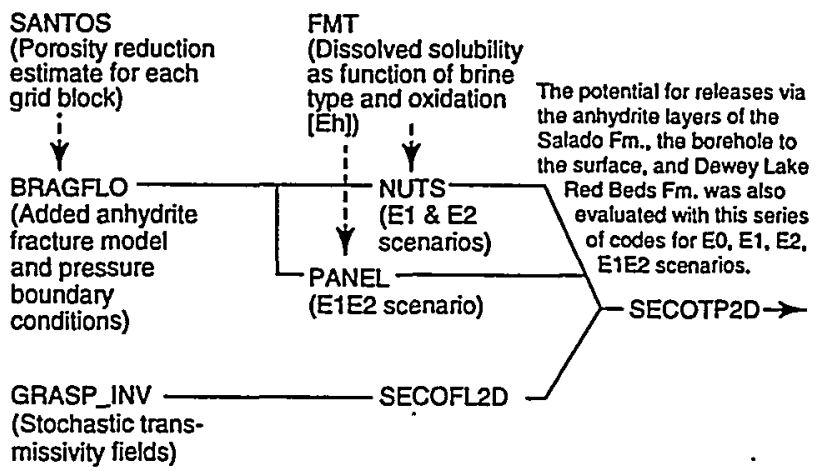

TRI-6342-5853-1

Fig. 15. Changes in components of the exposure pathway model for long-term release via leaking borehole and Culebra brine aquifer (Rechard, 1998). 


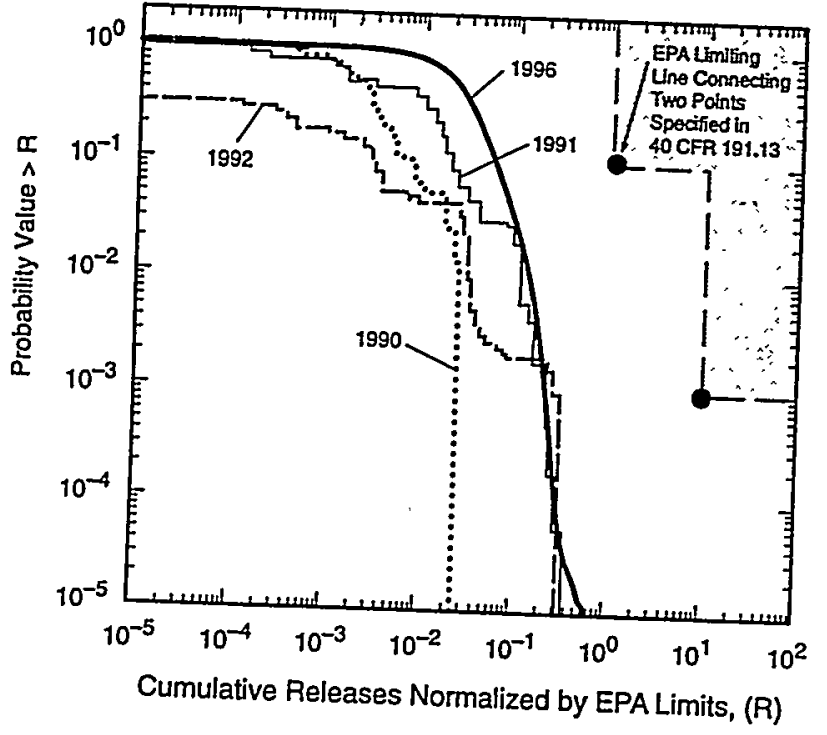

(a) Direct Releases to the Surface during Drilling

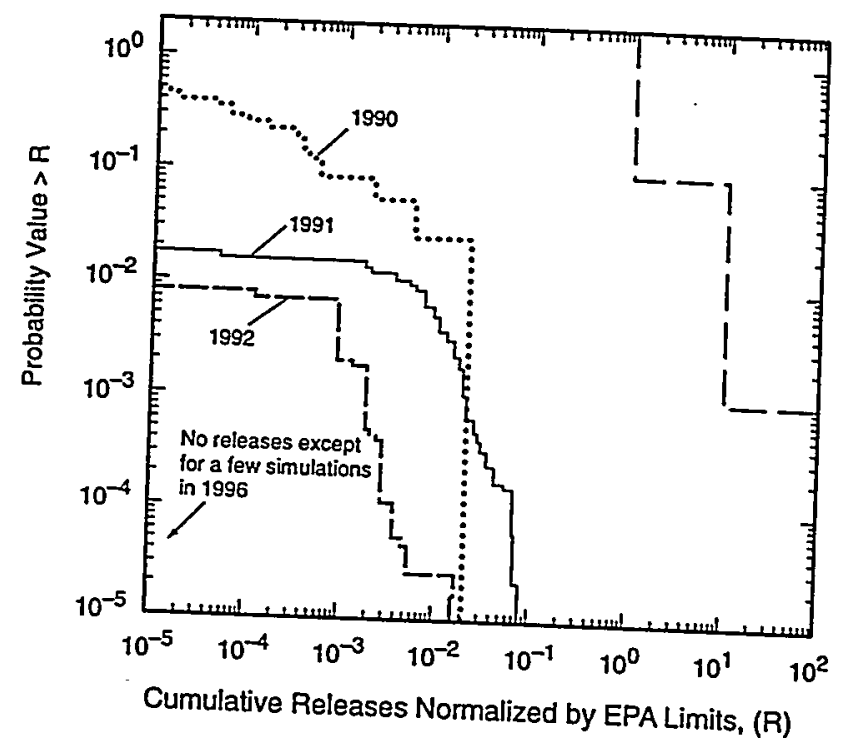

TRI-6342-6012-0

(b) Releases via Groundwater Pathway through Culebra Fig. 16. Changes in the distribution of cumulative releases (normalized by the EPA limits) for (a) direct releases to the surface
during drilling and (b) release via groundwater pathway through Culebra. Since the first complete performance in 1990 ,
direct releases to the surface have dominated overall releases to the 